Cahiers $d u$ MONDE RUSSE

\section{Cahiers du monde russe}

Russie - Empire russe - Union soviétique et États indépendants

$62 / 4 \mid 2021$

Varia

\title{
РЕЖИМЫ ПУБЛИЧНОСТИ И ВЕРХОВНАЯ ВЛАСТЬ В МОСКОВСКОМ ЦАРСТВЕ И РОССИЙСКОЙ ИМПЕРИИ
}

[Regimes of Publicity and the Supreme Authority in the Tsardom of Moscow and the Russian Empire]

\section{Евгений Акельев}

\section{(2) OpenEdition} Journals

\section{Édition électronique}

URL : https://journals.openedition.org/monderusse/13015

DOI : 10.4000/monderusse. 13015

ISSN : $1777-5388$

\section{Éditeur}

Éditions de l'EHESS

\section{Édition imprimée}

Date de publication : 1 décembre 2021

Pagination : 785-814

ISBN : 978-2-7132-2895-7

ISSN : $1252-6576$

\section{Référence électronique}

Евгений Акельев, «Режимы публичности и верховная власть в Московском царстве и Российской империи», Cahiers du monde russe [Онлайн], 62/4 | 2021, Выложить онлайн 01 décembre 2021, Наводить справки в 03 septembre 2022. URL: http://journals.openedition.org/ monderusse/13015 ; DOI: https://doi.org/10.4000/monderusse.13015

Ce document a été généré automatiquement le 3 septembre 2022

All rights reserved 


\section{РЕЖИМЫ ПУБЛИЧНОСТИ И}

\section{ВЕРХОВНАЯ ВЛАСТЬ В МОСКОВСКОМ ЦАРСТВЕ И РОССИЙСКОЙ ИМПЕРИИ}

[Regimes of Publicity and the Supreme Authority in the Tsardom of Moscow and the Russian Empire]

\section{Евгений Акельев}

\section{RÉFÉRENCE}

Т. АТНАШЕВ, Т. ВАЙЗЕР, М. ВЕЛИЖЕВ, СОСТ., НЕСОВЕРШЕННАЯ ПУБЛИЧНАЯ СФЕРА. ИСТОРИЯ РЕЖИМОВ ПУБЛИЧНОСТИ В РОССИИ. СБОРНИК СТАТЕЙ, МОСКВА: НОВОЕ ЛИТЕРАТУРНОЕ ОБОЗРЕНИЕ, 2021, $744 \mathrm{C}$.

Д.И. АНТОНОВ, ЦАРИ И САМОЗВАНЦЫ: БОРЬБА ИДЕЙ В РОССИИ СМУТНОГО ВРЕМЕНИ, МОСКВА: РГГУ, 2019, 312 С.

Е.В. АНИСИМОВ, ДЕРЖАВА И ТОПОР. ЦАРСКАЯ ВЛАСТЬ, ПОЛИТИЧЕСКИЙ СЫСК И РУССКОЕ ОБЩЕСТВО В ХVIII ВЕКЕ, МОСКВА: НОВОЕ ЛИТЕРАТУРНОЕ ОБОЗРЕНИЕ, 2019, 424 С.

\section{NOTE DE L'AUTEUR}

ПУБЛИКАЦИЯ ПОДГОТОВЛЕНА В РАМКАХ ПРОГРАММЫ ФУНДАМЕНТАЛЬНЫХ ИССЛЕДОВАНИЙ НИУ ВШЭ В 2021 Г. Я БЛАГОДАРЮ ЗА ЦЕННЫЕ ЗАМЕЧАНИЯ О.Е. КОШЕЛЕВУ И А.В. ЖУКОВСКУЮ.

1 КНИГА ЮРГЕНА ХАБЕРМАСА «СТРУКТУРНАЯ ТРАНСФОРМАЦИЯ ПУБЛИЧНОЙ СФЕРЫ» ${ }^{1}$ (1962) СТИМУЛИРОВАЛА ОСОБОЕ НАПРАВЛЕНИЕ ИСТОРИЧЕСКИХ ИССЛЕДОВАНИЙ ФЕНОМЕНА ПУБЛИЧНОСТИ И ПУБЛИЧНОЙ КОММУНИКАЦИИ В САМЫХ РАЗЛИЧНЫХ СТРАНАХ И САМЫЕ РАЗЛИЧНЫЕ ПЕРИОДЫ ИСТОРИИ ${ }^{2}$. ЭТОТ ТРЕНД, КОНЕЧНО, НЕ ОСТАВИЛ В СТОРОНЕ И СПЕЦИАЛИСТОВ ПО РОССИЙСКОЙ ИСТОРИИ. ОДНАКО 
КОНКРЕТНО-ИСТОРИЧЕСКИЕ ИССЛЕДОВАНИЯ, В КОТОРЫХ КОНЦЕПТ ПУБЛИЧНОЙ СФЕРЫ» ПОСЛЕДОВАТЕЛЬНО И С ПОЛЬЗОЙ ПРИМЕНЕН В КАЧЕСТВЕ ИНСТРУМЕНТА НАУЧНОГО АНАЛИЗА, ОТНОСЯТСЯ ПРЕИМУЩЕСТВЕННО К ПОЗДНЕИМПЕРСКОМУ И СОВЕТСКОМУ ПЕРИОДАМ ${ }^{3}$. НЕ ВЫХОДИТ ЗА РАМКИ ХІХ-ХХІ ВВ. И НЕДАВНО ОПУБЛИКОВАННЫЙ ИСКЛЮЧИТЕЛЬНО ВАЖНЫЙ СБОРНИК СТАТЕЙ «НЕСОВЕРШЕННАЯ ПУБЛИЧНАЯ СФЕРА. ИСТОРИЯ РЕЖИМОВ ПУБЛИЧНОСТИ В РОССИИ» (М., 2021) С ПРОГРАММНОЙ СТАТЬЕЙ ТИМУРА АТНАШЕВА, МИХАИЛА ВЕЛИЖЕВА И ТАТЬЯНЫ ВАЙЗЕР. В ЭТОМ ОЧЕРКЕ МНЕ ХОТЕЛОСЬ БЫ ПОСТАВИТЬ ВОПРОС О ТОМ, КАКИЕ ПЕРСПЕКТИВЫ ИМЕЕТ ПРИМЕНЕНИЕ КОНЦЕПТУАЛЬНОГО АППАРАТА Ю.ХАБЕРМАСА, ЕГО ПОСЛЕДОВАТЕЛЕЙ И КРИТИКОВ ДЛЯ ИЗУЧЕНИЯ «РЕЖИМОВ ПУБЛИЧНОСТИ» В МОСКОВСКОМ ЦАРСТВЕ И РОССИЙСКОЙ ИМПЕРИИ XVII-XVIII ВВ.

ОБОЗНАЧЕННЫЙ ВОПРОС СЛИШКОМ ОБЪЕМНЫЙ И СЛОЖНЫЙ, ЧТОБЫ НА НЕГО МОЖНО БЫЛО ДАТЬ ОБОСНОВАННЫЙ ОТВЕТ В КОРОТКОМ ЭССЕ. ЕГО РАЗРЕШЕНИЕ ТРЕБУЕТ НЕ ТОЛЬКО ОБСТОЯТЕЛЬНОГО РАЗБОРА РАЗВИТИЯ КОНЦЕПЦИИ Ю.ХАБЕРМАСА, ЕГО ПОСЛЕДОВАТЕЛЕЙ И ОПЫТА ЕЕ ПРИМЕНЕНИЯ ПО ОТНОШЕНИЮ К СРЕДНЕВЕКОВЬЮ НЕЕВРОПЕЙСКИМ ОБЩЕСТВАМ ${ }^{5}$, НО ТАКЖЕ ПРОРАБОТКИ МНОЖЕСТВА КОНКРЕТНОИСТОРИЧЕСКИХ ИССЛЕДОВАНИЙ, В КОТОРЫХ ТАК ИЛИ ИНАЧЕ ЗАТРАГИВАЕТСЯ ПРОБЛЕМА ПУБЛИЧНОСТИ В РОССИИ XVII-XVIII ВВ., ПУСТЬ И БЕЗ ОБРАЩЕНИЯ К ТЕОРИИ «ПУБЛИЧНОЙ СФЕРЫ». ЗДЕСЬ Я СТАВЛЮ ПЕРЕД СОБОЙ БОЛЕЕ СКРОМНУЮ И ОГРАНИЧЕННУЮ ЗАДАЧУ. Я ПОПРОБУЮ, ОТТОЛКНУВШИСЬ ОТ СБОРНИКА СТАТЕЙ «НЕСОВЕРШЕННАЯ ПУБЛИЧНАЯ СФЕРА», ОБРАТИТЬСЯ К ДВУМ КНИГАМ, НАПИСАННЫМ НА ОСНОВЕ РАЗЛИЧНЫХ КОРПУСОВ РОССИЙСКИХ ИСТОЧНИКОВ XVII-XVIII ВВ.: МОНОГРАФИИ Д.И.АНТОНОВА ЩЦАРИ И САМОЗВАНЦЫ: БОРЬБА ИДЕЙ В РОССИИ СМУТНОГО ВРЕМЕНИ» (М., 2019) И РАБОТЕ Е.В.АНИСИМОВА «ДЕРЖАВА И ТОПОР : ЦАРСКАЯ ВЛАСТЬ, ПОЛИТИЧЕСКИЙ СЫСК И РУССКОЕ ОБЩЕСТВО В XVIII ВЕКЕ» (М., 2019).

СРАЗУ СТОИТ ОГОВОРИТЬСЯ, ЧТО Д.И. АНТОНОВ И Е.В. АНИСИМОВ НЕ ОБРАЩАЮТСЯ К ПРОБЛЕМАМ ПУБЛИЧНОЙ СФЕРЫ И ПУБЛИЧНОЙ КОММУНИКАЦИИ СПЕЦИАЛЬНО; В ИХ ИССЛЕДОВАНИЯХ РЕШАЮТСЯ ДРУГИЕ ЗАДАЧИ (О КОТОРЫХ Я СКАЖУ НИЖЕ), ПОЭТОМУ ЭТИХ АВТОРОВ НЕЛЬЗЯ КРИТИКОВАТЬ ЗА ТО, ЧТО ОНИ, НЕ ЗАДАВАЯСЬ СООТВЕТСТВУЮЩИМИ ВОПРОСАМИ, НЕ ОБРАТИЛИ ВНИМАНИЯ НА ТЕ ИЛИ ИНЫЕ АСПЕКТЫ, СВЯЗАННЫЕ С ИСТОРИЕЙ «РЕЖИМОВ ПУБЛИЧНОСТИ» В РОССИИ. Я И НЕ СОБИРАЮСЬ ЗАНИМАТЬСЯ ТАКОЙ КРИТИКОЙ. ТО, ЧТО Я ПОПРОБУЮ СДЕЛАТЬ, - ЭТО ПРОЧИТАТЬ ИХ КНИГИ СКВОЗЬ ПРИЗМУ ТОЙ ОПТИКИ, КОТОРУЮ ЗАДАЕТ СБОРНИК «НЕСОВЕРШЕННАЯ ПУБЛИЧНАЯ СФЕРА». В ХОДЕ ЭТОГО ЭКСПЕРИМЕНТА Я ПОПРОБУЮ ПОНЯТЬ, НАСКОЛЬКО ИСТОРИЧЕСКИЕ ИСТОЧНИКИ XVII-XVIII В., НА КОТОРЫХ ОСНОВАНЫ ВЫБРАННЫЕ КНИГИ (И Я ПОКАЖУ, ЧТО ОНИ ВЫБРАНЫ НЕ СЛУЧАЙНО), ДАЮТ ВОЗМОЖНОСТЬ ПРОДОЛЖИТЬ РАЗГОВОР О «РЕЖИМАХ ПУБЛИЧНОСТИ» В РОССИИ, НО УЖЕ ПРИМЕНИТЕЛЬНО К МОСКОВСКОМУ И РАННЕИМПЕРСКОМУ ПЕРИОДАМ.

\section{Теория и практика изучения «режимов публичности» в Российской империи XIX в.}

4 "This investigation endeavors to analyze the type "bourgeois public sphere"», - ТАК НАЧИНАЕТ СВОЕ ИССЛЕДОВАНИЕ ЮРГЕН ХАБЕРМАС. ОТ «ТИПА РЕПРЕЗЕНТАТИВНОЙ ПУБЛИЧНОСТИ», ВОЗНИКШЕЙ В ПРИДВОРНОМ ОБЩЕСТВЕ И СЛУЖИВШЕЙ 
РЕПРЕЗЕНТАЦИИ ГОСПОДСТВА СУВЕРЕНА, УЧЕНЫЙ ПЕРЕХОДИТ К ПРОСЛЕЖИВАНИЮ ГЕНЕЗИСА И ВЫЯВЛЕНИЮ НАИБОЛЕЕ СУЩЕСТВЕННЫХ ЧЕРТ ИНОГО ТИПА ПУБЛИЧНОСТИ, КОТОРАЯ ФОРМИРУЕТСЯ В АНГЛИИ, ФРАНЦИИ И ГЕРМАНСКИХ ЗЕМЛЯХ С КОНЦА ХVII В. ТОРГОВЦЫ, БАНКИРЫ, ВЛАДЕЛЬЦЫ МАНУФАКТУР И ДРУГИЕ ОБРАЗОВАННЫЕ ПРЕДСТАВИТЕЛИ «НОВОЙ БУРЖУАЗИИ», РАНЕЕ БЫВШИЕ ЛИШЬ АБСТРАКТНЫМ ОБЪЕКТОМ ГОСУДАРСТВЕННОЙ ПОЛИТИКИ, НАЧИНАЮТ ОСОЗНАВАТЬ СЕБЯ В КАЧЕСТВЕ ХОРОШО ИНФОРМИРОВАННОГО И ПОЛНОЦЕННОГО УЧАСТНИКА СОЦИАЛЬНЫХ ОТНОШЕНИЙ И АКТИВНОГО ОППОНЕНТА ГОСУДАРСТВЕННОЙ ВЛАСТИ. ЭТА НОВАЯ «ПУБЛИЧНАЯ СФЕРА», КОТОРУЮ ХАБЕРМАС И НАЗЫВАЕТ «БУРЖУАЗНОЙ», СОЗДАЕТ СВОЮ КОММУНИКАТИВНУЮ СРЕДУ (КАФЕ, САЛОНЫ, ГАЗЕТЫ И ДР.) ДЛЯ ОБМЕНА ИНФОРМАЦИЕЙ И ОТКРЫТОГО ОБСУЖДЕНИЯ ВОПРОСОВ, КАСАЮЩИХСЯ ВСЕГО ОБЩЕСТВА, И ПОСТЕПЕННО НАЧИНАЕТ ВЛИЯТЬ НА «БОЛЬШУЮ ПОЛИТИКУ». ПРИ ЭТОМ ХАБЕРМАС ОСОБО ПОДЧЕРКИВАЕТ В ПРЕДИСЛОВИИ, ЧТО РЕЧЬ ИДЕТ О КОНКРЕТНОМ ИСТОРИЧЕСКОМ ЯВЛЕНИИ, КОТОРОЕ НЕОТДЕЛИМО ОТ ТОГО ОБЩЕСТВА, В КОТОРОМ ОНО ВОЗНИКЛО, И НЕ МОЖЕТ В КАЧЕСТВЕ ИДЕАЛЬНОГО ТИПА БЫТЬ ПРИМЕНЕНО К ДРУГИМ ИСТОРИЧЕСКИМ СИТУАЦИЯМ, ДАЖЕ ЕСЛИ ОНИ И ОБНАРУЖИВАЮТ НЕКОТОРЫЕ ЧЕРТЫ «БУРЖУАЗНОЙ ПУБЛИЧНОЙ СФЕРЫ» ${ }^{6}$.

ОДНАКО УЖЕ ПЕРВЫЕ КРИТИКИ И ПОСЛЕДОВАТЕЛИ ХАБЕРМАСА ПОСТАВИЛИ ПОД СОМНЕНИЕ ЕГО ПРЕДСТАВЛЕНИЕ «О ЕДИНОЙ ГОМОГЕННОЙ БУРЖУАЗНОЙ ПУБЛИЧНОЙ СФЕРЕ», ОБРАТИВ ВНИМАНИЕ НА ЗНАЧЕНИЕ ДРУГИХ, АЛЬТЕРНАТИВНЫХ, ПУБЛИЧНЫХ СФЕР И ПУБЛИЧНЫХ ДИСКУРСОВ 7 . КРОМЕ ЭТОГО, ВОЗНИКАЕТ ВОПРОС, КАКОЕ НАПОЛНЕНИЕ ПРИОБРЕТАЕТ КОНЦЕПТУАЛЬНОЕ ПОНЯТИЕ «ПУБЛИЧНАЯ СФЕРА» (ПОНИМАЕМОЕ КАК «АРЕНА ОБЩЕСТВЕННЫХ ДЕБАТОВ И ДИСКУССИЙ», СОСТОЯЩАЯ ИЗ «МНОЖЕСТВА ФОРМАЛЬНЫХ И НЕФОРМАЛЬНЫХ МЕСТ», ДЛЯ ОБСУЖДЕНИЯ «ВОПРОСОВ, ПРЕДСТАВЛЯЮЩИХ ОБЩИЙ ИНТЕРЕС» $\left.{ }^{8}\right)$, ЕСЛИ ЕГО ПРИМЕНИТЬ К ИЗУЧЕНИЮ ДРУГИХ ИСТОРИЧЕСКИХ ОБЩЕСТВ.

ЭТОТ ВАЖНЫЙ ВОПРОС И МОЖНО СЧИТАТЬ ОТПРАВНЫМ ДЛЯ СОСТАВИТЕЛЕЙ СБОРНИКА «НЕСОВЕРШЕННАЯ ПУБЛИЧНАЯ СФЕРА. ИСТОРИЯ РЕЖИМОВ ПУБЛИЧНОСТИ В РОССИИ», ГЛАВНОЙ ЦЕЛЬЮ КОТОРОГО ЯВЛЯЕТСЯ РАССМОТРЕНИЕ «РАБОТАЮЩИХ ПРАКТИК И РЕЖИМОВ ПУБЛИЧНОСТИ [В РОССИИ] ЗА ПОСЛЕДНИЕ ДВЕСТИ ЛЕТ» (С. 7). ВО ВСТУПИТЕЛЬНОЙ СТАТЬЕ, КОТОРАЯ ИМЕЕТ ПРОГРАММНЫЙ ХАРАКТЕР («ДВЕСТИ ЛЕТ ОПЫТА: ОТ БУРЖУАЗНОЙ ПУБЛИЧНОЙ СФЕРЫ К РОССИЙСКИМ РЕЖИМАМ ПУБЛИЧНОСТИ»), СОСТАВИТЕЛИ СБОРНИКА ТИМУР АТНАШЕВ, МИХАИЛ ВЕЛИЖЕВ И ТАТЬЯНА ВАЙЗЕР, КОНЕЧНО, ОГОВАРИВАЮТСЯ, ЧТО ПРИМЕНИТЕЛЬНО К РУССКОЙ И СОВЕТСКОЙ ИСТОРИИ «МЫ НЕ МОЖЕМ ГОВОРИТЬ О “БУРЖУАЗНОЙ ПУБЛИЧНОЙ СФЕРЕ”, КОТОРАЯ ПРЕДПОЛАГАЕТ СОДЕРЖАТЕЛЬНЫЕ И ГЛАСНЫЕ ДЕБАТЫ ГРАЖДАН ОБ ОБЩЕМ ДЛЯ НИХ ИНТЕРЕСЕ И ПРИВОДИТ К ПОЛИТИЧЕСКИ ЗНАЧИМОМУ И КОНСОЛИДИРОВАННОМУ (ПО САМЫМ ВАЖНЫМ ВОПРОСАМ) ОБЩЕСТВЕННОМУ МНЕНИЮ» (С. 57). ПРИМЕНЯЯ КОНЦЕПТ «ПУБЛИЧНОЙ СФЕРЫ» К РОССИЙСКОЙ ИСТОРИИ, СОСТАВИТЕЛИ И АВТОРЫ СБОРНИКА СКОРЕЕ РАССЧИТЫВАЮТ НА ТО, ЧТО ТЕОРИЯ Ю. ХАБЕРМАСА ДАСТ НАМ НЕКОТОРЫЙ ИМПУЛЬС ДЛЯ АНАЛИЗА КОНКРЕТНОГО ИСТОРИЧЕСКОГО МАТЕРИАЛА, ПОЗВОЛИТ НАМ СФОРМУЛИРОВАТЬ НОВЫЕ ИССЛЕДОВАТЕЛЬСКИЕ ВОПРОСЫ И ПОЗВОЛИТ ПО-НОВОМУ ВЗГЛЯНУТЬ НА НАШИ ИСТОЧНИКИ:

В НАШЕМ СБОРНИКЕ БОЛЬШИНСТВО АВТОРОВ МОЖНО ОТНЕСТИ К ТОМУ ТИПУ ПОСЛЕДОВАТЕЛЕЙ-И-КРИТИКОВ ХАБЕРМАСА, КТО ПРИМЕНЯЕТ И АДАПТИРУЕТ 
«ИДЕАЛЬНУЮ» БУРЖУАЗНУЮ МОДЕЛЬ ПУБЛИЧНОЙ СФЕРЫ К РАЗЛИЧНЫМ ИСТОРИЧЕСКИМ ПЕРИОДАМ И АНАЛИЗИРУЕТ ЭМПИРИЧЕСКИЕ КЕЙСЫ НА ФОНЕ ЭТОЙ НОРМАТИВНОЙ МОДЕЛИ (КАК ПОДДЕРЖИВАЮЩИЕ ЕЕ ИЛИ ПРОТИВОРЕЧАЩИЕ ЕЙ). ПРИ ЭТОМ НАМ КАЖЕТСЯ ВАЖНЫМ, СЛЕДУЯ ОРИГИНАЛЬНОМУ ХОДУ РАННЕГО ХАБЕРМАСА, ВЕРНУТЬСЯ К ПЕРЕОСМЫСЛЕНИЮ ПОЛИТИЧЕСКОЙ ФИЛОСОФИИ ПУБЛИЧНОСТИ НА ОСНОВЕ И ПОСЛЕ АНАЛИЗА ОТЕЧЕСТВЕННОГО ИСТОРИЧЕСКОГО МАТЕРИАЛА (С. 44).

ХАРАКТЕРИЗУЯ СОБСТВЕННЫЙ ПОДХОД К ИЗУЧЕНИЮ ФЕНОМЕНА ПУБЛИЧНОСТИ В РОССИИ, АВТОРЫ СБОРНИКА ОБОСНОВЫВАЮТ «СОЧЕТАНИЕ ДВУХ ПЕРСПЕКТИВ» ПРИ АНАЛИЗЕ КОНКРЕТНЫХ ПУБЛИЧНЫХ ДИСКУРСОВ. ВО-ПЕРВЫХ, НУЖНО ВЫЯВИТЬ И ПРОАНАЛИЗИРОВАТЬ ТЕ «ИНТЕЛЛЕКТУАЛЬНЫЕ И ЯЗЫКОВЫЕ ХОДЫ», КОТОРЫЕ БЫЛИ ИСПОЛЬЗОВАНЫ «ГОВОРЯЩИМ», ЧТОБЫ ПОНЯТЬ ЗНАЧЕНИЕ ДАННОГО ПУБЛИЧНОГО ВЫСКАЗЫВАНИЯ. ДЛЯ ЭТОГО ПРЕДЛАГАЕТСЯ ПРИМЕНЯТЬ РАЗЛИЧНЫЕ МЕТОДЫ ИНТЕЛЛЕКТУАЛЬНОЙ ИСТОРИИ (В ТОМ ЧИСЛЕ МЕТОДЫ КЕМБРИДЖСКОЙ ШКОЛЫ ${ }^{9}$ ). ВОВТОРЫХ, НЕОБХОДИМО ПОПЫТАТЬСЯ ВЫЯВИТЬ ЗНАЧИМОСТЬ (Т.Е. ПОЛИТИЧЕСКИЙ И СОЦИАЛЬНЫЙ ВЕС) ДАННОГО ПУБЛИЧНОГО ВЫСКАЗЫВАНИЯ. НА ЭТОМ ЭТАПЕ ИССЛЕДОВАНИЯ АКЦЕНТ ПЕРЕНОСИТСЯ НА АНАЛИЗ ТОГО «РЕЖИМА КОММУНИКАЦИИ», В КОТОРОЕ БЫЛ ВКЛЮЧЕН ГОВОРЯЩИЙ, Т.Е. НА СТЕПЕНЬ ПУБЛИЧНОСТИ ЕГО ВЫСКАЗЫВАНИЯ, МЕСТА АВТОРА И ЕГО СЛУШАТЕЛЕЙ В ПОЛИТИЧЕСКОЙ И СОЦИАЛЬНОЙ ИЕРАРХИИ И Т.Д. ИМЕННО СИНТЕЗ ЭТИХ ДВУХ ПОДХОДОВ, ПО МНЕНИЮ СОСТАВИТЕЛЕЙ, И ДАЕТ НАМ ВОЗМОЖНОСТЬ ВЫЯВИТЬ «ЛОКАЛЬНЫЙ РЕЖИМ ПУБЛИЧНОСТИ В КОНКРЕТНУЮ ЭПОХУ И В ЗАДАННОМ ОБЩЕСТВЕННОМ ПРОСТРАНСТВЕ» (С. 44-45).

СОСТАВИТЕЛИ СБОРНИКА ОБЪЯСНЯЮТ КЛЮЧЕВОЕ ДЛЯ НИХ ПОНЯТИЕ «РЕЖИМА ПУБЛИЧНОСТИ» СЛЕДУЮЩИМ ОБРАЗОМ: «РЕЖИМЫ ПУБЛИЧНОСТИ ЗАДАЮТ КОНВЕНЦИИ И ПРАВИЛА ПУБЛИЧНЫХ ВЫСКАЗЫВАНИЙ В РАЗЛИЧНЫХ ЖАНРАХ, А ТАКЖЕ РАМКИ ВОЗМОЖНЫХ РЕАКЦИЙ НА ПОЛИТИЧЕСКУЮ РЕЧЬ, ХУДОЖЕСТВЕННЫЕ ИЛИ ПУБЛИЦИСТИЧЕСКИЕ ПРОИЗВЕДЕНИЯ. В ЗАВИСИМОСТИ ОТ РЕЖИМА ПУБЛИЧНОСТИ РЕАКЦИЯ МОЖЕТ ПРЕДСТАВЛЯТЬ СОБОЙ А) ПОЛЕМИЧЕСКИЙ ОТВЕТ; Б) ЦЕНЗУРУ, РЕПРЕССИИ, САНКЦИИ; ЛИБО, НАПРОТИВ, В) РАВНОДУШНОЕ ИЛИ ДАЖЕ СНИСХОДИТЕЛЬНОЕ ОТСУТСТВИЕ РЕАКЦИИ НА ВЫСКАЗЫВАНИЕ» (С. 50). ВЫЯВЛЕНИЕ «РЕЖИМОВ ПУБЛИЧНОСТИ» ПОЗВОЛЯЕТ ПОНЯТЬ, «ПРИ КАКИХ УСЛОВИЯХ СЛОВА И ДЕБАТЫ ОБРЕТАЮТ ПОЛИТИЧЕСКИЙ ВЕС И ЗНАЧИМОСТЬ, СТАНОВЯТСЯ СОЦИАЛЬНОПОЛИТИЧЕСКИМИ ОРУДИЯМИ И ДЕЙСТВИЯМИ, А КОГДА СЛОВА И ДЕБАТЫ ОКАЗЫВАЮТСЯ БЕССИЛЬНЫ ИЛИ НЕСЛЫШНЫ ДЛЯ ДРУГИХ СОГРАЖДАН» (С. 46).

СОСТАВИТЕЛИ ФОРМУЛИРУЮТ ШИРОКУЮ ПРОГРАММУ АНАЛИЗА «НАЦИОНАЛЬНЫХ И ЛОКАЛЬНЫХ РЕЖИМОВ ПУБЛИЧНОСТИ», КОТОРАЯ ВКЛЮЧАЕТ В СЕБЯ ТАКИЕ ТЕМЫ, ВОПРОСЫ И ПРОБЛЕМЫ, КАК РЕКОНСТРУКЦИЯ РАЗЛИЧНЫХ ЩПРАКТИК, ФОРМ И ЖАНРОВ» ПУБЛИЧНЫХ ВЫСКАЗЫВАНИЙ (ОТ ПАМФЛЕТОВ И ОТКРЫТЫХ ПИСЕМ ДО КУХОННЫХ БЕСЕД), А ТАКЖЕ ИНСТИТУТОВ ИЛИ «ЛОКУСОВ», В КОТОРЫХ СОЗДАЮТСЯ УСЛОВИЯ ДЛЯ ПУБЛИЧНЫХ ДЕБАТОВ; РОЛЬ СОЦИАЛЬНЫХ ХАРАКТЕРИСТИК, ОБРАЗОВАНИЯ И ПОЛА ДЛЯ ДОСТУПА УЧАСТНИКОВ К РАЗЛИЧНЫМ ФОРМАМ ПУБЛИЧНОЙ КОММУНИКАЦИИ; ФУНКЦИОНИРОВАНИЕ РАЗЛИЧНЫХ ФОРМАЛЬНЫХ И НЕФОРМАЛЬНЫХ МЕХАНИЗМОВ ОГРАНИЧЕНИЯ» ПУБЛИЧНОЙ РЕЧИ (ОТ ЦЕНЗУРЫ ДО САМОЦЕНЗУРЫ, ОБЩЕСТВЕННЫХ КОНВЕНЦИЙ И ПРАВИЛ, РЕГУЛИРУЮЩИХ ПУБЛИЧНЫЕ ВЫСКАЗЫВАНИЯ); «СОЦИАЛЬНО-ЭКОНОМИЧЕСКИЕ, ЮРИДИЧЕСКИЕ И ПОЛИТИЧЕСКИЕ ОСНОВАНИЯ ДЛЯ САМОСТОЯТЕЛЬНОСТИ (ЗАВИСИМОСТИ) АГЕНТОВ, УЧАСТВУЮЩИХ В ПУБЛИЧНОЙ КОММУНИКАЦИИ» (с. 50-51). 

ВОСЕМНАДЦАТЬ ИССЛЕДОВАТЕЛЬСКИХ СТАТЕЙ, ОХВАТЫВАЮЩИХ ДВА СТОЛЕТИЯ - ОТ НАЧАЛА ХІХ В. ДО СОВРЕМЕННОСТИ. СОБЛЮДАЯ ХРОНОЛОГИЧЕСКИЕ ГРАНИЦЫ НАШЕГО ОЧЕРКА, МЫ ОГРАНИЧИМСЯ РАССМОТРЕНИЕМ ЛИШЬ ТЕХ РАБОТ, В КОТОРЫХ ИЗУЧАЮТСЯ РАЗЛИЧНЫЕ АСПЕКТЫ ПУБЛИЧНОСТИ ДОРЕВОЛЮЦИОННОЙ РОССИИ.

ИССЛЕДОВАТЕЛЬСКИЙ БЛОК СБОРНИКА ОТКРЫВАЕТ СТАТЬЯ МИХАИЛА ВЕЛИЖЕВА «ПОЛИТИК ПОНЕВОЛЕ? ИСТОРИОГРАФ, МОНАРХ И ПУБЛИЧНАЯ СФЕРА В РОССИИ НАЧАЛА ХІХ ВЕКА», ПОСВЯЩЕННАЯ АНАЛИЗУ РАЗЛИЧНЫХ ДОПУСТИМЫХ И НЕДОПУСТИМЫХ ФОРМ ПУБЛИЧНЫХ ДИСКУРСОВ В ВЫСШЕМ РОССИЙСКОМ ОБЩЕСТВЕ НАЧАЛА ХІХВ. - ОТ САЛОННЫХ БЕСЕД ДО ОСТРОГО ПОЛЕМИЧЕСКОГО ВЫЗОВА, БРОШЕННОГО САМОМУ ЦАРЮ. В ФОКУСЕ ВНИМАНИЯ ИССЛЕДОВАТЕЛЯ - ЗНАМЕНИТАЯ ЗАПИСКА Н.М. КАРАМЗИНА «О ДРЕВНЕЙ И НОВОЙ РОССИИ В ЕЕ ПОЛИТИЧЕСКОМ И ГРАЖДАНСКОМ ОТНОШЕНИЯХ», ОДИН ИЗ ВАЖНЕЙШИХ ПАМЯТНИКОВ РОССИЙСКОГО КОНСЕРВАТИЗМА, ИСТОРИЯ КОТОРОЙ ДО СИХ ПОР ОСТАЕТСЯ В ЗНАЧИТЕЛЬНОЙ СТЕПЕНИ МАЛОИЗВЕСТНОЙ, КАК С ТОЧКИ ЗРЕНИЯ ТЕКСТОЛОГИИ, ТАК И БАЗОВЫХ ИСТОЧНИКОВЕДЧЕСКИХ АСПЕКТОВ (ТАКИХ КАК ЦЕЛЬ И ОБСТОЯТЕЛЬСТВА СОЗДАНИЯ ЭТОГО ТЕКСТА). ПРОАНАЛИЗИРОВАВ ИСТОРИЧЕСКИЙ КОНТЕКСТ, «ПРАВИЛА КОММУНИКАЦИИ В РАМКАХ ПРИДВОРНОГО ЭТИКЕТА» И «ЯЗЫКОВЫЕ СТРАТЕГИИ» КАРАМЗИНА, М.Б. ВЕЛИЖЕВ ПОДТВЕРЖДАЕТ ИДЕЮ А.Л. ЗОРИНА О ТОМ, ЧТО «ЗАПИСКА» БЫЛА ИЗНАЧАЛЬНО ПРЕДНАЗНАЧЕНА СЕСТРЕ ИМПЕРАТОРА ВЕЛИКОЙ КНЯГИНЕ ЕКАТЕРИНЕ ПАВЛОВНЕ И ДОЛЖНА БЫЛА ПОМОЧЬ ЕЙ УБЕДИТЬ ИМПЕРАТОРА ОТКАЗАТЬСЯ ОТ ИДЕИ ОГРАНИЧЕНИЯ САМОДЕРЖАВНОЙ ВЛАСТИ: «ВОЗМОЖНО, ТЕКСТ КАРАМЗИНА СЛУЖИЛ СВОЕОБРАЗНЫМ РЕПЕРТУАРОМ ИСТОРИЧЕСКИХ И ПОЛИТИЧЕСКИХ АРГУМЕНТОВ, КОТОРЫЕ ЕКАТЕРИНЕ ПАВЛОВНЕ СЛЕДОВАЛО ИСПОЛЬЗОВАТЬ В РАЗГОВОРАХ С ВЕНЦЕНОСНЫМ БРАТОМ (С ТОЙ ОГОВОРКОЙ, ЧТО ИХ БЕСЕДА НАВЕРНЯКА ШЛА БЫ НА ФРАНЦУЗСКОМ ЯЗЫКЕ). В ТАКОМ СЛУЧАЕ НОРМЫ ПУБЛИЧНОГО ПОВЕДЕНИЯ, АКТУАЛЬНЫЕ ДЛЯ ПРИДВОРНОГО СЕГМЕНТА ПУБЛИЧНОЙ СФЕРЫ, ОКАЗАЛИСЬ БЫ СОБЛЮДЕНЫ: ОПРЕДЕЛЕНИЯ И ФОРМУЛЫ, НЕВОЗМОЖНЫЕ В УСТАХ ПОДДАННОГО, МОГЛИ ТЕМ НЕ МЕНЕЕ ПРОЗВУЧАТЬ ИЗ УСТ БЛИЖАЙШЕГО К МОНАРХУ ЧЛЕНА ИМПЕРАТОРСКОЙ ФАМИЛИИ» (С. 108). ОДНАКО ЕКАТЕРИНА ПАВЛОВНА, ПЕРЕДАВ «ЗАПИСКУ» АЛЕКСАНДРУ І, РЕЗКО ИЗМЕНИЛА ЗНАЧИМОСТЬ ЭТОГО ТЕКСТА: ИЗ ИНСТРУКЦИИ ДЛЯ БЕСЕДЫ С МОНАРХОМ ОН ПРЕВРАТИЛСЯ В «ОСТРУЮ ПОЛИТИЧЕСКУЮ РЕПЛИКУ», СВИДЕТЕЛЬСТВОВАВШУЮ «О КРАЙНЕМ НЕДОВОЛЬСТВЕ РЕФОРМАМИ В СРЕДЕ МОСКОВСКОГО ДВОРЯНСТВА» (С. 89). «ИЗ ИСТОРИОГРАФА И ПОСЛУШНОГО КЛИЕНТА ВЕЛИКОЙ КНЯГИНИ КАРАМЗИН ПРЕВРАТИЛСЯ В ПОЛИТИКА И РАДИКАЛЬНОГО КРИТИКА ИМПЕРАТОРСКИХ ДЕЙСТВИЙ, БРОСИВШЕГО ВЫЗОВ САМОМУ ЦАРЮ» (С. 111). ОДНАКО ВПОСЛЕДСТВИИ Н.М. КАРАМЗИН «НАШЕЛ В СЕБЕ СИЛЫ ИНТЕРПРЕТИРОВАТЬ НОВУЮ РОЛЬ И СДЕЛАЛ ЕЕ ЧАСТЬЮ СОБСТВЕННОГО ПУБЛИЧНОГО ОБРАЗА»: В ПОСЛЕДУЮЩИЕ ГОДЫ ИСТОРИК УЖЕ СОЗНАТЕЛЬНО СОЗДАВАЛ «НОВЫЙ ОБРАЗ ИДЕАЛЬНОГО НЕПОДКУПНОГО СОВЕТНИКА ЦАРЯ» (С. 111-112).

ПОЧЕМУ ВЕЛИКАЯ КНЯГИНЯ ЕКАТЕРИНА ПАВЛОВНА РАССМАТРИВАЛА ОБЩЕСТВЕННОЕ МНЕНИЕ (ВЫРАЗИТЕЛЕМ КОТОРОГО НЕВОЛЬНО ВЫСТУПИЛ Н.М. КАРАМЗИН) КАК «КОЗЫРЬ» В ПОЛИТИЧЕСКОЙ ИНТРИГЕ ПРОТИВ КОНСТИТУЦИОННЫХ ЗАМЫСЛОВ АЛЕКСАНДРА І, ОТЧАСТИ ПОЗВОЛЯЕТ ПОНЯТЬ СТАТЬЯ ВИКТОРИИ ФРЕДЕ «ОБЩЕСТВЕННОЕ МНЕНИЕ, ЕГО ОБЛИК СВЕРХУ. НЕГЛАСНЫЙ КОМИТЕТ АЛЕКСАНДРА І». В НЕЙ СПЕЦИАЛЬНО РАССМАТРИВАЕТСЯ РОЛЬ ОБЩЕСТВЕННОГО МНЕНИЯ В РАБОТЕ

Cahiers du monde russe, $62 / 4$ | 2021 
ЗНАМЕНИТОГО НЕГЛАСНОГО КОМИТЕТА. ВИКТОРИЯ ФРЕДЕ ПОДЧЕРКИВАЕТ, ЧТО СОВЕЩАНИЯ АЛЕКСАНДРА І С ЕГО «МОЛОДЫМИ ДРУЗЬЯМИ» НЕ СЛУЧАЙНО ПРОХОДИЛИ В ОБСТАНОВКЕ СТРОГОЙ СЕКРЕТНОСТИ. «СЕКРЕТНОСТЬ И ЗАМКНУТОСТЬ ГРУППЫ, ЕЕ КОНСПИРАТИВНЫЙ ЭЛЕМЕНТ, ОТДЕЛЯЛИ ЕЕ ОТ ПОСТОЯННЫХ ПОСЕТИТЕЛЕЙ ДВОРА, ПОДЧЕРКИВАЯ ЕЕ ЭЛИТНЫЙ СТАТУС КАК АРКАНУМА ВЛАСТИ» (И ЗДЕСЬ В. ФРЕДЕ ИСПОЛЬЗУЕТ ТЕРМИНОЛОГИЮ ХАБЕРМАСА - С. 124). ОДНАКО У ТАКОЙ ЗАКРЫТОСТИ БЫЛА СВОЯ ВНУТРЕННЯЯ ЛОГИКА. «ВЫСОКИЕ НРАВСТВЕННЫЕ КАЧЕСТВА И ПРЕЖДЕ ВСЕГО СПОСОБНОСТЬ ПОДЧИНИТЬ ЛИЧНЫЕ ИНТЕРЕСЫ ОБЩЕМУ БЛАГУ БЫЛИ В ГЛАЗАХ ЧЛЕНОВ НЕГЛАСНОГО КОМИТЕТА НЕОБХОДИМЫМ УСЛОВИЕМ ДЛЯ ВЫСТУПЛЕНИЯ НА ПОЛИТИЧЕСКОЙ АРЕНЕ» (С. 131), В ТО ВРЕМЯ КАК СТОЛИЧНОЕ ДВОРЯНСТВО, ПО УБЕЖДЕНИЮ ЧЛЕНОВ НЕГЛАСНОГО КОМИТЕТА, НЕ ОБЛАДАЛО СПОСОБНОСТЬЮ К ЗДРАВОМУ РАССУЖДЕНИЮ, ТАК КАК БЫЛО ДВИЖИМО, ГЛАВНЫМ ОБРАЗОМ, ЭГОИСТИЧЕСКИМИ ИНТЕРЕСАМИ, ПОЧЕМУ В АРИСТОКРАТИЧЕСКОМ ОБЩЕСТВЕ ЦАРИЛИ РАЗНОГЛАСИЯ И ИНТРИГИ (С. 132-133). НО П.А.СТРОГАНОВ, В.П. КОЧУБЕЙ, А. ЧАРТОРЫЙСКИЙ И Н.Н.НОВОСИЛЬЦЕВ, «В ДУХЕ РАВЕНСТВА» ОБСУЖДАЯ С АЛЕКСАНДРОМ I ТАКИЕ ВОПРОСЫ, КАК СОЗДАНИЕ КОНСТИТУЦИИ ИЛИ ОСВОБОЖДЕНИЕ КРЕСТЬЯН, ОДНОВРЕМЕННО С ЭТИМ ОСТАВАЛИСЬ ЧАСТЬЮ ВЫСШЕГО ОБЩЕСТВА, ПРОДОЛЖАЛИ ПОСЕЩАТЬ САЛОНЫ, КРУЖКИ, ЗВАННЫЕ УЖИНЫ, «ВПИТЫВАЯ СУЖДЕНИЯ ДРУГИХ И СОЗДАВАЯ СВОИ СОБСТВЕННЫЕ» (С.117). САМ АЛЕКСАНДР БЫЛ ОЧЕНЬ ЧУВСТВИТЕЛЕН К СВОЕЙ РЕПУТАЦИИ И ПРОСИЛ НОВОСИЛЬЦЕВА ДОКЛАДЫВАТЬ ЕМУ О ТОМ, ЧТО О НЕМ ГОВОРЯТ В ВЫСШЕМ СВЕТЕ. ИМЕННО СТРАХИ ЧЛЕНОВ НЕГЛАСНОГО КОМИТЕТА ОТНОСИТЕЛЬНО ВОЗМОЖНОЙ РЕАКЦИИ ДВОРЯНСТВА, ВИДИМО, И ПОМЕШАЛИ РЕАЛИЗАЦИИ ЕГО НАИБОЛЕЕ ЗНАЧИМЫХ ИНИЦИАТИВ.

КИРИЛЛ ЗУБКОВ В СТАТЬЕ «ЛИТЕРАТУРНЫЕ ПРЕМИИ ЭПОХИ “ВЕЛИКИХ РЕФОРМ" В КОМПАРАТИВНОЙ ПЕРСПЕКТИВЕ: УВАРОВСКАЯ НАГРАДА ДЛЯ ДРАМАТУРГОВ КАК ИНСТИТУТ ПУБЛИЧНОЙ СФЕРЫ» ДОКАЗЫВАЕТ, ЧТО АНАЛИТИЧЕСКАЯ КАТЕГОРИЯ «ПУБЛИЧНОЙ СФЕРЫ» НЕ ТОЛЬКО ПРИМЕНИМА К ИСТОРИИ ЛИТЕРАТУРНЫХ ПРЕМИЙ В РОССИИ; БОЛЕЕ ТОГО, ИНСТИТУТ ЛИТЕРАТУРНЫХ ПРЕМИЙ, СУЩЕСТВОВАВШИЙ В РАЗЛИЧНЫХ ЕВРОПЕЙСКИХ СТРАНАХ, ОТКРЫВАЕТ ИНТЕРЕСНЫЕ ПЕРСПЕКТИВЫ ДЛЯ ЕГО СРАВНИТЕЛЬНОГО ИЗУЧЕНИЯ С ЦЕЛЬЮ ВЫЯСНЕНИЯ «СПЕЦИФИКИ ПУБЛИЧНОЙ СФЕРЫ В УСЛОВИЯХ РОССИЙСКОЙ ИМПЕРИИ ВТОРОЙ ПОЛОВИНЫ ХІХ ВЕКА» (С. 153). В ФОКУСЕ ИССЛЕДОВАНИЯ - ПЕРВАЯ РОССИЙСКАЯ ЛИТЕРАТУРНАЯ ПРЕМИЯ, УЧРЕЖДЕННАЯ В 1856 Г. ЧАСТНЫМ ЛИЦОМ, ВИДНЫМ АРХЕОЛОГОМ А.С. УВАРОВЫМ, В ПАМЯТЬ О СВОЕМ ОТЦЕ, БЫВШЕМ МИНИСТРЕ НАРОДНОГО ПРОСВЕЩЕНИЯ С.С. УВАРОВЕ. АВТОР ДОКАЗЫВАЕТ, ЧТО ОРГАНИЗАТОРЫ ОРИЕНТИРОВАЛИСЬ НА ФРАНЦУЗСКИЕ ЛИТЕРАТУРНЫЕ И НАУЧНЫЕ ПРЕМИИ, ВОКРУГ КОТОРЫХ ВОЗНИКАЛИ НЕЗАВИСИМЫЕ ОТ ГОСУДАРСТВА СООБЩЕСТВА ЛИТЕРАТОРОВ И УЧЕНЫХ, ЯВЛЯВШИЕСЯ «ОДНОЙ ИЗ ФОРМ, В КОТОРЫХ ПУБЛИЧНАЯ СФЕРА МОГЛА РАЗВИВАТЬСЯ КАК АЛЬТЕРНАТИВА ЦЕНТРАЛЬНОЙ ВЛАСТИ» (С. 153). В РОССИЙСКОМ ЖЕ ПУБЛИЧНОМ ПРОСТРАНСТВЕ ЭТОТ ИНСТИТУТ ПРИОБРЁЛ СВОИ УНИКАЛЬНЫЕ «ГИБРИДНЫЕ» ЧЕРТЫ. АВТОР ПОЛАГАЕТ, ЧТО В ИСТОРИИ УВАРОВСКОЙ ЛИТЕРАТУРНОЙ ПРЕМИИ, КАК В КАПЛЕ ВОДЫ, ОТРАЗИЛИСЬ НЕКОТОРЫЕ ГЕНЕРАЛЬНЫЕ ТЕНДЕНЦИИ ЭПОХИ ВЕЛИКИХ РЕФОРМ, ВЫРАЖАВШИЕСЯ, МЕЖДУ ПРОЧИМ, В ТОМ, ЧТО МНОГИЕ СОЗДАВАЕМЫЕ ГОСУДАРСТВОМ ПУБЛИЧНЫЕ ИНСТИТУТЫ ДОЛЖНЫ БЫЛИ «ФУНКЦИОНИРОВАТЬ КАК СВОЕГО РОДА СИМБИОЗ РАЗВИВАЮЩЕЙСЯ ПУБЛИЧНОЙ СФЕРЫ И ГОСУДАРСТВА». ТАК, «ВО ВТОРОЙ ПОЛОВИНЕ 1850-Х ГОДОВ НА СЛУЖБУ В ЦЕНЗУРУ СТРЕМИЛИСЬ ПРИНЯТЬ КАК МОЖНО БОЛЬШЕ ПИСАТЕЛЕЙ, КОТОРЫЕ, ПО ВСЕЙ 
ВИДИМОСТИ, ДОЛЖНЫ БЫЛИ ПРЕВРАТИТЬ ЦЕНЗУРУ В СВОЕОБРАЗНОГО ПОСРЕДНИКА МЕЖДУ ГОСУДАРСТВОМ И ЛИТЕРАТУРНЫМ СООБЩЕСТВОМ» (С. 173). В УСЛОВИЯХ НАРАСТАЮЩЕГО КОНФЛИКТА МЕЖДУ ГОСУДАРСТВОМ И ОБЩЕСТВОМ В 1860-ЕГГ. ИНСТИТУТ ЛИТЕРАТУРНОЙ ПРЕМИИ, ФУНКЦИОНИРОВАВШИЙ ПОД ЭГИДОЙ ГОСУДАРСТВЕННОЙ АКАДЕМИИ НАУК, ПАРАДОКСАЛЬНЫМ ОБРАЗОМ СТАЛ ВОСПРИНИМАТЬСЯ «КАК БЮРОКРАТИЧЕСКАЯ ОРГАНИЗАЦИЯ, ПРОТИВОСТОЯЩАЯ “ПУБЛИКЕ” И НЕ ДАЮЩАЯ ЭТОЙ ПУБЛИКЕ ВЫСКАЗАТЬ СВОЮ ТОЧКУ ЗРЕНИЯ» (С. 172).

РАЗМЫШЛЯЯ О ФЕНОМЕНЕ ПОЗДНЕИМПЕРСКОЙ «ПУБЛИЧНОЙ СФЕРЫ» В РОССИИ, ДЖОН НЕЛЬСОН В СТАТЬЕ «ОТМЕНА ТЕАТРАЛЬНОЙ МОНОПОЛИИ И ЕЕ ЗНАЧЕНИЕ: КАК МУЗЫКА И ТЕАТР ОБЪЕДИНИЛИСЬ В СПОРЕ С НИКОЛАЕМ II И ДОКТРИНОЙ ОФИЦИАЛЬНОЙ НАРОДНОСТИ» ФОКУСИРУЕТ СВОЕ ВНИМАНИЕ НА ТАКОЙ СПЕЦИФИЧЕСКОЙ ФОРМЕ ПУБЛИЧНОГО ВЫСКАЗЫВАНИЯ, КАК МУЗЫКА. ОПЕРА БЫЛА В МЕНЬШЕЙ СТЕПЕНИ ПОДВЕРЖЕНА ЦЕНЗУРЕ, А С 1882 Г. ТЕАТРЫ МОГЛИ БЫТЬ ЧАСТНЫМИ, ПРИЧЕМ НЕКОТОРЫЕ ИЗ НИХ (НАПРИМЕР, МАМОНТОВСКАЯ ЧАСТНАЯ ОПЕРА) УСПЕШНО КОНКУРИРОВАЛИ С ИМПЕРАТОРСКИМИ ТЕАТРАМИ. Д. НЕЛЬСОН ПОЛАГАЕТ, ЧТО «ОТМЕНА МОНОПОЛИИ ИМПЕРСКИХ ТЕАТРОВ ОТКРЫЛА ДОРОГУ ПУБЛИЧНОМУ ВЫРАЖЕНИЮ ОППОЗИЦИОННЫХ НАСТРОЕНИЙ, СРЕДОТОЧИЕМ КОТОРЫХ СТАЛИ ЧАСТНЫЕ ТЕАТРЫ» (С. 176). ИМЕННО В ЧАСТНЫХ ТЕАТРАХ МОСКВЫ СОСТОЯЛИСЬ ПОСТАНОВКИ ОПЕР Н.А. РИМСКОГО-КОРСАКОВА, НЕСОМНЕННО СОДЕРЖАЩИХ В СЕБЕ ОСТРЫЕ ПОЛИТИЧЕСКИЕ РЕПЛИКИ («ЦАРСКАЯ НЕВЕСТА» 1899 Г., «КАЩЕЙ БЕССМЕРТНЫЙ» 1902 Г., «ЗОЛОТОЙ ПЕТУШОК» 1908 Г.). АУ ДИТОРИЕЙ ЧАСТНЫХ ТЕАТРОВ ЯВЛЯЛИСЬ «ПРЕДСТАВИТЕЛИ ИНТЕЛЛИГЕНЦИИ, НОВОЙ БУРЖУАЗИИ И КУПЕЧЕСТВА, У КОТОРЫХ ПРАВОМЕРНОСТЬ САМОДЕРЖАВИЯ К ТОМУ ВРЕМЕНИ УЖЕ ВЫЗЫВАЛА СОМНЕНИЯ» (С. 197). ПРИМЕЧАТЕЛЬНО, ЧТО ВАЖНЕЙШУЮ РОЛЬ В ПРОЦЕССЕ РАЗВИТИЯ ЧАСТНЫХ ТЕАТРОВ ИГРАЛИ ПРЕДСТАВИТЕЛИ ПРОМЫШЛЕННЫХ КРУГОВ, ПРИЧЕМ МНОГИЕ ПРОИСХОДИЛИ ИЗ СТАРООБРЯДЧЕСКИХ СЕМЕЙ, КОТОРЫЕ ОДНОВРЕМЕННО С ЭТИМ ПРИНИМАЛИ УЧАСТИЕ И В ДРУГИХ ФОРМАХ ПРОТЕСТА (НАПРИМЕР, С.Т. МОРОЗОВ ФИНАНСИРОВАЛ НЕЛЕГАЛЬНУЮ СОЦИАЛЬНО-ДЕМОКРАТИЧЕСКУЮ ГАЗЕТУ «ИСКРА»). ПО МЫСЛИ НЕЛЬСОНА, ЧАСТНЫЙ ТЕАТР ЯВЛЯЛСЯ ВАЖНЫМ ЭЛЕМЕНТОМ «НОВОЙ ПУБЛИЧНОЙ СФЕРЫ», В КОТОРОЙ ОСУЩЕСТВЛЯЛАСЬ КРИТИКА РЕЖИМА НЕОГРАНИЧЕННОГО САМОДЕРЖАВИЯ. «УСПЕХ ЧАСТНЫХ ТЕАТРОВ У ПРЕДСТАВИТЕЛЕЙ РАСТУЩЕГО СРЕДНЕГО КЛАССА СПОСОБСТВОВАЛ - НАРЯДУ С ПУБЛИЧНЫМИ ТЕАТРАМИ И КРИТИКОЙ В ПРЕССЕ - УСИЛЕНИЮ РАДИКАЛЬНЫХ НАСТРОЕНИЙ В РУССКОМ ОБЩЕСТВЕ В СВЯЗИ С СОБЫТИЯМИ 1905-1907 ГОДОВ И ПЕРЕОСМЫСЛЕНИЮ ДОКТРИНЫ ОФИЦИАЛЬНОЙ НАРОДНОСТИ» (С. 198).

РАБОТУ ДЖОНА НЕЛЬСОНА УДАЧНО ДОПОЛНЯЕТ ИССЛЕДОВАНИЕ ДЖОВАНИ САВИНО («ПУБЛИЧНАЯ СФЕРА И ВНЕШНЯЯ ПОЛИТИКА РУССКОГО НАЦИОНАЛИЗМА: ГАЛИЦКОРУССКОЕ ОБЩЕСТВО И “ГАЛИЦКИЙ ВОПРОС”, 1902-1915»), КОТОРОЕ ПОКАЗЫВАЕТ, ЧТО «ПУБЛИЧНАЯ СФЕРА В ПОЗДНЕИМПЕРСКОЙ РОССИИ БЫЛА ПРОСТРАНСТВОМ РАЗНЫХ ПОЛИТИЧЕСКИХ И СОЦИАЛЬНЫХ ТЕЧЕНИЙ», В ТОМ ЧИСЛЕ И КОНСЕРВАТИВНЫХ. В ФОКУСЕ ЕЕ ИССЛЕДОВАНИЯ - ГАЛИЦКО-РУССКОЕ БЛАГОТВОРИТЕЛЬНОЕ ОБЩЕСТВО (1902-1917), КОТОРОЕ ЯВЛЯЛОСЬ ОДНИМ ИЗ ВАЖНЕЙШИХ ОБЪЕДИНЕНИЙ «НАЦИОНАЛИСТИЧЕСКОГО ЛАГЕРЯ». Д. САВИНО РАССМАТРИВАЕТ ИСТОРИЮ ГАЛИЦКОРУССКОГО БЛАГОТВОРИТЕЛЬНОГО ОБЩЕСТВА СКВОЗЬ ПРИЗМУ КОНЦЕПТА ПУБЛИЧНОЙ СФЕРЫ. УЧРЕЖДЕННОЕ В 1902 Г. «ПРЕДСТАВИТЕЛЯМИ АКАДЕМИЧЕСКОГО МИРА, ЧИНОВНИЧЕСТВА, ДУХОВЕНСТВА И ДВОРЯНСТВА», ОБЩЕСТВО ПЫТАЛОСЬ «СОЗДАТЬ 
НОВУЮ СЕТЬ ПОДДЕРЖКИ РУСОФИЛЬСТВА В ГАЛИЦИИ ВНУТРИ РОССИЙСКОГО ОБЩЕСТВА И ИСПОЛЬЗОВАТЬ ПОДДЕРЖКУ ДЛЯ ДАВЛЕНИЯ НА ГОСУДАРСТВЕННЫЕ ВЛАСТИ С ЦЕЛЬЮ ВМЕШАТЕЛЬСТВА САНКТ-ПЕТЕРБУРГА ВО ВНУТРЕННЮЮ ПОЛИТИКУ АВСТРО-ВЕНГРИИ» (С. 209-210). ИНЫМИ СЛОВАМИ, ЕГО ПОВЕСТКА БЫЛА «ПО СУТИ ПОЛИТИЧЕСКОЙ» (С. 207). ПОСЛЕ РЕВОЛЮЦИИ 1905 Г., КОГДА В РОССИЙСКОЙ ИМПЕРИИ СФОРМИРОВАЛСЯ НОВЫЙ РЕЖИМ ПУБЛИЧНОСТИ, ДОСТУП К ПУБЛИКЕ ПОЛУЧИЛИ НЕ ТОЛЬКО ЛИБЕРАЛЫ И РЕВОЛЮЦИОНЕРЫ, НО ТАКЖЕ И ЗАЩИТНИКИ САМОДЕРЖАВИЯ, В ЧИСЛЕ КОТОРЫХ БЫЛО ГАЛИЦКО-РУССКОЕ БЛАГОТВОРИТЕЛЬНОЕ ОБЩЕСТВО: ЕГО ЛИДЕР А.С. БУДИЛОВИЧ ПРИНЯЛ УЧАСТИЕ В СОЗДАНИИ ЖУРНАЛА «ОКРАИНЫ РОССИИ» (1906 Г.), А ЧЛЕН И ВПОСЛЕДСТВИИ ПРЕДСЕДАТЕЛЬ ОБЩЕСТВА ГРАФ В.А. БОБРИНСКИЙ СТАЛ АКТИВНОМ ЧЛЕНОМ ГОСУДАРСТВЕННОЙ ДУМЫ ВТОРОГО, ТРЕТЬЕГО И ЧЕТВЕРТОГО СОЗЫВОВ. Д.САВИНО ПОКАЗЫВАЕТ, ЧТО РАБОТА ГАЛИЦКО-РУССКОГО БЛАГОТВОРИТЕЛЬНОГО ОБЩЕСТВА СПОСОБСТВОВАЛА ЗАКРЕПЛЕНИЮ ЩГАЛИЦКОРУССКОГО НАРРАТИВА» И В ЦЕЛОМ «НАЦИОНАЛИСТИЧЕСКОГО ДИСКУРСА» В ОБЩЕСТВЕННОМ МНЕНИИ.

АЛЕКСАНДР КОРОБЕЙНИКОВ В СТАТЬЕ «ИМПЕРСКАЯ ТРАНСФОРМАЦИЯ ПУБЛИЧНОЙ СФЕРЫ: ПЕЧАТНОЕ СЛОВО И ПУБЛИЧНЫЙ ДЕБАТ КАК СРЕДСТВО ФОРМИРОВАНИЯ ОБЩЕСТВЕННЫХ ДВИЖЕНИЙ В СИБИРИ» СТАВИТ ИНТЕРЕСНЫЙ И ВАЖНЫЙ ВОПРОС О ТОМ, КАК РАЗВИТИЕ МОДЕРНЫХ СРЕДСТВ ПЕРЕМЕЩЕНИЯ И ПОЯВЛЕНИЕ НОВЫХ ОБРАЗОВАТЕЛЬНЫХ ВОЗМОЖНОСТЕЙ ДЛЯ ВЫХОДЦЕВ ИЗ СИБИРИ ВЛИЯЛИ НА ФОРМИРОВАНИЕ ПУБЛИЧНОЙ СФЕРЫ (ИЛИ КАКИХ-ТО ЕЕ ЭЛЕМЕНТОВ) НА ОТДАЛЕННЫХ ОКРАИНАХ РОССИЙСКОЙ ИМПЕРИИ. АВТОР ПОКАЗЫВАЕТ, ЧТО КЛЮЧЕВОЕ ЗНАЧЕНИЕ ИМЕЛО ПОЯВЛЕНИЕ МЕСТНОЙ ИНТЕЛЛИГЕНЦИИ, КОТОРАЯ ВЫСТУПАЛА В РОЛИ ВАЖНОГО АКТОРА В ПРОЦЕССЕ СОЗДАНИЯ «СИБИРСКОЙ ПУБЛИЧНОЙ СФЕРЫ». НА ФОРМИРОВАНИЕ СИБИРСКОЙ ИНТЕЛЛИГЕНЦИИ ПОВЛИЯЛО НЕСКОЛЬКО ФАКТОРОВ. СРЕДИ НИХ - ПОЛИТИЧЕСКАЯ ССЫЛКА, КОТОРАЯ СПОСОБСТВОВАЛА ПЕРЕМЕЩЕНИЮ В СИБИРЬ «ЯЗЫКА ПРОСВЕЩЕНИЯ» И «ЭЛЕМЕНТОВ ОБЩЕСТВЕННОСТИ», НОСИТЕЛЯМИ КОТОРЫХ ЯВЛЯЛИСЬ ПОЛИТИЧЕСКИЕ ОСУЖДЕННЫЕ (С. 239). ВТОРЫМ ВАЖНЫМ ФАКТОРОМ БЫЛО ТО, ЧТО НАЧИНАЯ С СЕРЕДИНЫ ХІХ В. В СТОЛИЧНЫЕ УНИВЕРСИТЕТЫ ПОСТУПАЛО ВСЕ БОЛЬШЕ ВЫХОДЦЕВ ИЗ СИБИРИ. «УСВОИВ ТАКИЕ МЕХАНИЗМЫ ПУБЛИЧНОСТИ, КАК КРИТИЧЕСКИЕ ОБСУЖДЕНИЯ СОЦИАЛЬНО-ПОЛИТИЧЕСКИХ И ЛИТЕРАТУРНЫХ ТЕКСТОВ, ДИСКУССИИ, ПУБЛИЧНЫЕ ВЫСТУПЛЕНИЯ, СТУДЕНТЫ ОРГАНИЗОВАЛИ КРУЖОК СИБИРСКИХ ПАТРИОТОВ, РАЗБИРАЯ ПРОБЛЕМЫ ЭКОНОМИЧЕСКОЙ, ПОЛИТИЧЕСКОЙ И КУЛЬТУРНОЙ ОТСТАЛОСТИ СИБИРИ. ПОМИМО ЭТОГО, ОНИ КРИТИКОВАЛИ ПРАВИТЕЛЬСТВЕННЫЕ МЕРЫ, ХОДИЛИ НА ДЕМОНСТРАЦИИ, БЕСЕДОВАЛИ О РЕВОЛЮЦИИ И РЕФОРМАХ В ИМПЕРИИ» (С. 240). ТАКИМ ОБРАЗОМ В «ПРОСВЕЩЕННОЙ» МЕТРОПОЛИИ СИБИРЯКИ УСВАИВАЛИ МОДЕЛИ ПУБЛИЧНОЙ АКТИВНОСТИ И НЕКОТОРЫЕ ВАЖНЫЕ ИДЕИ (ТАКИЕ, КАК ОБЛАСТНИЧЕСТВО), КОТОРЫЕ ЗАТЕМ ВМЕСТЕ С НИМИ ПЕРЕМЕЩАЛИСЬ «НА ПРОСТРАНСТВО СИБИРИ» (С. 241). ВСЕ ЭТО СПОСОБСТВОВАЛО ПОСТЕПЕННОМУ ФОРМИРОВАНИЮ В САМЫХ ОТДАЛЕННЫХ СИБИРСКИХ УГОЛКАХ РОССИЙСКОЙ ИМПЕРИИ «“ИНОРОДЧЕСКИХ” ОБЩЕСТВЕННЫХ ПРОСТРАНСТВ» (С. 251-255).

В СТАТЬЕ СТИВЕНА ЛОВЕЛЛА «ПУБЛИЧНАЯ СФЕРА В РОССИИ В ЭПОХУ СТЕНОГРАФИИ» В ЦЕНТРЕ ВНИМАНИЯ ОКАЗЫВАЮТСЯ НЕ СТОЛЬКО САМИ ПУБЛИЧНЫЕ ВЫСКАЗЫВАНИЯ И НЕ ИНСТИТУТЫ ПУБЛИЧНОЙ СФЕРЫ, СКОЛЬКО ФОРМЫ ПУБЛИЧНОГО ДИСКУРСА. ЗНАЧЕНИЕ ТАКОЙ ОПТИКИ СЛОЖНО ПЕРЕОЦЕНИТЬ: «ВЕДЬ ЧТО ИМЕННО МОЖНО 
ВЫСКАЗАТЬ ПУБЛИЧНО, В ЗНАЧИТЕЛЬНОЙ МЕРЕ ЗАВИСИТ ОТ ТОГО, КАКИМИ СРЕДСТВАМИ ДЛЯ ЭТОГО МЫ РАСПОЛАГАЕМ» (С. 259-260). КОНЕЧНО, НЕ СЛУЧАЙНО РАСПРОСТРАНЕНИЕ ТЕХНОЛОГИИ БЫСТРОЙ ЗАПИСИ УСТНОЙ РЕЧИ И ПОДГОТОВКА СООТВЕТСТВУЮЩИХ СПЕЦИАЛИСТОВ НАЧАЛАСЬ В РОССИИ В 1860-ЕГГ., В ЭПОХУ ВЕЛИКИХ РЕФОРМ АЛЕКСАНДРА ІІ, КОТОРУЮ С. ЛОВЕЛЛ НАЗЫВАЕТ «ПЕРВОЙ ЭПОХОЙ “ГЛАСНОСТИ"». «В 1860-Е ГОДЫ НЕ ТОЛЬКО РАСПРОСТРАНИЛОСЬ САМО ПОНЯТИЕ ПУБЛИЧНОСТИ, НО ПОЯВИЛАСЬ И НОВАЯ ТЕХНОЛОГИЯ, ПОЗВОЛЯВШАЯ ФИКСИРОВАТЬ ЭТУ “ПУБЛИЧНОСТЬ”, - СТЕНОГРАФИЯ» (С. 260). ПОТРЕБНОСТЬ В СТЕНОГРАФИИ ИМЕННО В ЭТУ ЭПОХУ ОБЪЯСНЯЕТСЯ, В ПЕРВУЮ ОЧЕРЕДЬ, НЕОБХОДИМОСТЬЮ ТЕХНИЧЕСКИ ОБЕСПЕЧИТЬ НОВЫЕ ОБЩЕСТВЕННЫЕ ИНСТИТУТЫ - ГЛАСНЫЕ СУДЫ И ЗЕМСТВА. «НОВЫЙ СПОСОБ ФИКСАЦИИ “ЖИВОГО СЛОВА” БЫЛ ПРИЗВАН СПОСОБСТВОВАТЬ ДОСТИЖЕНИЮ ГЛАВНЫХ ЦЕЛЕЙ ЭПОХИ РЕФОРМ - “ПУБЛИЧНОСТИ" И “ГЛАСНОСТИ”. ПОДДЕРЖАНИЕ “ПУБЛИЧНОСТИ" ТРЕБОВАЛО ДОСТОВЕРНОЙ ПЕРЕДАЧИ “ПУБЛИКЕ” ПРОИЗНЕСЕННЫХ РЕЧЕЙ» (С. 260). НО НАСТОЯЩИМ «ЗОЛОТЫМ ВЕКОМ» РУССКОЙ СТЕНОГРАММЫ СТАЛА ЭПОХА ГОСУДАРСТВЕННОЙ ДУМЫ (1906-1917). НЕСМОТРЯ НА ТО, ЧТО ДУМА ОКАЗЫВАЛА НЕЗНАЧИТЕЛЬНОЕ ВЛИЯНИЕ НА ПРИНЯТИЕ ВАЖНЫХ ПОЛИТИЧЕСКИХ РЕШЕНИЙ, ЕЕ ЗНАЧЕНИЕ В РАЗВИТИИ РОССИЙСКОЙ ПОЗДНЕИМПЕРСКОЙ ПУБЛИЧНОЙ СФЕРЫ СЛОЖНО ПЕРЕЦЕНИТЬ. АВТОР СРАВНИВАЕТ ЗАСЕДАНИЯ ДУМЫ С ТЕАТРОМ: «ТАВРИЧЕСКИЙ ДВОРЕЦ ИДЕАЛЬНО ВЫПОЛНЯЛ ФУНКЦИЮ ПОЛИТИЧЕСКОГО ТЕАТРА, В КОТОРОМ МОГЛИ ВЫСТУПАТЬ ОРАТОРЫ САМЫХ РАЗНЫХ МАСТЕЙ... НО, КАК И ЛЮБОМУ ТЕАТРУ, РОССИЙСКОМУ ПАРЛАМЕНТУ ТРЕБОВАЛАСЬ ПУБЛИКА, А ДЛЯ ЭТОГО НАДО БЫЛО ПЕЧАТАТЬ СТЕНОГРАММЫ» (С. 284). ОДНАКО ВЛАСТЬ И ОБЩЕСТВО СМОТРЕЛИ НА «ГЛАСНОСТЬ», «ПУБЛИЧНОСТЬ» И НОВУЮ ТЕХНОЛОГИЮ ФИКСАЦИИ ПУБЛИЧНОГО СЛОВА ПО-РАЗНОМУ. В ПЛАНЫ АГЕНТОВ ВЛАСТИ ВОВСЕ НЕ ВХОДИЛО ШИРОКОЕ РАЗВИТИЕ СВОБОДЫ СЛОВА И ГЛАСНОСТИ; ОНИ РАССЧИТЫВАЛИ, СКОРЕЕ, НА ПОЛУЧЕНИЕ ДОСТОВЕРНОЙ ИНФОРМАЦИИ О РОССИЙСКОМ ОБЩЕСТВЕ «ЗА СЧЕТ ТОЧНОЙ ПЕРЕДАЧИ БО́ЛЬШИХ ОБЪЕМОВ ИНФОРМАЦИИ» ДЛЯ БОЛЕЕ ЭФФЕКТИВНОГО АДМИНИСТРИРОВАНИЯ (С. 262). НО РАСПРОСТРАНЕНИЕ СТЕНОГРАФИИ ИМЕЛО ДЛЯ ГОСУДАРСТВА НЕОЖИДАННЫЙ ЭФФЕКТ: СЛОЖИВШАЯСЯ В ЭПОХУ ВЕЛИКИХ РЕФОРМ «КУЛЬТУРА ПУБЛИЧНОГО ВЫСКАЗЫВАНИЯ», ОБЕСПЕЧЕННАЯ СТЕНОГРАФИЕЙ, ПРОДОЛЖАЛА СУЩЕСТВОВАТЬ В САМЫХ РАЗЛИЧНЫХ СФЕРАХ (ОТ СУДЕБНЫХ ЗАСЕДАНИЙ ДО УНИВЕРСИТЕТСКИХ АУДИТОРИЙ) ДАЖЕ В ЭПОХУ КОНТРРЕФОРМ И «НАЛОЖИЛА ЗАМЕТНЫЙ ОТПЕЧАТОК НА ПУБЛИЧНУЮ КУЛЬТУРУ В РОССИИ» (С. 309). ПО МНЕНИЮ С. ЛОВЕЛЛА, В ДАННОМ СЛУЧАЕ НА ПРИМЕРЕ РОССИИ МЫ МОЖЕМ НАБЛЮДАТЬ ПРОТИВОРЕЧИЕ, КОТОРОЕ БЫЛО ОТМЕЧЕНО ХАБЕРМАСОМ: «С ОДНОЙ СТОРОНЫ, УСИЛЕНИЕ ГОСУДАРСТВЕННОЙ ВЛАСТИ МОНАРХА, С ДРУГОЙ УСЛОВИЯ ДЛЯ РАЗВИТИЯ ПУБЛИЧНОСТИ, КОТОРЫЕ СОЗДАЮТСЯ БЛАГОДАРЯ ФОРМИРОВАНИЮ ГОСУДАРСТВЕННЫХ ИНСТИТУТОВ. ИЗНАЧАЛЬНО СТЕНОГРАФИЯ В РОССИИ БЫЛА ПРИЗВАНА СПОСОБСТВОВАТЬ УКРЕПЛЕНИЮ И МОДЕРНИЗАЦИИ ПРАВИТЕЛЬСТВЕННЫХ ПРОЕКТОВ, НО ОНА ГЛАВНЫМ ОБРАЗОМ СТИМУЛИРОВАЛА ВОЗНИКНОВЕНИЕ ЛИБЕРАЛЬНОЙ (И РАДИКАЛЬНОЙ) ОБЩЕСТВЕННОСТИ» (С. 266). ПОСЛЕ ПРИХОДА К ВЛАСТИ БОЛЬШЕВИКОВ СТЕНОГРАФИЯ ИГРАЛА ВАЖНУЮ РОЛЬ В ОБЕСПЕЧЕНИИ КОЛЛЕКТИВНОГО РУКОВОДСТВА И ВНУТРИПАРТИЙНОЙ ДЕМОКРАТИИ (С.299-300). НО В ПЕРИОД СТАЛИНСКОЙ ДИКТАТУРЫ СТЕНОГРАФИЯ УЖЕ СЛУЖИТ ОБЩИМ ЦЕЛЯМ «СТАЛИНСКОЙ ПУБЛИЧНОЙ СФЕРЫ» - ОДОБРЕНИЮ ДЕЙСТВИЙ ВОЖДЯ И КОНТРОЛЮ ЗА ПРОТИВНИКАМИ РЕЖИМА. ОДНАКО ВОЗНИКАЕТ ВОПРОС, НАСКОЛЬКО СОВЕТСКАЯ «СТЕНОГРАММА» ПРОДОЛЖАЛА ОСТАВАТЬСЯ СТЕНОГРАММОЙ, ЕСЛИ В 
«1930-Е ГОДЫ СТЕНОГРАФИЧЕСКИЕ ОТЧЕТЫ О ПОЛИТИЧЕСКИХ ЗАСЕДАНИЯХ СУЩЕСТВЕННО ОТЛИЧАЛИСЬ ОТ ТОГО, ЧТО НА НИХ В ДЕЙСТВИТЕЛЬНОСТИ говОРИЛОСь» (с. 307-308).

В КАЧЕСТВЕ ЗАКЛЮЧИТЕЛЬНОГО ТЕКСТА В СБОРНИКЕ ПРИВОДЯТСЯ РАЗМЫШЛЕНИЯ НАД ПРОЧИТАННЫМИ МАТЕРИАЛАМИ ЭЛЛЕН РУТТЕН («НЕСОВЕРШЕНСТВО И ПУБЛИЧНАЯ СФЕРА: ЭПИЛОГ»), КОТОРАЯ ВЕРНО ПОДМЕТИЛА, ЧТО КРАСНОЙ НИТЬЮ, ПРОХОДЯЩЕЙ ЧЕРЕЗ ВСЕ РАБОТЫ, ЯВЛЯЕТСЯ ПРОБЛЕМА «ПРОТИВОРЕЧИВОСТИ И ПРИНЦИПИАЛЬНОГО НЕСОВЕРШЕНСТВА ОБСУЖДАЕМЫХ ПУБЛИЧНЫХ РЕЖИМОВ» ${ }^{10}$ (С. 719-720). СОСТАВИТЕЛИ, КОТОРЫЕ, КОНЕЧНО, ОБРАТИЛИ ВНИМАНИЕ НА ТО, ЧТО ВСЕ СОБРАННЫЕ В РАМКАХ ДАННОГО СБОРНИКА СТАТЬИ РАССМАТРИВАЮТ «ИНСТИТУТЫ И КОММУНИКАТИВНЫЕ СРЕДЫ, ГДЕ ПРОЯВЛЯЮТСЯ СОЦИАЛЬНО ЗНАЧИМЫЕ ЭФФЕКТЫ ПУБЛИЧНОСТИ (ВКЛЮЧАЯ “ОБЩЕСТВЕННОЕ МНЕНИЕ”), НО С ОГРАНИЧЕННЫМ ИЛИ СЛАБЫМ ВЛИЯНИЕМ НА РЕШЕНИЯ» (С. 73), ПОПЫТАЛИСЬ ОСМЫСЛИТЬ ЭТОТ РЕЗУЛЬТАТ И ДАЖЕ ПРЕДЛОЖИЛИ ПРЕВРАТИТЬ ЕГО В ПОЛЕЗНЫЙ АНАЛИТИЧЕСКИЙ ИНСТРУМЕНТ. ДЛЯ ЭТОГО РАЗРАБОТЧИКИ КОНЦЕПЦИИ «НЕСОВЕРШЕННОЙ ПУБЛИЧНОЙ СФЕРЫ» ОБРАЩАЮТСЯ К ИДЕЯМ ОДНОГО ИЗ ТЕОРЕТИКОВ ПУБЛИЧНОЙ СФЕРЫ НЭНСИ ФРЕЙЗЕР О НЕОБХОДИМОСТИ РАЗДЕЛЯТЬ ПУБЛИЧНЫЕ СФЕРЫ НА ДВЕ КАТЕГОРИИ - «СИЛЬНУЮ» И «СЛАБУЮ» ПУБЛИКУ ${ }^{11}$. «СИЛЬНАЯ ПУБЛИКА - ЭТО ПУБЛИКА, ИМЕЮЩАЯ НЕ ТОЛЬКО ПРАВО ОБСУЖДАТЬ, НО И ЮРИДИЧЕСКИЕ И ПОЛИТИЧЕСКИЕ ПОЛНОМОЧИЯ ПРИНИМАТЬ РЕШЕНИЯ, ТОГДА КАК СЛАБАЯ ПУБЛИЧНАЯ СФЕРА ВСЕГО ЛИШЬ ОКАЗЫВАЕТ ВЛИЯНИЕ НА ТЕХ, КТО РЕАЛЬНО ПРИНИМАЕТ РЕШЕНИЯ. СЛАБАЯ ЖЕ ПУБЛИКА МОЖЕТ ТОЛЬКО РАССУЖДАТЬ И ИМЕЕТ ЛИШЬ КОСВЕННОЕ ВЛИЯНИЕ НА ОФИЦИАЛЬНЫЕ РЕЗОЛЮЦИИ», ОДНАКО «СОЗДАЕТ ОПРЕДЕЛЕННУЮ КОММУНИКАТИВНУЮ ВЛАСТЬ, ПУСТЬ И СЛАБУЮ» (С. 73-74). СОСТАВИТЕЛИ СБОРНИКА СПРАВЕДЛИВО ПОЛАГАЮТ, ЧТО ЭТО РАЗЛИЧЕНИЕ ПУБЛИК ИМЕЕТ ВАЖНОЕ ИНСТРУМЕНТАЛЬНОЕ ЗНАЧЕНИЕ ДЛЯ ОСМЫСЛЕНИЯ РЕЖИМОВ ПУБЛИЧНОСТИ В РОССИИ. ОДНОЙ ИЗ ЗАДАЧ СОСТАВИТЕЛЕЙ И АВТОРОВ СБОРНИКА КАК РАЗ И БЫЛО «НАЙТИ АДЕКВАТНЫЕ СПОСОБЫ ОПИСАНИЯ И ПОНИМАНИЯ РАЗНООБРАЗИЯ СЛАБЫХ ИМПЕРСКИХ И СОВЕТСКИХ ПУБЛИК И СООТВЕТСТВУЮЩИХ РЕЖИМОВ ПУБЛИЧНОСТИ КАК В ПОЛИТИЧЕСКОЙ СФЕРЕ, ТАК И В ОБЛАСТИ КУЛЬТУРЫ И ХУДОЖЕСТВЕННОГО ТВОРЧЕСТВА» (С. 74).

В ЗАКЛЮЧЕНИЕ ХОЧУ ОБРАТИТЬ ВНИМАНИЕ НА ОДИН ВАЖНЫЙ МОМЕНТ, КОТОРЫЙ, КАК МНЕ КАЖЕТСЯ, СОСТАВИТЕЛИ СБОРНИКИ УПУСТИЛИ ИЗ ВИДУ. ПОЧЕМУ В КАЧЕСТВЕ ОТПРАВНОЙ ТОЧКИ ДЛЯ ИССЛЕДОВАНИЯ «РАБОТАЮЩИХ ПРАКТИК И РЕЖИМОВ ПУБЛИЧНОСТИ» В РОССИИ БЕРЕТСЯ НАЧАЛО ХІХВ.? К СОЖАЛЕНИЮ, ВО ВСТУПИТЕЛЬНОЙ СТАТЬЕ НИКАКОГО ОБОСНОВАНИЯ НИЖНЕЙ ХРОНОЛОГИЧЕСКОЙ ГРАНИЦЫ НЕТ, НО ЕГО, КАЖЕТСЯ, МОЖНО ОБНАРУЖИТЬ В ОДНОЙ ИЗ ИССЛЕДОВАТЕЛЬСКИХ СТАТЬЕЙ. АЛЕКСАНДР КОРОБЕЙНИКОВ ПИШЕТ: «НЕСМОТРЯ НА ПРОМЫШЛЕННУЮ И СОЦИАЛЬНУЮ ОТСТАЛОСТЬ, А ТАКЖЕ САМОДЕРЖАВНЫЕ ПОДОЗРЕНИЯ В ОТНОШЕНИИ НЕЗАВИСИМЫХ (АВТОНОМНЫХ) ПРОСТРАНСТВ И ОБЩЕСТВ, К КОНЦУ XVIII ВЕКА В РОССИЙСКОЙ ИМПЕРИИ ПРОИСХОДИЛО ЗАРОЖДЕНИЕ ПУБЛИЧНОЙ СФЕРЫ: ПОЯВЛЯЛИСЬ КЛУБЫ, НАУЧНЫЕ И ЛИТЕРАТУРНЫЕ ИНСТИТУЦИИ, ТЕАТРЫ, САЛОНЫ И Т. Д.» (С. 233) ${ }^{12}$. ОДНАКО ТАКОЙ ВЗГЛЯД, КАК МНЕ КАЖЕТСЯ, СОЗДАЕТ НЕКОТОРЫЙ ДИССОНАНС С ПРОГРАММНОЙ СТАТЬЕЙ И ДРУГИМИ ИССЛЕДОВАТЕЛЬСКИМИ РАБОТАМИ РЕЦЕНЗИРУЕМОГО СБОРНИКА. ДЕЙСТВИТЕЛЬНО, «НЕСОВЕРШЕННАЯ ПУБЛИЧНАЯ СФЕРА» ПРЕКРАСНО ПОКАЗЫВАЕТ, ЧТО ПРИМЕНЕНИЕ ИДЕАЛЬНОГО ТИПА «БУРЖУАЗНОЙ ПУБЛИЧНОЙ СФЕРЫ» ПРОБЛЕМАТИЧНО ДАЖЕ ДЛЯ 
РОССИЙСКОГО ХІХ В., НО ЭТО ОТНЮДЬ НЕ ОЗНАЧАЕТ, ЧТО «МЫ ДОЛЖНЫ ОТВЕРГНУТЬ КОНЦЕПЦИЮ ХАБЕРМАСА»: РУСИСТАМ «СЛЕДУЕТ ЕЕ ДОРАБОТАТЬ, ЧТОБЫ СДЕЛАТЬ ПРИМЕНИМОЙ И К “СМЕШАННЫМ” СЛУЧАЯМ, СОЧЕТАЮЩИМ В СЕБЕ “БУРЖУАЗНЫЕ” И “АБСОЛЮТИСТСКИЕ” ЧЕРТЫ» (С. 259). НО В ТАКОМ СЛУЧАЕ, В КАКОЙ СТЕПЕНИ КОНЦЕПЦИЯ «РОССИЙСКИХ РЕЖИМОВ ПУБЛИЧНОСТИ», СФОРМУЛИРОВАННАЯ В СБОРНИКЕ «НЕСОВЕРШЕННАЯ ПУБЛИЧНАЯ СФЕРА», МОЖЕТ БЫТЬ ПРИМЕНЕНА К МОСКОВСКОМУ И РАННЕИМПЕРСКОМУ ПЕРИОДАМ? КАКИМИ ИСТОЧНИКАМИ МЫ ДЛЯ ЭТОГО РАСПОЛАГАЕМ?

\section{Памятники публицистики Московского царства: от истории идей к реконструкции «режимов публичности»?}

КНИГА ПРОФЕССОРА РОССИЙСКОГО ГОСУДАРСТВЕННОГО ГУМАНИТАРНОГО УНИВЕРСИТЕТА Д.И.АНТОНОВА ЩЦАРИ И САМОЗВАНЦЫ: БОРЬБА ИДЕЙ В РОССИИ СМУТНОГО ВРЕМЕНИ» ЯВЛЯЕТСЯ ЗНАЧИТЕЛЬНО ПЕРЕРАБОТАННОЙ ВЕРСИЕЙ КНИГИ 2009 Г., КОТОРАЯ БЫЛА НАПИСАНА НА ОСНОВЕ ЕГО КАНДИДАТСКОЙ ДИССЕРТАЦИИ ${ }^{13}$. В ЦЕНТРЕ ВНИМАНИЯ АВТОРА НАХОДИТСЯ «БОРЬБА ИДЕЙ» «О СМУТНОМ ВРЕМЕНИ (ЕГО ПРИЧИНАХ И СЛЕДСТВИЯХ, ГЕРОЯХ И АНТИГЕРОЯХ)», РАЗВЕРНУВШАЯСЯ В СРЕДЕ «РУССКИХ КНИЖНИКОВ» - СОВРЕМЕННИКОВ И УЧАСТНИКОВ СОБЫТИЙ ${ }^{14}$. Д.И. АНТОНОВ СТРЕМИТСЯ ПОНЯТЬ, КАКИМ ОБРАЗОМ САМИ ЛЮДИ, ПЕРЕЖИВШИЕ СМУТУ И УЧАСТВОВАВШИЕ В УНИКАЛЬНЫХ СОБЫТИЯХ «МЕЖДУЦАРСТВИЯ», ИХ ВОСПРИНИМАЛИ.

РАБОТА ОСНОВЫВАЕТСЯ «НА СЕМИОТИЧЕСКОМ И ФЕНОМЕНОЛОГИЧЕСКОМ ПОДХОДАХ», РАНЕЕ ПРИМЕНЯВШИХСЯ К ИСТОЧНИКАМ XVI-XVII ВВ. Б.А.УСПЕНСКИМ, А.Л. ЮРГАНОВЫМ, А.И.ФИЛЮШКИНЫМ И ДР., КОТОРЫЕ ПРЕДПОЛАГАЮТ «ГЕРМЕНЕВТИЧЕСКИЙ АНАЛИЗ ТЕКСТОВ, ИССЛЕДОВАНИЕ ЗНАКОВЫХ СИСТЕМ, ИХ ФУНКЦИОНИРОВАНИЯ И ЭВОЛЮЦИИ» (С. 12-13). АВТОР ПОЯСНЯЕТ, ЧТО ЕГО ПОДХОД СХОДЕН С ТЕМ, ЧТО ИСПОЛЬЗОВАЛ Б.А. УСПЕНСКИЙ, КОТОРЫЙ ОПРЕДЕЛИЛ ЕГО ТАК: «КУЛЬТУРНО-СЕМИОТИЧЕСКИЙ ПОДХОД К ИСТОРИИ ПРЕДПОЛАГАЕТ АПЕЛЛЯЦИЮ К ВНУТРЕННЕЙ ТОЧКЕ ЗРЕНИЯ САМИХ УЧАСТНИКОВ ИСТОРИЧЕСКОГО ПРОЦЕССА: ЗНАЧИМЫМ ПРИЗНАЕТСЯ ТО, ЧТО ЯВЛЯЕТСЯ ЗНАЧИМЫМ С ИХ ТОЧКИ ЗРЕНИЯ» ${ }^{15}$. ПРИ ЭТОМ Д.И. АНТОНОВ ОГОВАРИВАЕТСЯ, ЧТО ЕГО ИССЛЕДОВАТЕЛЬСКИЕ ЗАДАЧИ ВЫХОДЯТ ЗА РАМКИ «ГЕРМЕНЕВТИЧЕСКОГО АНАЛИЗА ОТДЕЛЬНОГО ИСТОЧНИКА». В КОНЕЧНОМ ИТОГЕ НЕОБХОДИМО ПРИЙТИ К «РЕКОНСТРУКЦИИ ПРЕДСТАВЛЕНИЙ И ЗНАКОВЫХ СИСТЕМ, ОТРАЗИВШИХСЯ В ШИРОКОМ КРУГЕ ТЕКСТОВ», А ОТ НИХ ПЕРЕЙТИ К ВОССТАНОВЛЕНИЮ «МИФОЛОГЕМ», ВЛИЯВШИХ НА «ВОСПРИЯТИЕ ЛЮДЬМИ КОНКРЕТНЫХ СОБЫТИЙ, РЕАКЦИЮ СОВРЕМЕННИКОВ НА ПРОИСХОДЯЩЕЕ ИЛИ ЕГО РЕТРОСПЕКТИВНЫЙ АНАЛИЗ» (С. 14-15).

ИССЛЕДОВАНИЕ СТРОИТСЯ ВОКРУГ ТРЕХ ПЕРЕСЕКАЮЩИХСЯ ТЕМАТИЧЕСКИХ ЛИНИЙ:

1. НОВЫЕ ПОЛИТИЧЕСКИЕ ПРАКТИКИ, ВОЗНИКШИЕ В СМУТНОЕ ВРЕМЯ, ТАКИЕ КАК ИЗБРАНИЕ ЦАРЯ НА ПРЕСТОЛ, СВЕДЕНИЕ РАНЕЕ ИЗБРАННОГО ЦАРЯ С ПРЕСТОЛА, ПРИНЕСЕНИЕ ГОСУДАРЕМ КЛЯТВЫ ПРИ ИЗБРАНИИ И ДР., ФОРМЫ ИХ ЛЕГИТИМАЦИИ ИЛИ ДЕЛЕГИТИМАЦИИ, А ТАКЖЕ ВОСПРИЯТИЕ ЭТИХ ПРАКТИК СОВРЕМЕННИКАМИ КАК В СМУТНОЕ ВРЕМЯ, ТАК И В ПОСЛЕДУЮЩИЕ ГОДЫ (ПРЕИМУЩЕСТВЕННО ГЛАВЫ 1 И 4, А ТАКЖЕ ЭКСКУРС 1); 
2. ОТНОШЕНИЕ К ИЗБРАННЫМ ЦАРЯМ И НЕКОТОРЫМ СОБЫТИЯМ ЭПОХИ СМУТЫ В САМЫХ РАЗЛИЧНЫХ ОБЩЕСТВЕННЫХ КРУГАХ - ОТ ТАК НАЗЫВАЕМОЙ «КНИЖНОЙ КУЛЬТУРЫ» ДО «НАРОДНОЙ СРЕДЫ» (ГЛАВЫ 2, 3 И 6);

3. ПРИЧИНЫ И «МЕХАНИКА» СМУТНОГО ВРЕМЕНИ В ВОСПРИЯТИИ «КНИЖНИКОВ» (СПЕЦИАЛЬНО ГЛАВА 5).

КАЖДАЯ ИССЛЕДОВАТЕЛЬСКАЯ ЛИНИЯ ПРОСЛЕЖИВАЕТСЯ НА ОСНОВЕ ГЛУБОКОГО АНАЛИЗА БОЛЬШОГО КРУГА ИСТОЧНИКОВ, ОДНАКО ОСНОВНЫМ ДЛЯ АВТОРА ЯВЛЯЕТСЯ КОРПУС «АВТОРСКИХ ИСТОРИЧЕСКИХ И ПУБЛИЦИСТИЧЕСКИХ СОЧИНЕНИЙ, ПОСВЯЩЕННЫХ СМУТЕ» (С. 9). ИЗ ВСЕХ ИСТОЧНИКОВ АВТОР ОСОБЕННО ВЫДЕЛЯЕТ ТРИ «ОПОРНЫХ» ТЕКСТА (С. 21): «СКАЗАНИЕ» («ИСТОРИЯ В ПАМЯТЬ ПРЕДИДУЩИМ РОДОМ») КЕЛАРЯ ТРОИЦЕ-СЕРГИЕВА МОНАСТЫРЯ АВРААМИЯ ПАЛИЦЫНА, «ВРЕМЕННИК» ДЬЯКА ИВАНА ТИМОФЕЕВА И «СЛОВЕСА ДНЕЙ, И ЦАРЕЙ, И СВЯТИТЕЛЕЙ МОСКОВСКИХ, ЕЖЕ ЕСТЬ В РОССИИ» КНЯЗЯ ИВАНА ХВОРОСТИНИНА. В ПЕРВОЙ ГЛАВЕ РЕКОНСТРУИРОВАН КАНОН ИЗБРАНИЯ» ЦАРЯ, КОТОРЫЙ СФОРМИРОВАЛСЯ В КОНЦЕ XVI В., ОКАЗАЛ БОЛЬШОЕ ВЛИЯНИЕ И НА КНИЖНОСТЬ, И НА КОНКРЕТНЫЕ СОБЫТИЯ СМУТНОГО ВРЕМЕНИ, А ПОТОМ, ЭВОЛЮЦИОНИРУЯ, ВОСПРОИЗВОДИЛСЯ НА ПРОТЯЖЕНИИ ХVII СТОЛЕТИЯ ПРИ ИЗБРАНИИ МИХАИЛА ФЕДОРОВИЧА НА ЦАРСТВО, А ЗАТЕМ И ПРИ ЛЕГИТИМАЦИИ ВЛАСТИ СЛЕДУЮЩИХ ГОСУДАРЕЙ ДИНАСТИИ РОМАНОВЫХ. ВО ВТОРОЙ, ТРЕТЬЕЙ И ШЕСТОЙ ГЛАВАХ АНАЛИЗИРУЮТСЯ НЕГАТИВНЫЕ ОБРАЗЫ БОРИСА ГОДУНОВА, ЛЖЕДМИТРИЯ, ВАСИЛИЯ ШУЙСКОГО И ПОЛЬСКИХ ИНТЕРВЕНТОВ. ТО, ЧТО ЭТИ ОБРАЗЫ В ВОСПРИЯТИИ МНОГИХ СОВРЕМЕННИКОВ И БЛИЖАЙШИХ ПОТОМКОВ ЯВЛЯЛИСЬ ПРЕИМУЩЕСТВЕННО НЕГАТИВНЫМИ, БЫЛО ХОРОШО ИЗВЕСТНО И РАНЬШЕ. НО Д.И.АНТОНОВ ВПЕРВЫЕ КОМПЛЕКСНО ПОКАЗАЛ, КАК ЭТИ ОБРАЗЫ ВЫСТРАИВАЛИСЬ И НА КАКИХ МИФАХ ОСНОВЫВАЛИСЬ. В ЧЕТВЕРТОЙ ГЛАВЕ, ПОСВЯЩЕННОЙ ПРЕДСТАВЛЕНИЯМ О ПРИСЯГЕ И КРЕСТНОМ ЦЕЛОВАНИИ, ВПЕРВЫЕ ПОКАЗАНО, КАК ЭТИ ПРЕДСТАВЛЕНИЯ ПОВЛИЯЛИ НА ДЕЙСТВИЯ ПРАВИТЕЛЕЙ В ГОДЫ СМУТЫ И НА ИХ ОЦЕНКУ СОВРЕМЕННИКАМИ. К ЭТОЙ ГЛАВЕ ПРИМЫКАЕТ ЭКСКУРС 1, ПОСВЯЩЕННЫЙ ЭВОЛЮЦИИ ПРЕДСТАВЛЕНИЙ О ПРИСЯГЕ В XVII В. И ИХ ВЛИЯНИЮ НА ИСПОЛЬЗОВАНИЕ КРЕСТОЦЕЛОВАНИЯ В СУДЕБНОЙ ПРАКТИКЕ. ТАКИМ ОБРАЗОМ, ИССЛЕДОВАНИЕ Д.И. АНТОНОВА ПОЗВОЛЯЕТ ЧИТАТЕЛЮ ВЗГЛЯНУТЬ НА ЭПОХУ СМУТЫ ГЛАЗАМИ СОВРЕМЕННИКОВ, ПОНЯТЬ, ЧЕМ МОТИВИРОВАЛИСЬ ПОСТУПКИ И ОЦЕНКИ МНОГИХ ЛЮДЕЙ - И «КНИЖНИКОВ», И ПРАВИТЕЛЕЙ, И ПРОЧИХ АКТОРОВ, УЧАСТВОВАВШИХ В ИЗБИРАТЕЛЬНЫХ КОМПАНИЯХ И ДРУГИХ УНИКАЛЬНЫХ СОБЫТИЯХ ЭПОХИ МЕЖДУЦАРСТВИЯ.

ХОТЯ В ИССЛЕДОВАТЕЛЬСКУЮ ПРОГРАММУ АВТОРА НЕ ВОШЛО СПЕЦИАЛЬНОЕ РАССМОТРЕНИЕ ВОПРОСОВ О ТОМ, В КАКИХ ИМЕННО СОЦИАЛЬНЫХ КРУГАХ РАСПРОСТРАНЯЛИСЬ РЕКОНСТРУИРОВАННЫЕ «МИФОЛОГЕМЫ» И КАКИМ ОБРАЗОМ ЭТО ПРОИСХОДИЛО, Д.И. АНТОНОВ ИНОГДА ОБРАЩАЕТСЯ К ЭТИМ ВОПРОСАМ. НАПРИМЕР, В ТРЕТЬЕЙ ГЛАВЕ, ПОСВЯЩЕННОЙ «МИФОЛОГИЧЕСКОЙ БИОГРАФИИ ПЕРВОГО ЛЖЕДМИТРИЯ», Д.И. АНТОНОВ СТАВИТ ЧРЕЗВЫЧАЙНО ИНТЕРЕСНУЮ И ВАЖНУЮ (ОСОБЕННО В КОНТЕКСТЕ ОБСУЖДАЕМОЙ ЗДЕСЬ КОНЦЕПЦИИ ПУБЛИЧНОЙ СФЕРЫ) ПРОБЛЕМУ. ПОСЛЕ ВСТУПЛЕНИЯ В РУССКИЕ ЗЕМЛИ ЛЖЕДМИТРИЯ І ОСЕНЬЮ 1604 Г. И НАЧАЛА МАССОВОГО ПЕРЕХОДА ПОД ЗНАМЕНА «ЧУДОМ СПАСШЕГОСЯ ЦАРЕВИЧА» КАЗАКОВ И ДЕТЕЙ БОЯРСКИХ МОСКОВСКОЕ ПРАВИТЕЛЬСТВО БОРИСА ГОДУНОВА, А ЗАТЕМ И ВАСИЛИЯ ШУЙСКОГО БЫЛО ПОСТАВЛЕНО В ПОИСТИНЕ УНИКАЛЬНУЮ ИСТОРИЧЕСКУЮ СИТУАЦИЮ, НЕ ХАРАКТЕРНУЮ ДЛЯ ПОЛИТИЧЕСКОЙ КУЛЬТУРЫ XVI В.: 
ТЕПЕРЬ ОКАЗАЛОСЬ НЕОБХОДИМО ВЕСТИ БОРЬБУ ПРОТИВ СВОЕГО ПОЛИТИЧЕСКОГО ПРОТИВНИКА НЕ ТОЛЬКО ОРУЖИЕМ, НО И СЛОВОМ, С ЦЕЛЬЮ ЗАВОЕВАТЬ УМЫ РОССИЙСКИХ ПОДДАННЫХ (С.70). КАК ПРАВИТЕЛЬСТВО ЭТО ДЕЛАЛО? КАКИЕ ИДЕИ ТРАНСЛИРОВАЛО? И В КАКОЙ СТЕПЕНИ ЭТИ ИДЕИ БЫЛИ ВОСПРИНЯТЫ «КНИЖНОЙ» И «НАРОДНОЙ» СРЕДАМИ? Д.И. АНТОНОВ УВЛЕКАТЕЛЬНО РАССМАТРИВАЕТ ЭТИ ВОПРОСЫ, СРАВНИВАЯ ПРАВИТЕЛЬСТВЕННЫЕ МАНИФЕСТЫ, ПАМЯТНИКИ ПУБЛИЦИСТИКИ И ПОЗДНИЕ ЗАПИСИ ФОЛЬКЛОРА (ИСТОРИЧЕСКИЕ ПЕСНИ).

ПЕРЕХОДЯ ОТ ХАРАКТЕРИСТИКИ КНИГИ К ТЕМ ПЕРСПЕКТИВАМ, КОТОРЫЕ ОТКРЫВАЮТСЯ ПРИ ЕЕ РАССМОТРЕНИИ СКВОЗЬ ПРИЗМУ ТЕОРИИ «ПУБЛИЧНОЙ СФЕРЫ», ОБРАТИМСЯ К НЕКОТОРЫМ ОБЩИМ ИСТОЧНИКОВЕДЧЕСКИМ ОСОБЕННОСТЯМ ПУБЛИЦИСТИКИ (НА ИЗУЧЕНИИ КОТОРОЙ И ОСНОВАНА КНИГА Д.И. АНТОНОВА). СОГЛАСНО ИСТОЧНИКОВЕДЧЕСКОЙ КОНЦЕПЦИИ, РАЗРАБОТАННОЙ В ИСТОРИКО-АРХИВНОМ ИНСТИТУТЕ И РОССИЙСКОМ ГОСУДАРСТВЕННОМ ГУМАНИТАРНОМ УНИВЕРСИТЕТЕ, В ОСНОВЕ КЛАССИФИКАЦИИ ИСТОРИЧЕСКИХ ИСТОЧНИКОВ (И ОТНЕСЕНИЯ КОНКРЕТНОГО ПАМЯТНИКА К ТОМУ ИЛИ ИНОМУ ВИДУ, НАПРИМЕР, ПУБЛИЦИСТИКЕ) ДОЛЖНЫ ЛЕЖАТЬ НЕКОТОРЫЕ «СУЩЕСТВЕННЫЕ ИММАНЕНТНЫЕ ИСТОРИЧЕСКИМ ИСТОЧНИКАМ ХАРАКТЕРИСТИКИ» ${ }^{16}$. ПО МНЕНИЮ М.Ф. РУМЯНЦЕВОЙ, В ОТНОШЕНИИ ПУБЛИЦИСТИКИ ТАКИМИ ХАРАКТЕРИСТИКАМИ СЛЕДУЕТ СЧИТАТЬ СЛЕДУЮЩИЕ ЭЛЕМЕНТЫ:

А) ПАМЯТНИКИ ПУБЛИЦИСТИКИ ВОЗНИКАЮТ «В ОБЩЕСТВЕННОЙ СФЕРЕ» (ИНЫМИ СЛОВАМИ, ПРЕДСТАВЛЯЮТ СОБОЙ ПУБЛИЧНЫЕ ВЫСКАЗЫВАНИЯ);

Б) ОНИ ДОЛЖНЫ БЫТЬ ПОСВЯЩЕНЫ ОБСУЖДЕНИЮ КАКИХ-ТО ОБЩЕЗНАЧИМЫХ ПРОБЛЕМ;

В) ОНИ ДОЛЖНЫ ВЫРАЖАТЬ МНЕНИЕ ПО ЭТОЙ ПРОБЛЕМЕ ОПРЕДЕЛЕННОЙ СоцИАЛЬНОЙ ГРУППЫ ${ }^{17}$.

РУКОВОДСТВУЯСЬ ЭТИМИ КРИТЕРИЯМИ (КОТОРЫЕ МНЕ КАЖУТСЯ ПРАВИЛЬНЫМИ), МЫ МОЖЕМ БЕЗОШИБОЧНО ОТНЕСТИ К ПУБЛИЦИСТИКЕ, НАПРИМЕР, «ОТВЕТ КИРИЛЛОВСКИХ СТАРЦЕВ НА ПОСЛАНИЕ ИОСИФА ВОЛОЦКОГО ОБ ОСУЖДЕНИИ ЕРЕТИКОВ» НАЧАЛА XVI В., ТАК КАК ОНО:

А) АДРЕСОВАНО ПУБЛИЧНОЙ ВЛАСТИ (ВЕЛИКОМУ КНЯЗЮ ВАСИЛИЮ ІІІ), НО ПРИ ЭТОМ ПРЕДСТАВЛЯЕТ СОБОЙ ОТКРЫТОЕ ПИСЬМО, О ЧЕМ СВИДЕТЕЛЬСТВУЕТ ЕГО БЫТОВАНИЕ ВО МНОЖЕСТВЕ СПИСКОВ;

Б) ПОСВЯЩЕНО ЧРЕЗВЫЧАЙНО АКТУАЛЬНОЙ ДЛЯ ТОГО ВРЕМЕНИ ТЕМЕ ОТНОШЕНИЯ ЦЕРКВИ И ГОСУДАРСТВА К «ЕРЕТИКАМ»;

В) ВЫРАЖАЕТ КОНСОЛИДИРОВАННОЕ МНЕНИЕ ВСЕХ ЗАВОЛЖСКИХ СТАРЦЕВ», ВЫРАБОТКА КОТОРОГО ПРЕДПОЛАГАЛА ОБСУЖДЕНИЕ ДАННОЙ ОБЩЕСТВЕННО ВАЖНОЙ ПРОБЛЕМЫ УЧАСТНИКАМИ НА КАКИХ-ТО ПУБЛИЧНЫХ ПЛОЩАДКАХ», ЧТО ЕЩЕ РАЗ УКАЗЫВАЕТ НА РОЖДЕНИЕ ИСТОЧНИКА В «ПУБЛИЧНОЙ СФЕРЕ» 18.

НЕ СЛУЧАЙНО ИМЕННО АКТИВНОЕ ИЗУЧЕНИЕ ПАМЯТНИКОВ ПУБЛИЦИСТИКИ В СОВЕТСКОЙ ИСТОРИОГРАФИИ ПОЗВОЛИЛО ПОКАЗАТЬ, ЧТО В МОСКОВСКОЙ РУСИ СУЩЕСТВОВАЛА «ПУБЛИЧНАЯ БОРЬБА КОНЦЕПЦИЙ» ДАЖЕ «В УСЛОВИЯХ НЕРАЗВИТОСТИ ПЕЧАТНОГО ДЕЛА И УЗОСТИ ВОЗМОЖНОСТЕЙ ДЛЯ ДИСКУССИЙ» ${ }^{19}$. К.Ю. ЕРУСАЛИМСКИЙ ДАЖЕ СЧИТАЕТ, ЧТО РАБОТЫ А.А. ЗИМИНА О И.С. ПЕРЕСВЕТОВЕ МОЖНО РАССМАТРИВАТЬ КАК «ПЕРВЫЙ ШАГ К ДИСКУССИИ О ФОРМИРОВАНИИ “ПУБЛИЧНОЙ СФЕРЫ" В РОССИИ ДО РЕФОРМ ПЕТРА І» (ЯВНО ОТСЫЛАЯ НАС К КОНЦЕПЦИИ Ю.ХАБЕРМАСА ${ }^{20}$. НО ВСЕ ЖЕ ПАМЯТНИКИ РУССКОЙ ПУБЛИЦИСТИКИ МОСКОВСКОГО ПЕРИОДА ИЗУЧАЛИСЬ И ПРОДОЛЖАЮТ ИЗУЧАТЬСЯ (В ТОМ ЧИСЛЕ В КНИГЕ Д.И.АНТОНОВА) ПРЕИМУЩЕСТВЕННО С ТОЧКИ ЗРЕНИЯ ОБЩЕСТВЕННОПОЛИТИЧЕСКИХ ИДЕЙ ИЛИ «МИФОЛОГЕМ», ВЫРАЖЕННЫХ В ПАМЯТНИКЕ, НО НЕ ТОЙ 
«ОБЩЕСТВЕННОЙ СФЕРЫ», В КОТОРОЙ ЭТИ ИСТОЧНИКИ БЫЛИ ПОРОЖДЕНЫ И ФУНКЦИОНИРОВАЛИ. МЕЖДУ ТЕМ, НАИБОЛЕЕ «СУЩЕСТВЕННЫЕ ИММАНЕНТНЫЕ» ОСОБЕННОСТИ ПУБЛИЦИСТИКИ КАК ИСТОРИЧЕСКОГО ИСТОЧНИКА УКАЗЫВАЮТ НАМ НА ТАКУЮ ПЕРСПЕКТИВУ. ДЕЙСТВИТЕЛЬНО, ДЛЯ НАС ВАЖНО ПОНЯТЬ НЕ ТОЛЬКО СМЫСЛ КОНКРЕТНОГО ПУБЛИЧНОГО ВЫСКАЗЫВАНИЯ, НО ТАКЖЕ И ТО, КАК И ПОЧЕМУ ОНО ВОЗНИКЛО, К КОМУ БЫЛО АДРЕСОВАНО, КАК ТРАНСЛИРОВАЛОСЬ, КТО БЫЛИ ЕГО АДРЕСАТЫ И РЕАЛЬНЫЕ «СЛУШАТЕЛИ» И Т.Д. ПРОДЕМОНСТРИРУЕМ ЭТО НА КОНКРЕТНОМ ПРИМЕРЕ. В ПЯТОЙ ГЛАВЕ КНИГИ Д.И. АНТОНОВА СПЕЦИАЛЬНО РАССМАТРИВАЕТСЯ РЕФЛЕКСИЯ О СМУТЕ И О РОССИЙСКОЙ ВЛАСТИ ОСОБОГО «КНИЖНИКА» - ДЬЯКА ИВАНА ТИМОФЕЕВА, КОТОРЫЙ ИМЕЛ СОВЕРШЕННО УНИКАЛЬНЫЙ ИСТОРИЧЕСКИЙ ОПЫТ: В ЦАРСТВОВАНИЕ БОРИСА ГОДУНОВА СЛУЖИЛ В ОДНОМ ИЗ ПРИКАЗОВ, А ЗНАЧИТ, КАЖДЫЙ ДЕНЬ НАХОДИЛСЯ В КРЕМЛЕ, ЗАТЕМ ПРИНИМАЛ УЧАСТИЕ В ПОХОДЕ ПРОТИВ ЛЖЕДМИТРИЯ І, ПЕРЕЖИЛ ОСАДУ МОСКВЫ БОЛОТНИКОВЫМ, ПОТОМ СЛУЖИЛ В НОВГОРОДЕ, ГДЕ СБЛИЗИЛСЯ С МИХАИЛОМ СКОПИНЫМ-ШУЙСКИМ, ПОСЛЕ ЧЕГО ЕМУ ПРИШЛОСЬ ПЕРЕЖИТЬ ШВЕДСКУЮ ОККУПАЦИЮ НОВГОРОДА (С. 24). Д.И. АНТОНОВ ПЫТАЕТСЯ ПОНЯТЬ, «КАК ТИМОФЕЕВ ПРЕДСТАВЛЯЛ ВЛАСТЬ, В ЧЕМ ВИДЕЛ СУТЬ КАТАКЛИЗМОВ И ЧЕМ ОТЛИЧАЮТСЯ ЕГО ПРЕДСТАВЛЕНИЯ ОТ ТЕХ, ЧТО РАСПРОСТРАНИЛИСЬ В ДРУГИХ ТЕКСТАХ» (С. 136) 21 . В ОТЛИЧИЕ ОТ МНОГИХ СОВРЕМЕННИКОВ, ИВАН ТИМОФЕЕВ СВЯЗЫВАЛ СМУТУ С ПРАВЛЕНИЕМ ИВАНА ГРОЗНОГО: ДЬЯК СОЖАЛЕЛ О ТОМ, ЧТО ЦАРЬ, БУДУЧИ «К ЯРОСТИ УДОБЬ ПОДВИЖЕН», УЧРЕДИЛ ОПРИЧНИНУ И СОВЕРШИЛ ВЕЛИКОЕ МНОЖЕСТВО ЗЛОДЕЯНИЙ. ИМЕННО ЭТИМ ГОСУДАРЬ НАВЕЛ НА СЕБЯ И НА ВСЮ РУССКУЮ ЗЕМЛЮ ГНЕВ БОЖИЙ, В РЕЗУЛЬТАТЕ ЧЕГО ВОЗНИКЛА СМУТА (С. 137-138, 151). НО ТАКАЯ КРИТИКА «ИСТИННОГО ЦАРЯ» ДАЕТСЯ ДЬЯКУ НЕПРОСТО: ТИМОФЕЕВ ПОВТОРЯЕТ ИЗВЕСТНУЮ В КНИЖНОСТИ ИДЕЮ О НЕОБХОДИМОСТИ «ТАИТИ ЦАРЕВЫ ТАЙНЫ» И НЕСКОЛЬКО РАЗ ПОДЧЕРКИВАЕТ, ЧТО «О ТАКОВЫХ [ИСТИННЫХ ЦАРЯХ] ТВОРИТИ ТЩАННО И СТРАХОПРИСТУПНО СПИСАТЕЛЕ ОБЫКОША И НАС НАУЧАША» (С. 141). НО СОВСЕМ ДРУГОЕ ДЕЛО - ПРАВИТЕЛИ, «НАСКАКАЮЩИЕ НА ЦАРСТВО» (БОРИС ГОДУНОВ, ЛЖЕДМИТРИЙ, ВАСИЛИЙ ШУЙСКИЙ). ТАКОВЫХ «СПИСАТЕЛИ» (Т.Е. ПИСАТЕЛИ) ПРОСТО ОБЯЗАНЫ ОБЛИЧАТЬ, ИНАЧЕ БУДУТ НЕСТИ ОТВЕТСТВЕННОСТЬ НА СТРАШНОМ СУДЕ («...СИЦЕВЫХ ЯВЕ ОТ БЛАГИХ ПО ВСЕМУ ОТДЕЛИСЯ СУД: НЕОБЛИЧНАГО ЖЕ УМОЛЧАНИЯ РАДИ, ЕЖЕ О ТЕХ НЕЧЕСТИВЫХ СПИСАТЕЛЕ, МНЮ, С СИМИ РАВНЕЕ ИСТЯЖУТСЯ» - С. 140). ЭТО ИНТЕРЕСНЫЙ ФРАГМЕНТ «ВРЕМЕННИКА», КОТОРЫЙ ПРОЛИВАЕТ СВЕТ НА ПРЕДСТАВЛЕНИЯ ИВАНА ТИМОФЕЕВа О «КНИЖНИКАХ» («СПИСАТЕЛЯХ»), ИХ ОБЯЗАННОСТЯХ И ДАЖЕ ОТВЕТСТВЕННОСТИ. ОТСЮДА СЛЕДУЕТ ОРИЕНТАЦИЯ «СПИСАТЕЛЯ» НА НЕКОТОРУЮ ЧИТАТЕЛЬСКУЮ АУДИТОРИЮ (ИНАЧЕ ДЛЯ ЧЕГО НУЖНО БЫЛО «ОБЛИЧАТЬ», ЕСЛИ ОБЛИЧЕНИЕ НИКТО НЕ ПРОЧИТАЕТ)? НО НА КАКУЮ ПУБЛИКУ ОРИЕНТИРОВАЛСЯ ИВАН ТИМОФЕЕВ, И КТО В ДЕЙСТВИТЕЛЬНОСТИ БЫЛИ ЕГО ЧИТАТЕЛЯМИ? К СОЖАЛЕНИЮ, Д.И. АНТОНОВ ВООБЩЕ НЕ ЗАДАЕТСЯ ТАКИМИ ВОПРОСАМИ, ОГРАНИЧИВШИСЬ ЛИШЬ КРАТКИМ ЗАМЕЧАНИЕМ О ТОМ, ЧТО ПАМЯТНИК «СОХРАНИЛСЯ В ЕДИНСТВЕННОМ СПИСКЕ И ЯВНО НЕ СТАЛ ПОПУЛЯРНЫМ У СОВРЕМЕННИКОВ, В ЧЕМ ВИНОВАТ, ОТЧАСТИ, СЛОЖНЫЙ И ВИТИЕВАТЫЙ СТИЛЬ ДЬЯКА» (c. 136). НО ВСЕ-ТАКИ НЕКОТОРАЯ ИНФОРМАЦИЯ О РЕАЛЬНЫХ ЧИТАТЕЛЯХ ВРЕМЕННИКА» ИМЕЕТСЯ. В САМОЙ РУКОПИСИ (Т.Е. ЕДИНСТВЕННОМ СОХРАНИВШИМСЯ СПИСКЕ) СООБЩАЕТСЯ, ЧТО «НОВГОРОДСКИЙ МИТРОПОЛИТ ИСИДОР ПОНУЖДАЕТ БЫВАЮЩАЯ 
ПРЕДЛОЖИТИ ПИСАНИЮ ДЬЯКА ИВАНА ТИМОФЕЕВА» ${ }^{22}$. ЗНАЧИТ, САМОМУ ПИСЬМУ ПРЕДШЕСТВОВАЛО НЕКОТОРОЕ ОБСУЖДЕНИЕ СОБЫТИЙ СМУТЫ И ИХ СМЫСЛА В ОПРЕДЕЛЕННЫХ КРУГАХ, ЧТО ПРИВЕЛО К ВЫРАБОТКЕ НЕКОТОРЫХ ОБЩИХ ВЗГЛЯДОВ, КОТОРЫЕ ДОЛЖНЫ БЫЛИ БЫТЬ ЗАФИКСИРОВАНЫ ВО «ВРЕМЕННИКЕ», К ЧЕМУ И «ПРИНУДИЛ» ДЬЯКА САМЫЙ АВТОРИТЕТНЫЙ ЧЕЛОВЕК ДАННОГО КРУГА НОВГОРОДСКИЙ МИТРОПОЛИТ ИСИДОР. НО ДЛЯ ЧЕГО ЭТИ ВЗГЛЯДЫ ДОЛЖНЫ БЫЛИ БЫТЬ ЗАФИКСИРОВАНЫ, ЕСЛИ ИХ НЕ СЛЕДОВАЛО АДРЕСОВАТЬ КАКОЙ-ТО ПУБЛИКЕ? НАС НЕ ДОЛЖЕН ВВЕСТИ В ЗАБЛУЖДЕНИЕ ТОТ ФАКТ, ЧТО «ВРЕМЕННИК» ПОКА ИЗВЕСТЕН В ОДНОМ ЕДИНСТВЕННОМ СПИСКЕ. ВЕДЬ ЭТА РУКОПИСЬ - НЕ АВТОРСКИЙ АВТОГРАФ, А СПИСОК 1630-Х ГГ. (ДО 1699 Г. ПРИНАДЛЕЖАВШИЙ КАКОМУ-ТО ЕУТИФИЮ СИДОРОВУ ПОПОВУ, А ПОТОМ КАК-ТО ОКАЗАВШИЙСЯ ВО ФЛОРИЩЕВОЙ ПУСТЫНИ), СДЕЛАННЫЙ С КАКОГО-ТО ДРУГОГО, ДО НАС НЕ ДОШЕДШЕГО, НО УЖЕ ПОПОРЧЕННОГО СПИСКА ${ }^{23}$. ЗНАЧИТ, НЕ МОЖЕТ БЫТЬ СОМНЕНИЙ В ТОМ, ЧТО СУЩЕСТВОВАЛИ И ДРУГИЕ СПИСКИ. ЭТО КРАСНОРЕЧИВО ПОДТВЕРЖДАЕТ И ОБНАРУЖЕННАЯ О.А. ДЕРЖАВИНОЙ «СКАЗКА» ДЬЯКА ТИМОФЕЯ КУДРЯВЦЕВА, КОТОРОМУ В 60-Е ГГ. XVII В. БЫЛО ПОРУЧЕНО ПИСАТЬ ПРОДОЛЖЕНИЕ СТЕПЕННОЙ КНИГИ:

ГОСТЬ МАТВЕЙ ВАСИЛЬЕВ СКАЗЫВАЛ МНЕ ПРО ДЬЯКА ИВАНА ТИМОФЕЕВА, - БЫЛ ДЕ ОН КНИГОЧТЕЦ И ВРЕМЕННЫХ КНИГ ПИСЕЦ, А ЖАЛОВАЛ ДЕ ЕГО ЗА ТО БОЯРИН КНЯЗЬ ИВАН МИХАЙЛОВИЧ ВОРОТЫНСКИЙ, И ПОТОМУ ИВАНОВЫХ КНИГ ИЛИ СПИСКА С ТЕХ КНИГ У СТОЛЬНИКА У КНЯЗЯ ИВАНА АЛЕКСЕЕВИЧА ВОРОТЫНСКОГО ЧАЯТ. ДА КУПЧИНА ГЕРАСИМ ДЬЯКОВ ПРО ЛЕТОПИСНЫЕ КНИГИ ТОГО ДЕ ДЬЯКА ИВАНА ТИМОФЕЕВА СКАЗЫВАЛ МНЕ: ЧАЯТ ДЕ ТЕ ИВАНОВЫ ЛЕТОПИСНЫЕ КНИГИ ОСТАЛИСЬ ПОСЛЕ БОЯРИНА КНЯЗЯ АЛЕКСЕЯ МИХАЙЛОВИЧА ЛЬВОВА, В ДОМУ ЕВО 24.

ЗНАЧИТ, «ВРЕМЕННИК» ЧИТАЛ НЕ ТОЛЬКО НЕКИЙ ЕУТИФИЙ СИДОРОВ ПОПОВ (ЧЕЙ СПИСОК ДОШЕЛ ДО НАШИХ ДНЕЙ); У ИВАНА ТИМОФЕЕВА БЫЛИ, ПОМИМО НОВГОРОДСКОГО МИТРОПОЛИТА ИСИДОРА, ВЫСОКИЕ ПОКРОВИТЕЛИ И ПОЧИТАТЕЛИ, СРЕДИ КОТОРЫХ ТАКИЕ ИЗВЕСТНЫЕ ЛЮДИ, КАК БОЯРЕ КН. И.М. ВОРОТЫНСКИЙ И КН. А.М. ЛЬВОВ. НО О ИВАНЕ ТИМОФЕЕВЕ И ЕГО ТРУДАХ ХОРОШО ЗНАЛИ НЕ ТОЛЬКО ПРИ ДВОРЕ, НО ТАКЖЕ И В ТОРГОВЫХ КРУГАХ (НЕ СЛУЧАЙНО ЖЕ ТИМОФЕЙ КУДРЯВЦЕВ ИСКАЛ ИНФОРМАЦИЮ ОБ ИВАНЕ ТИМОФЕЕВЕ СРЕДИ КУПЦОВ).

НЕСОМНЕННО, ОПИСАННЫЕ МНОЙ ФАКТЫ ХОРОШО ИЗВЕСТНЫ Д.И. АНТОНОВУ, НО ОНИ НЕ ОКАЗАЛИСЬ ДЛЯ НЕГО ВАЖНЫ ВВИДУ ТЕХ ЗАДАЧ, КОТОРЫЕ ОН ПЕРЕД СОБОЙ СТАВИЛ. ЕСЛИ ПОЛЬЗОВАТЬСЯ КОНЦЕПТУАЛЬНЫМ АППАРАТОМ СОСТАВИТЕЛЕЙ СБОРНИКА «НЕСОВЕРШЕННАЯ ПУБЛИЧНАЯ СФЕРА», ИССЛЕДОВАТЕЛЬ СОСРЕДОТОЧИЛ СВОЕ ВНИМАНИЕ НА ТОМ, ЧТОБЫ ПОНЯТЬ ЗНАЧЕНИЕ КАЖДОГО КОНКРЕТНОГО ПРОИЗВЕДЕНИЯ, НО НЕ УДЕЛИЛ ВНИМАНИЯ ИХ ЗНАЧИМОСТИ, Т.Е. ТЕМ «РЕЖИМАМ КОММУНИКАЦИИ», В КОТОРЫЕ БЫЛИ ВОВЛЕЧЕНЫ АВТОРЫ И ЧИТАТЕЛИ ЭТИХ ПРОИЗВЕДЕНИЙ. МЕЖДУ ТЕМ, ИМЕННО ТАКАЯ ПЕРСПЕКТИВА ПОЗВОЛИЛА БЫ РЕКОНСТРУИРОВАТЬ НЕ ТОЛЬКО ИДЕИ И МИФОЛОГЕМЫ, НО ТАКЖЕ ХАРАКТЕРНЫЕ ОСОБЕННОСТИ ПУБЛИЧНОЙ КОММУНИКАЦИИ И СПЕЦИФИЧЕСКИЕ ЧЕРТЫ «ПУБЛИЧНЫХ СФЕР» МОСКОВСКОЙ РУСИ ${ }^{25}$.

ВОЗВРАЩАЯСЬ К КНИГЕ Д.И. АНТОНОВА, КОТОРАЯ НАВЕЛА НАС ЭТИ РАЗМЫШЛЕНИЯ О ПЕРСПЕКТИВАХ ИЗУЧЕНИЯ ПАМЯТНИКОВ ПУБЛИЦИСТИКИ, ОТМЕТИМ ЕЩЕ ОДНУ ОСОБЕННОСТЬ ЭТОГО ИССЛЕДОВАНИЯ. СКВОЗНЫМ ДЛЯ ВСЕХ ЧАСТЕЙ КНИГИ ЯВЛЯЕТСЯ ВАЖНЕЙШИЙ ВОПРОС О ТОМ, КАКОЕ ВОЗДЕЙСТВИЕ ОКАЗАЛ ОПЫТ СМУТЫ НА «ЖИЗНЕННЫЙ МИР» ЛЮДЕЙ МОСКОВСКОГО ЦАРСТВА ХVII В. АВТОР ПОКАЗЫВАЕТ, КАК «КАТАСТРОФИЧЕСКИЕ СОБЫТИЯ, РАЗВИВАВШИЕСЯ В ПЕРИОД МЕЖДУЦАРСТВИЯ..., 
ПОКОЛЕБАЛИ ВАЖНЕЙШИЕ ИДЕОЛОГЕМЫ МОСКОВСКОЙ РУСИ» (С.9). ДАЖЕ ПОСЛЕ ПРЕОДОЛЕНИЯ СМУТЫ РУСЬ НЕ СМОГЛА ОСТАТЬСЯ ПРЕЖНЕЙ, ИБО НАКОПИВШИЕСЯ ПРОТИВОРЕЧИЯ «НЕ МОГЛИ БЫТЬ ОРГАНИЧНО УСВОЕНЫ КУЛЬТУРОЙ». НЕ СЛУЧАЙНО Д.И. АНТОНОВ НАЗЫВАЕТ РОССИЙСКИЙ ХVII В. «ОСЕНЬЮ РУССКОГО СРЕДНЕВЕКОВЬЯ» (С. 168). ОДНИМ ИЗ ВАЖНЕЙШИХ ЕЕ СИМПТОМОВ СТАЛА ДЕСАКРАЛИЗАЦИЯ ИНСТИТУТА ЦАРСКОЙ ВЛАСТИ, КОТОРАЯ ПРИВЕЛА К ВОЗНИКНОВЕНИЮ ИНСТИТУТА «СЛОВА И ДЕЛА», ОГРОМНОГО КОЛИЧЕСТВА СУДЕБНО-СЛЕДСТВЕННЫХ ДЕЛ О «НЕПРИГОЖИХ РЕЧАХ», А ЗАТЕМ И СПЕЦИАЛЬНЫХ ОРГАНОВ ПОЛИТИЧЕСКОГО СЫСКА.

\section{Политические судебно-следственные процессы XVIII в.: публичные высказывания на грани позволенного и запрещенного}

КНИГА Е.В. АНИСИМОВА «ДЕРЖАВА И ТОПОР: ЦАРСКАЯ ВЛАСТЬ, ПОЛИТИЧЕСКИЙ СЫСК И РУССКОЕ ОБЩЕСТВО В XVIII ВЕКЕ» (М.: НОВОЕ ЛИТЕРАТУРНОЕ ОБОЗРЕНИЕ, 2019) ПРЕДСТАВЛЯЕТ СОБОЙ ПЕРЕРАБОТАННЫЙ ВАРИАНТ МОНОГРАФИИ «ДЫБА И КНУТ. ПОЛИТИЧЕСКИЙ СЫСК И РУССКОЕ ОБЩЕСТВО В XVIII ВЕКЕ» 1999Г. ОНА ХОРОШО ИЗВЕСТНА УЧЕНОЙ ПУБЛИКЕ. В ФОКУСЕ АВТОРА - ПОЛИТИЧЕСКИЙ СЫСК XVIII В. «КАК ИНСТИТУТ ПО ПРЕИМУЩЕСТВУ ВНЕСУДЕБНОГО И НЕЗАКОННОГО ПРЕСЛЕДОВАНИЯ ГОСУДАРСТВЕННЫХ (ПОЛИТИЧЕСКИХ) ПРЕСТУПНИКОВ В XVIII В.». Е.В. АНИСИМОВ ПЫТАЕТСЯ ПРОСЛЕДИТЬ, КАК В РОССИИ СФОРМИРОВАЛАСЬ СИСТЕМА ТАКОГО ПРЕСЛЕДОВАНИЯ ПОЛИТИЧЕСКИХ ПРЕСТУПНИКОВ, И КАК ОНА РАЗВИВАЛАСЬ И ФУНКЦИОНИРОВАЛА В ТЕЧЕНИЕ XVIII В. ${ }^{26}$ ПРИ ЭТОМ АВТОР ПРИВЛЕК ЗНАЧИТЕЛЬНЫЙ КОРПУС СУДЕБНО-СЛЕДСТВЕННЫХ ДЕЛ ПРЕИМУЩЕСТВЕННО ИЗ ФОНДОВ ТАЙНОЙ КАНЦЕЛЯРИИ И ЭКСПЕДИЦИИ (РГАДА, Ф. 6 И 7), А ТАКЖЕ ОТЧАСТИ ПРЕОБРАЖЕНСКОГО ПРИКАЗА (РГАДА, Ф. 371).

КРУГ СЮЖЕТОВ, РАССМАТРИВАЕМЫХ В КНИГЕ, ШИРОК, НО ВСЕ ОНИ ПРИЗВАНЫ ОТВЕТИТЬ НА СЛЕДУЮЩИЕ КЛЮЧЕВЫЕ ВОПРОСЫ:

1. КАК ПРОИСХОДИЛА КРИМИНАЛИЗАЦИЯ, А ЗАТЕМ И ДЕКРИМИНАЛИЗАЦИЯ ОПРЕДЕЛЕННЫХ СОЦИАЛЬНЫХ ДЕЙСТВИЙ, КОТОРЫЕ В КАКОЙ-ТО МОМЕНТ БЫЛИ СЕРЬЕЗНЫМИ И ЖЕСТОКО НАКАЗУЕМЫМИ ГОСУДАРСТВЕННЫМИ ПРЕСТУПЛЕНИЯМИ, НО ЗАТЕМ ПЕРЕСТАЛИ ЯВЛЯТЬСЯ ТАКОВЫМИ (ГЛАВА 1);

2. КАК ЭТИ ПРОЦЕССЫ КРИМИНАЛИЗАЦИИ И ДЕКРИМИНАЛИЗАЦИИ ВЛИЯЛИ НА РАЗВИТИЕ ИНСТИТУТОВ ПОЛИТИЧЕСКОГО СЫСКА В РОССИИ XVII-XVIII ВВ. (ГЛАВЫ 2 И ОТЧАСТИ ГЛАВА 3);

3. КАКОВА БЫЛА ТЕХНОЛОГИЯ УГОЛОВНОГО ПРЕСЛЕДОВАНИЯ ПОЛИТИЧЕСКИХ ПРЕСТУПЛЕНИЙ В РОССИИ XVIII В. - ОТ ПОЛУЧЕНИЯ ИНФОРМАЦИИ О ПРЕСТУПЛЕНИИ, ПОИСКА И АРЕСТА ОБВИНЯЕМЫХ И СВИДЕТЕЛЕЙ ДО МЕХАНИЗМОВ РАССЛЕДОВАНИЯ, В ТОМ ЧИСЛЕ ПЫТКИ, ВЫНЕСЕНИЯ ПРИГОВОРОВ И НАКАЗАНИЯ ОБВИНЯЕМЫХ (ЧАСТИЧНО ГЛАВА 3 И ГЛАВЫ 4-9).

В ПЕРВОЙ ГЛАВЕ ПОКАЗАНО, ЧТО ПОД ГОСУДАРСТВЕННЫМИ ПРЕСТУПЛЕНИЯМИ ЛЮДИ ПЕРВОЙ ПОЛОВИНЫ XVIII В. ПОНИМАЛИ ШИРОКИЙ КРУГ ДЕЯНИЙ, НАПРАВЛЕННЫХ ПРОТИВ ГОСУДАРЯ, ЕГО ВЛАСТИ И ЧЕСТИ. Е.В. АНИСИМОВ РАССМАТРИВАЕТ ПРИ ЭТОМ НЕ ТОЛЬКО ПАМЯТНИКИ ЗАКОНОДАТЕЛЬСТВА, НО ТАКЖЕ ПРАКТИКУ УГОЛОВНОГО ПРЕСЛЕДОВАНИЯ. ЭТО КРАЙНЕ ВАЖНО, ТАК КАК МЕЖДУ ЗАКОНОДАТЕЛЬСТВОМ И ПРАКТИКОЙ МОГ БЫТЬ (И ДЕЙСТВИТЕЛЬНО БЫЛ) ЗНАЧИТЕЛЬНЫЙ ЗАЗОР. ТАК, 
«НЕПРИГОЖИЕ РЕЧИ» НЕ БЫЛИ ВКЛЮЧЕНЫ В КОРПУС ГОСУДАРСТВЕННЫХ ПРЕСТУПЛЕНИЙ НА УРОВНЕ ЗАКОНОДАТЕЛЬСТВА ДО ИЗДАНИЯ АРТИКУЛА ВОИНСКОГО 1715 Г., НО НА ПРАКТИКЕ ПРОИЗНЕСЕНИЕ «НЕИСТОВЫХ СЛОВ» О ГОСУДАРЕ ПРЕСЛЕДОВАЛОСЬ В ТЕЧЕНИЕ XVII В., А ОСОБЕННО В ПЕРВОМ ДЕСЯТИЛЕТИИ XVIII В. (ЭТА КАТЕГОРИЯ СОСТАВЛЯЛА ПОДАВЛЯЮЩЕЕ БОЛЬШИНСТВО ПОЛИТИЧЕСКИХ ПРОЦЕССОВ XVII-XVIII ВВ.). Е.В. АНИСИМОВ ПОЛАГАЕТ, ЧТО, С ТОЧКИ ЗРЕНИЯ ЛЮДЕЙ ПЕРВОЙ ПОЛОВИНЫ XVIII В., ВЛАСТИ ГОСУДАРЯ И ЕГО ПЕРСОНЕ УГРОЖАЛИ НЕ ТОЛЬКО, СОБСТВЕННО ГОВОРЯ, ДЕЙСТВИЯ (НАПРИМЕР, НЕПОДЧИНЕНИЕ ВЕРХОВНОЙ ВЛАСТИ), НО ТАКЖЕ И СЛОВА, КОТОРЫМ «ПРИДАВАЛСЯ МАГИЧЕСКИЙ СМЫСЛ»: «СЛОВО МОГЛО ВРЕДИТЬ, ПРИНОСИТЬ УЩЕРБ ПОДОБНО ФИЗИЧЕСКОМУ ДЕЙСТВИЮ» (И ПОЭТОМУ В «СЛОВЕ» ВПОЛНЕ МОГЛИ УСМАТРИВАТЬ ЗЛОЙ УМЫСЕЛ НА «ГОСУДАРЬСКОЕ ЗДОРОВЬЕ», ЧЕМУ ПОСВЯЩЕНА 1-Я СТАТЬЯ 2-Й ГЛАВЫ СОБОРНОГО УЛОЖЕНИЯ). ВПРОЧЕМ, «НЕПРИСТОЙНОЕ СЛОВО» ВСЕГДА НАКАЗЫВАЛОСЬ «С МЕНЬШЕЙ ЖЕСТОКОСТЬЮ, ЧЕМ СОБСТВЕННО ИЗМЕНА» ${ }^{27}$.

Е.В. АНИСИМОВУ УДАЛОСЬ ПОКАЗАТЬ, КАК В ПЕРВОЙ ЧЕТВЕРТИ ХVIII В. СФЕРА ГОСУДАРСТВЕННЫХ ПРЕСТУПЛЕНИЙ РАСШИРЯЛАСЬ, В НЕЕ ВКЛЮЧАЛИСЬ «ТЕ ДЕЯНИЯ, КОТОРЫЕ РАНЕЕ ТАКОВЫМИ НЕ ЯВЛЯЛИСЬ» (С. 16), ГРАНИЦА «ЗАКОННОГО» И «НЕЗАКОННОГО» ПОСТЕПЕННО СДВИГАЛАСЬ. НАПРИМЕР, ЗАКОНОДАТЕЛЬСТВО И ПРАКТИКА МОСКОВСКОГО ГОСУДАРСТВА ОТНЮДЬ НЕ ЗАПРЕЩАЛИ ВСЯКОЕ КОЛЛЕКТИВНОЕ ПОЛИТИЧЕСКОЕ ДЕЙСТВИЕ. В 22-Й СТАТЬЕ 2-Й ГЛАВЫ СОБОРНОГО УЛОЖЕНИЯ (КАК РАЗ ПОСВЯЩЕННОЙ ГОСУДАРСТВЕННЫМ ПРЕСТУПЛЕНИЯМ) ПРЕДПОЛАГАЛОСЬ, ЧТО «ЛЮДИ РАЗНЫХ ЧИНОВ» МОГУТ ЯВЛЯТЬСЯ В ОРГАНЫ ГОСУДАРСТВЕННОЙ ВЛАСТИ И ДАЖЕ К САМОМУ ГОСУДАРЮ С КОЛЛЕКТИВНЫМИ ОБРАЩЕНИЯМИ, КОТОРЫЕ ЦАРСКИЕ АДМИНИСТРАТОРЫ БЫЛИ НЕ ВПРАВЕ ОСТАВЛЯТЬ БЕЗ ВНИМАНИЯ, А ТЕМ БОЛЕЕ ПОД УГРОЗОЙ ЖЕСТОКОГО НАКАЗАНИЯ ЗАПРЕЩАЛОСЬ ПРЕДСТАВЛЯТЬ ЭТИ ЗАКОННЫЕ МИРНЫЕ КОЛЛЕКТИВНЫЕ ОБРАЩЕНИЯ «СКОПОМ И ЗАГОВОРОМ ${ }^{28}$. ЭТИМ ПРАВОМ МИРНОГО КОЛЛЕКТИВНОГО ОБРАЩЕНИЯ К ВЛАСТЯМ И САМОМУ ГОСУДАРЮ ЛЮДИ АКТИВНО ПОЛЬЗОВАЛИСЬ КАК В ДОПЕТРОВСКОЕ 29 , ТАК И В ПЕТРОВСКОЕ ВРЕМЯ. НАПРИМЕР, В КОНЦЕ 1705 Г. В МОСКВУ ПРИЕХАЛИ ВЫБОРНЫЕ ОТ СЛУЖИЛЫХ ЛЮДЕЙ 19 СИБИРСКИХ ГОРОДОВ С КОЛЛЕКТИВНОМ ЧЕЛОБИТЬЕМ О НЕВОЗМОЖНОСТИ ИСПОЛНЕНИЯ УКАЗА О НОШЕНИИ НЕМЕЦКОГО ПЛАТЬЯ» В СИЛУ ТОГО, ЧТО «ИМ В НЕМЕЦКОМ ДЕ ПЛАТЬЕ ОТ ВЕЛИКИХ СТУЖ ХОДИТЬ НИКОИМИ МЕРЫ НЕВОЗМОЖНО И ЗА НУЖДОЮ ЗДЕЛАТЬ НЕЧЕМ». ПРОШЕНИЕ БЫЛО РАССМОТРЕНО СНАЧАЛА В СИБИРСКОМ ПРИКАЗЕ, А ЗАТЕМ И САМИМ ПЕТРОМ І. ЭТО КОЛЛЕКТИВНОЕ ДЕЙСТВИЕ ВОЗЫМЕЛО ЭФФЕКТ: ЦАРЬ УКАЗАЛ «ТЕ ПОСЛАННЫЕ НАШИ, ВЕЛИКОГО ГОСУДАРЯ, ГРАМОТЫ ВСЕ ОСТАВИТЬ И ПО НИХ НИЧЕГО ЧИНИТЬ НЕ ВЕЛЕЛИ, А ВЕЛЕЛИ НОСИТЬ ПЛАТЬЕ, ТАК ЖЕ И СЕДЛА И ПРОТЧЕЕ ПОДОБНОЕ ТОМУ, КАК ХТО ЧТО ПОХОЧЕТ ${ }^{30}$. ОБРАШАЯСЬ К ГЛАВНОЙ ПРОБЛЕМАТИКЕ ДАННОГО ОЧЕРКА, ЗАМЕТИМ, ЧТО СОСТАВЛЕНИЮ ЭТОГО КОЛЛЕКТИВНОГО ОБРАЩЕНИЯ ПРЕДШЕСТВОВАЛО ПРЕДВАРИТЕЛЬНОЕ ОБСУЖДЕНИЕ, ВЫРАБОТКА КОНСОЛИДИРОВАННОГО МНЕНИЯ И ЕГО ЗАКРЕПЛЕНИЕ В ЧЕЛОБИТНОЙ ПРЕДСТАВИТЕЛЯМИ НЕСКОЛЬКИХ НАХОДЯЩИХСЯ НА ЗНАЧИТЕЛЬНОМ РАССТОЯНИИ ДРУГ ОТ ДРУГА ГОРОДОВ. НЕ СВИДЕТЕЛЬСТВУЮТ ЛИ ЭТО О СУЩЕСТВОВАНИИ В МОСКОВСКОМ ГОСУДАРСТВЕ РАЗЛИЧНЫХ «ПУБЛИЧНЫХ СФЕР», БОЛЕЕ ИЛИ МЕНЕЕ ВЫХОДЯЩИХ ЗА ПРЕДЕЛЫ ГОСУДАРСТВЕННОГО КОНТРОЛЯ?

В ДАЛЬНЕЙШЕМ «ПЕТРОВСКОЕ ЗАКОНОДАТЕЛЬСТВО КАТЕГОРИЧЕСКИ ЗАПРЕТИЛО ЛЮБЫЕ ПОПЫТКИ ОРГАНИЗОВЫВАТЬ И ПОДАВАТЬ ВЛАСТЯМ КОЛЛЕКТИВНЫЕ 
ЧЕЛОБИТНЫЕ» (С. 27). ВОЗМОЖНО, ПЕТР ЗДЕСЬ РУКОВОДСТВОВАЛСЯ И ЛИЧНЫМ НЕГАТИВНЫМ ОПЫТОМ, КОГДА СТРЕЛЕЦКИЙ БУНТ 1698Г. СОПРОВОЖДАЛСЯ СОСТАВЛЕНИЕМ КОЛЛЕКТИВНОЙ ЧЕЛОБИТНОЙ (А.Н. КАЗАКЕВИЧ СПРАВЕДЛИВО ЕЕ НАЗВАЛ «ПРОГРАММНЫМ ДОКУМЕНТОМ ВОССТАВШИХ»), КОТОРАЯ ОБСУЖДАЛАСЬ И ЗАЧИТЫВАЛАСЬ В СТРЕЛЕЦКИХ ПОЛКАХ. ЭТУ ЧЕЛОБИТНУЮ СТРЕЛЬЦЫ ПРОСТОДУШНО ПРОСИЛИ ПРОЧИТАТЬ В ЦАРСКИХ ПОЛКАХ НАКАНУНЕ СРАЖЕНИЯ ПОД ВОСКРЕСЕНСКИМ МОНАСТЫРЕМ, А В ДАЛЬНЕЙШЕМ НАМЕРЕВАЛИСЬ РАСПРОСТРАНИТЬ В СПИСКАХ СРЕДИ МОСКОВСКИХ ПОСАДСКИХ, БУДУЧИ УБЕЖДЕНЫ В ТОМ, ЧТО НЕ ЯВЛЯЮТСЯ ИЗМЕННИКАМИ, А РАТУЮТ ЗА ВОССТАНОВЛЕНИЕ В СТРАНЕ «БЛАГОЧЕСТИЯ», И КАЖДЫЙ ЗДРАВОМЫСЛЯЩИЙ ПРАВОСЛАВНЫЙ ЧЕЛОВЕК НЕПРЕМЕННО ДОЛЖЕН ИХ В ЭТОМ ПОДДЕРЖАТЬ ${ }^{31}$. МОЖНО ПРЕДПОЛОЖИТЬ, ЧТО ПОДОБНЫЕ ЭПИЗОДЫ И ИМЕЛ ВВИДУ ПЕТР, КОГДА СОБСТВЕННОРУЧНО ВНЕС В ВОИНСКИЙ АРТИКУЛ ПОЛОЖЕНИЕ О КАТЕГОРИЧЕСКОМ ЗАПРЕТЕ «ВСЕХ НЕПРИСТОЙНЫХ ПОДОЗРИТЕЛЬНЫХ СХОДБИЩ И СОБРАНИЙ», «ХОТЯ ДЛЯ СОВЕТОВ КАКИХ-НИБУДЬ (ХОТЯ И НЕ ДЛЯ ЗЛА)» ИЛИ «ЧТОБ ОБЩУЮ ЧЕЛОБИТНУЮ ПИСАТЬ». ЗАЧИНЩИКОВ КОЛЛЕКТИВНЫХ ЧЕЛОБИТНЫХ ОТНЫНЕ СЛЕДОВАЛО КАЗНИТЬ НЕЗАВИСИМО ОТ ПРИЧИНЫ ИХ ЖАЛОБЫ, А БИТЬ ЧЕЛОМ РАЗРЕШАЛОСЬ ТОЛЬКО «КАЖДОМУ О СЕБЕ И О СВОИХ ОБИДАХ..., А НЕ ОБЩЕ» (С. 27). ЗДЕСЬ МЫ МОЖЕМ ПОСТАВИТЬ ПОД СОМНЕНИЕ ТЕЗИС О ФОРМИРОВАНИИ РОССИЙСКОЙ «ПУБЛИЧНОЙ СФЕРЫ» В РЕЗУЛЬТАТЕ ПЕТРОВСКИХ КУЛЬТУРНЫХ ПРЕОБРАЗОВАНИЙ ${ }^{32}$. КОНЕЧНО, ПЕТР СОЗДАВАЛ НОВЫЙ ТИП ПРИДВОРНОЙ («РЕПРЕЗЕНТАТИВНОЙ») ПУБЛИЧНОСТИ С ЕГО ИНСТИТУТАМИ (ГАЗЕТА «ВЕДОМОСТИ», АССАМБЛЕИ И ДР.) И ПРАВИЛАМИ ПОВЕДЕНИЯ, НО ПРИ ЭТОМ ЖЕСТКО ПОДАВЛЯЛ ДРУГИЕ, НЕГОСУДАРСТВЕННЫЕ, ПУБЛИЧНЫЕ СФЕРЫ. НО НАСКОЛЬКО ЕМУ ЭТО УДАЛОСЬ? КАЖЕТСЯ, МАТЕРИАЛЫ КНИГИ Е.В.АНИСИМОВА ПОЗВОЛЯЮТ ОТВЕТИТЬ НА ЭТОТ ВОПРОС ОТРИЦАТЕЛЬНО. НАПРИМЕР, 10 СЕНТЯБРЯ 1723 Г. ПОДЬЯЧИЙ ИЗ ГОРОДА ЧЕРНИ ИВАН ПЕРХУРОВ, БУДУЧИ В ГОСТЯХ У ПРОТОПОПА МЕСТНОЙ СОБОРНОЙ ЦЕРКВИ ГРИГОРИЯ ОСИПОВА В БОЛЬШОЙ КОМПАНИИ, МЕЖДУ РАЗГОВОРАМИ О РАЗНЫХ ОБЩЕСТВЕННЫХ НЕПОРЯДКАХ ЗАЯВИЛ О СВОЕМ ЖЕЛАНИИ «ПРОСИТЬ СУДА НА ЕГО ИМПЕРАТОРСКОЕ ВЕЛИЧЕСТВО» И ДАЖЕ ОБСУДИЛ ДЕТАЛИ ТАКОЙ НЕОБЫЧНОЙ ПРОЦЕДУРЫ. СОБРАВШИЕСЯ ДУХОВНЫЕ ЛИЦА СПРАШИВАЛИ ПЕРХУРОВА: «ПЕРЕД КЕМ ТЫ БУДЕШЬ С ЕГО ВЕЛИЧЕСТВОМ СУДИТЦА»? В ОТВЕТ ПОДЬЯЧИЙ ОПИСЫВАЛ ОСОБЕННОСТИ СУДОУСТРОЙСТВА И УВЕРЯЛ КОМПАНИЮ, ЧТО «НЫНЕ НЕ ТОЛКО НА ТЕБЯ СУДА СЫСКАТЬ МОГУ, НЫНЕ И НА САМОГО ИМПЕРАТОРА [МОГУ] ПРОСИТЬ, И СУД ДЕ С НИМ ДАДУТ» ${ }^{33}$. ЗНАЧИТ, ИДЕЯ ПЕТРА О ТОМ, ЧТО «ЕГО ВЕЛИЧЕСТВО ЕСТЬ САМОВЛАСТНЫЙ МОНАРХ, КОТОРЫЙ НИКОМУ НА СВЕТЕ О СВОИХ ДЕЛАХ ОТВЕТУ ДАТЬ НЕ ДОЛЖЕН», ВЫРАЖЕННАЯ В НАПЕЧАТАННОМ АРТИКУЛЕ ВОИНСКОМ 1715 Г., К КОНЦУ ПРАВЛЕНИЯ ПЕРВОГО ИМПЕРАТОРА НЕ УКОРЕНИЛАСЬ ДАЖЕ ВО ВСЕХ ГОЛОВАХ ПРЕДСТАВИТЕЛЕЙ ИМПЕРСКОЙ БЮРОКРАТИИ, НЕ ГОВОРЯ УЖЕ О МНОГОЧИСЛЕННЫХ НЕОБРАЗОВАННЫХ ГРУППАХ НАСЕЛЕНИЯ, КОТОРЫЕ ДОЛЖНЫ БЫЛИ СОСТАВЛЯТЬ, ПО ТЕРМИНОЛОГИИ ХАБЕРМАСА, РАЗЛИЧНЫЕ «ПЛЕБЕЙСКИЕ ПУБЛИЧНЫЕ СФЕРЫ» ${ }^{34}$. ИЗУЧЕНИЕ ДЕЛ О «НЕПРИГОЖИХ РЕЧАХ» ПОДТВЕРЖДАЕТ ЭТО ПРЕДПОЛОЖЕНИЕ. Е.В. АНИСИМОВ ДАЖЕ ПРИШЕЛ К УБЕЖДЕНИЮ, ЧТО САМ ИНСТИТУТ ПОЛИТИЧЕСКОГО СЫСКА XVIII В. БЫЛ ЗАНЯТ «НЕ СТОЛЬКО РЕАЛЬНЫМИ ПРЕСТУПЛЕНИЯМИ, КОТОРЫЕ УГРОЖАЛИ ГОСБЕЗОПАСНОСТИ, СКОЛЬКО ПО ПРЕИМУЩЕСТВУ “БОРЬБОЙ С ДЛИННЫМИ ЯЗЫКАМИ"» (С. 60). ПРИЧЕМ, «ЕСЛИ ОЦЕНИТЬ В СОВОКУПНОСТИ ВСЕ, ЧТО ГОВОРИЛИ ЛЮДИ О ВЛАСТИ И ЗА ЧТО ОНИ ПОТОМ (ПО ДОНОСАМ) ОКАЗАЛИСЬ В КОЛОДНИЧЬЕЙ 
ПАЛАТЕ СЫСКНОГО ВЕДОМСТВА, ТО МОЖНО УТВЕРЖДАТЬ», ЧТО «ОБЩЕСТВЕННОЕ СОЗНАНИЕ ТОГО ВРЕМЕНИ» БЫЛО «ОЧЕНЬ, ПО-СОВРЕМЕННОМУ ГОВОРЯ, ПОЛИТИЗИРОВАННЫМ», ТАК КАК НИ ОДНО «ВАЖНОЕ ПОЛИТИЧЕСКОЕ СОБЫТИЕ НЕ ПРОХОДИЛО МИМО ВНИМАНИЯ ДВОРЯН, ГОРОЖАН, КРЕСТЬЯН ПОРОЙ САМЫХ ГЛУХИХ ДЕРЕВЕНЬ» (С. 60). ПРИ ЭТОМ «ПОДДАННЫЕ, ОСОБЕННО В СВОЕМ УЗКОМ КРУГУ, ДА ПОРОЙ И ПУБЛИЧНО, БЕЗ ВСЯКОГО ПОЧТЕНИЯ ВЫСКАЗЫВАЛИСЬ О СВОИХ ПРЕЖНИХ И НЫНЕШНИХ ПРАВИТЕЛЯХ КАК О ЗЕМНЫХ, ГРЕШНЫХ ЛЮДЯХ, ПОРОЙ БЕЗАПЕЛЛЯЦИОННО, ЦИНИЧНО И ГРУБО СУДИЛИ ИХ ПОСТУПКИ» (С. 45). ЛЮБОПЫТНО, ЧТО Е.В. АНИСИМОВ, НЕ ОБРАЩАЯСЬ СПЕЦИАЛЬНО К Ю. ХАБЕРМАСУ, ПО СУТИ СТАВИТ ПРОБЛЕМУ СУЩЕСТВОВАНИЯ РАЗЛИЧНЫХ НЕГОСУДАРСТВЕННЫХ «ФОРУМОВ» ДЛЯ ОБСУЖДЕНИЯ ОБЩЕСТВЕННО ВАЖНЫХ ПРОБЛЕМ. ДЕЙСТВИТЕЛЬНО, МНОГИЕ «НЕПРИГОЖИЕ РЕЧИ» ПРЕДСТАВЛЯЮТ СОБОЙ ПУБЛИЧНЫЕ ВЫСКАЗЫВАНИЯ, ПРЕДНАЗНАЧЕННЫЕ ДЛЯ ЛЮДЕЙ СВОЕГО КРУГА, И ОНИ, НЕСОМНЕННО, СВИДЕТЕЛЬСТВУЮТ ОБ ОБЩЕСТВЕННОМ СОЗНАНИИ», КОТОРОЕ К ТОМУ ЖЕ БЫЛО ВЕСЬМА «ПОЛИТИЗИРОВАННЫМ ${ }^{35}$.

41 НЕСОМНЕННО, «НЕВОЛЬНЫЙ» ВЫХОД АВТОР НА ПРОБЛЕМАТИКУ «ПУБЛИЧНЫХ СФЕР» ВО МНОГОМ ПРЕДОПРЕДЕЛЕН САМИМ МАТЕРИАЛОМ. ЖАЛЬ, ЧТО Е.В.АНИСИМОВ НЕ ОБРАТИЛ СПЕЦИАЛЬНОГО ВНИМАНИЯ НА ОБЩЕСТВО И ТЕ ОСОБЕННЫЕ ФОРМЫ ПУБЛИЧНОСТИ, ИНФОРМАЦИЯ О КОТОРЫХ ПРОСМАТРИВАЕТСЯ В СУДЕБНОСЛЕДСТВЕННЫХ ДЕЛАХ, ОГРАНИЧИВШИСЬ ЛИШЬ ОБЩИМИ ЗАМЕЧАНИЯМИ. ОН ПОЛНОСТЬЮ СОСРЕДОТОЧЕН НА ГОСУДАРСТВЕ И ИНСТИТУТЕ ПОЛИТИЧЕСКОГО СЫСКА, ЧТО В ПРИНЦИПЕ ОБУСЛОВЛЕНО ИССЛЕДОВАТЕЛЬСКИМИ ЗАДАЧАМИ, О КОТОРЫХ СКАЗАНО ВЫШЕ. НО, КАК МНЕ КАЖЕТСЯ, РАССМОТРЕНИЕ ПОЛИТИЧЕСКИХ ПРОЦЕССОВ В КОНТЕКСТЕ ПРОБЛЕМАТИКИ «РЕЖИМОВ ПУБЛИЧНОСТИ» ИНОГДА ПОЗВОЛЯЕТ ГЛУБЖЕ ПОНЯТЬ САМИ ЭТИ ПРОЦЕССЫ. ПОЗВОЛЮ СЕБЕ ЭТО ПРОДЕМОНСТРИРОВАТЬ НА ПРИМЕРЕ ОДНОГО КЕЙСА (ИЗ МНОЖЕСТВА ВОЗМОЖНЫХ).

В ДЕКАБРЕ 1704 Г. РАССЛЕДОВАЛОСЬ ДЕЛО О НИЖЕГОРОДСКОМ БУРЛАКЕ АНДРЕЕ ИВАНОВЕ, КОТОРЫЙ В ПУБЛИЧНОМ МЕСТЕ ЗАЯВИЛ, ЧТО ЗА НИМ ЕСТЬ ГОСУДАРЕВО ДЕЛО». ОКАЗАВШИСЬ В ПРЕОБРАЖЕНСКОМ ПРИКАЗЕ, НИЖЕГОРОДЕЦ ОБЪЯСНИЛ СВОЙ ПРИХОД ЖЕЛАНИЕМ «ИЗВЕЩАТЬ ГОСУДАРЮ, ЧТО ОН РАЗРУШАЕТ ВЕРУ ХРИСТИАНСКУЮ - ВЕЛИТ БОРОДЫ БРИТЬ, ПЛАТЬЕ НОСИТЬ НЕМЕЦКОЕ И ТАБАК ВЕЛИТ ТЯНУТЬ». ДЕЛО ЗАКОНЧИЛОСЬ ТЕМ, ЧТО ОБВИНЯЕМЫЙ «ПОГИБ В ЗАСТЕНКЕ ПОД ПЫТКАМИ». ДЛЯ Е.В. АНИСИМОВА ОНО ПРЕДСТАВЛЯЕТ СОБОЙ РЕДКИЙ СЛУЧАЙ «САМОИЗВЕТА», КОГДА «ПСИХИЧЕСКИ БОЛЬНЫЕ ЛЮДИ» ИЛИ «РЕЛИГИОЗНЫЕ ФАНАТИКИ» ДОНОСИЛИ САМИ НА СЕБЯ, ЖЕЛАЯ «“ПОСТРАДАТЬ” ЗА СВОИ ИДЕАЛЫ» (С. 110-111). НО ОБРАЩЕНИЕ К ПОДЛИННОМУ ДЕЛУ ${ }^{36}$ И ПРОЧТЕНИЕ ЕГО ПОД УГЛОМ ПРОБЛЕМАТИКИ «РЕЖИМОВ ПУБЛИЧНОСТИ» ПОЗВОЛЯЕТ НАРИСОВАТЬ ИНУЮ КАРТИНУ.

В ДЕЙСТВИТЕЛЬНОСТИ, Ф.Ю.РОМОДАНОВСКИЙ И ЕГО «ТОВАРИЩИ» ОБОСНОВАННО ПОДОЗРЕВАЛИ АНДРЕЯ ИВАНОВА В СВЯЗЯХ С КАКИМИ-ТО ОБРАЗОВАННЫМИ И ВЕСЬМА ОСВЕДОМЛЕННЫМИ ОБЩЕСТВЕННЫМИ КРУГАМИ. НА САМОМ ДЕЛЕ, НЕ УМЕЮЩИЙ ПОДПИСАТЬСЯ ПОД ДОПРОСОМ НИЖЕГОРОДСКИЙ БУРЛАК ВРЯД ЛИ МОГ ЗНАТЬ О ЗАПРЕЩЕНИИ БРАДОБРИТИЯ В КОРМЧЕЙ КНИГЕ (НА КОТОРУЮ ОН ССЫЛАЛСЯ НА СЛЕДСТВИИ), А УЖ ТЕМ БОЛЕЕ БЫТЬ В КУРСЕ ТОГО, ЧТО ГОСУДАРЬ В ТЕ ДНИ НАХОДИЛСЯ В ПРЕОБРАЖЕНСКОМ И ЗАНИМАЛСЯ, МЕЖДУ ПРОЧИМ, РАЗРАБОТКОЙ УКАЗА О БРАДОБРИТИИ, КОТОРЫЙ БЫЛ ОБНАРОДОВАН В НАЧАЛЕ 1705 Г. (Т.Е. СПУСТЯ НЕСКОЛЬКО НЕДЕЛЬ ПОСЛЕ РАССМАТРИВАЕМОГО ИНЦИДЕНТА) ${ }^{37}$. ЗНАЧИТ, КТО-ТО 
ПОДОСЛАЛ ЭТОГО МАЛООБРАЗОВАННОГО ЧЕЛОВЕКА К ГОСУДАРЮ С УГРОЖАЮЩЕЗЛОВЕЩИМ ОБЛИЧЕНИЕМ, ДА ЕЩЕ И В СТОЛЬ ПОДХОДЯЩИЙ ДЛЯ ЭТОГО МОМЕНТ. ТАКИМ ОБРАЗОМ, АНДРЕЙ ИВАНОВ БЫЛ НЕ ПРОСТО ОДИНОЧКОЙ, ДУШЕВНО БОЛЬНЫМ «САМОИЗВЕТЧИКОМ». ЕГО ОБРАЩЕНИЕ ПРЕДСТАВЛЯЛОСЬ СЛЕДОВАТЕЛЯМ (И, ВИДИМО, НЕ БЕЗ ПРИЧИНЫ) КОЛЛЕКТИВНЫМ ДЕЙСТВИЕМ КАКОЙ-ТО СОЦИАЛЬНОЙ ГРУППЫ, КОТОРАЯ СТРЕМИЛАСЬ ПОВЛИЯТЬ НА РЕШИМОСТЬ ГОСУДАРЯ ВВЕСТИ ОБЯЗАТЕЛЬНОЕ БРАДОБРИТИЕ И ПЫТАЛАСЬ ПРИ ЭТОМ ИСПОЛЬЗОВАТЬ ТРАДИЦИОННЫЙ ДЛЯ ПОЛИТИЧЕСКОЙ КУЛЬТУРЫ МОСКОВСКОЙ РУСИ ИНСТИТУТ «ОБЛИЧЕНИЯ».

СОГЛАСНО ПРЕДСТАВЛЕНИЯМ, РАСПРОСТРАНЕННЫМ СРЕДИ ЛЮДЕЙ МОСКОВСКОГО ГОСУДАРСТВА, «ОБЛИЧАТЬ» ВПАДШЕГО В «ЕРЕСЬ» ГОСУДАРЯ ДОЛЖНЫ БЫЛИ, В ПЕРВУЮ ОЧЕРЕДЬ, ДУХОВНЫЕ ЛИЦА. В 1703 Г. ПРЕЕМНИК ПАТРИАРХА АДРИАНА МЕСТОБЛЮСТИТЕЛЬ СТЕФАН ЯВОРСКИЙ ПОЛУЧИЛ АНОНИМНОЕ «ПОДМЕТНОЕ» ПИСЬМО, В КОТОРОМ ЕМУ ОБЪЯВЛЯЛОСЬ ПРОКЛЯТИЕ «ОТ ВСЕХ ХРИСТИАН» ЗА ТО, ЧТО ОН НЕ ОБЛИЧАЕТ ЦАРЯ, ВВОДЯЩЕГО «ПРОКЛЯТОЕ БРИТОБОРОДИЕ» И «БУСУРМАНСКОЕ ПЛАТИЕ». НО ЕСЛИ ТЕ, КТО ДОЛЖНЫ ОБЛИЧАТЬ, ЭТОГО НЕ ДЕЛАЮТ, ИХ ОБЯЗАННОСТЬ ДОЛЖНА БЫТЬ ИСПОЛНЕНА КЕМ-ТО ЕЩЕ. В 1699 Г. ИЗВЕСТНЫЙ МОСКОВСКИЙ ЮРОДИВЫЙ ИВАШКА НАГОЙ В РАЗГОВОРЕ С АРХИМАНДРИТОМ МОСКОВСКОГО ЗНАМЕНСКОГО МОНАСТЫРЯ ИОАСАФОМ ЗАЯВИЛ О НАМЕРЕНИИ «ИТИТЬ В ПРЕОБРАЖЕНСКОЕ ЦАРЯ ОБЛИЧАТЬ, ЧТО БОРОДЫ БРЕЕТ, И С НЕМЦАМИ ВОДИТЦА, И ВЕРА СТАЛА НЕМЕЦКАЯ». ЕМУ ЭТО КАЗАЛОСЬ НЕОБХОДИМЫМ ВВИДУ ТОГО, ЧТО ПАТРИАРХ АДРИАН ОТКАЗЫВАЛСЯ «ОБЛИЧАТЬ»: «ЖИВЕТ ИС КУСКА - ПИТЬ БЫ ЕМУ, ДА ЕСТЬ, ДА БЕРЕЖЕТ ДЕ МАНТИЮ ДА КЛАБУКА БЕЛОВА, ЗАТЕМ ДЕ ОН И НЕ ОБЛИЧАЕТ, А ВЫ ДЕ ВЛАСТИ ВСЕ НАКУПНЫЕ» ${ }^{38}$.

ПРИВЛЕЧЕНИЕ ДОПОЛНИТЕЛЬНЫХ МАТЕРИАЛОВ ПОКАЗЫВАЕТ, ЧТО Ф.Ю.РОМОДАНОВСКИЙ И ЕГО КОЛЛЕГИ НА СЛУЧАЙНО ПОЛАГАЛИ, ЧТО ЗА НЕГРАМОТНЫМ БУРЛАКОМ АНДРЕЕМ ИВАНОВЫМ СТОЯТ КАКИЕ-ТО ОЧЕНЬ ОБРАЗОВАННЫЕ И ОСВЕДОМЛЕННЫЕ ЛЮДИ, НАСТРОЕННЫЕ ВЕСЬМА РЕШИТЕЛЬНО. С ПОДОБНЫМИ ЭПИЗОДАМИ КОЛЛЕКТИВНОГО ПОЛИТИЧЕСКОГО ДЕЙСТВИЯ ВЛАСТЯМ

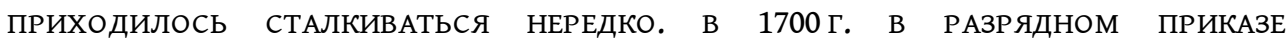
РАССЛЕДОВАЛОСЬ ДЕЛО О РАСКЛЕИВАНИИ В ПУБЛИЧНЫХ МЕСТАХ НЕКИХ ЛИСТОВ ПРОТИВ БРАДОБРИТИЯ. ВПЕРВЫЕ ТАКОЙ ЛИСТ БЫЛ ОБНАРУЖЕН 27 МАЯ 1700 Г. В СЕМИ ВЕРСТАХ ОТ ТРОИЦЕ-СЕРГИЕВА МОНАСТЫРЯ ПО НАПРАВЛЕНИЮ К МОСКВЕ НА СТОЯВШЕМ НА ДОРОГЕ КРЕСТЕ. 1 ИЮНЯ 1700 Г. ТОЧНО ТАКОЙ ЖЕ ЛИСТ ОКАЗАЛСЯ И НА ВОРОТАХ МИХАЙЛО-АРХАНГЕЛЬСКОГО МОНАСТЫРЯ В Г. ЮРЬЕВЕ-ПОЛЬСКОМ, А 18 ИЮНЯ 1700 Г. НА ГОРОДОВЫХ ВОРОТАХ В СУЗДАЛЕ. ХОТЯ САМ ЛИСТ НЕ СОХРАНИЛСЯ, ВНИМАТЕЛЬНОЕ ИЗУЧЕНИЕ ДЕЛА ПОЗВОЛЯЕТ ПО КОСВЕННЫМ ДАННЫМ РЕКОНСТРУИРОВАТЬ ЕГО СОДЕРЖАНИЕ. КОГДА 18 ИЮНЯ 1700 Г. ЛИСТ ПОЯВИЛСЯ НА ГОРОДСКИХ ВОРОТАХ ГОРОДА СУЗДАЛЯ И ЕГО ПРИНЕСЛИ В СУЗДАЛЬСКУЮ ПРИКАЗНУЮ ИЗБУ, ВОЕВОДА ВАСИЛИЙ ИСЛЕНЬЕВ ВЕЛЕЛ ЛИСТ ПРОЧЕСТЬ ВСЛУХ. ВО ВРЕМЯ ЧТЕНИЯ ПОДЬЯЧИЙ ФЕДОР МИХАЙЛОВ ВДРУГ ВОСКЛИКНУЛ: «О ТОМ И АРХИЕРЕЙ С ТВЕРСКИМ АРХИЕПИСКОПОМ ХОТЕЛИ СОБОРОВАТЬ!» НА ДОПРОСЕ ПОДЬЯЧИЙ ТАК ОБЪЯСНИЛ СВОИ СЛОВА: «СЛЫШАЛ ОН В ПРОШЛЫХ ГОДЕХ СУЗДАЛЬСКОГО МИТРОПОЛИТА ОТ КАЗНАЧЕЯ ИОНЫ ВОЛОГОЦКОГО О ТОМ, ЧТОБ ПРИТТИ ИМ, АРХИЕРЕЕМ, К ВЕЛИКОМУ ГОСУДАРЮ И БИТЬ ЧЕЛОМ, ЧТОБ БОРОД НЕ БРИТЬ». МОЖНО ПРЕДПОЛОЖИТЬ, ЧТО В ЭТОМ ЛИСТЕ ТАКЖЕ РЕЧЬ ШЛА О ПРИЗЫВЕ БИТЬ ЧЕЛОМ ГОСУДАРЮ «О ТОМ, ЧТОБЫ 
БОРОД НЕ БРИТЬ». СУДЯ ПО ВСЕМУ, ПРИЗЫВ БЫЛ ОБРАЩЕН К СЛУЖИЛЫМ ЛЮДЯМ , ТАК КАК СЛЕДСТВИЕ ПРОИЗВОДИЛОСЬ В РАЗРЯДНОМ ПРИКАЗЕ 39.

СТРЕМЯСЬ ПОДАВИТЬ ПОДОБНЫЕ КОЛЛЕКТИВНЫЕ ДЕЙСТВИЯ, ЦАРЬ И ЕГО АГЕНТЫ ДАЛЕКО НЕ ВСЕ ФОРМЫ ПУБЛИЧНОГО ОБСУЖДЕНИЯ ОБЩЕСТВЕННО ВАЖНЫХ ВОПРОСОВ РАССМАТРИВАЛИ КАК ПРЕСТУПНЫЕ. В 1714 Г. ПО УКАЗУ ПЕТРА І НА МОСКОВСКОМ ПЕЧАТНОМ ДВОРЕ БЫЛО ИЗДАНО СОЧИНЕНИЕ ДИМИТРИЯ РОСТОВСКОГО, ПОСВЯЩЕННОЕ ОПРОВЕРЖЕНИЮ МНЕНИЯ О ГРЕХОВНОСТИ БРАДОБРИТИЯ. ОНО НАЧИНАЕТСЯ ВОСПОМИНАНИЕМ ДИМИТРИЯ РОСТОВСКОГО, ОТНОСЯЩИМСЯ К ЛЕТУ 1705 Г. (Т.Е. ПЕРИОДУ АКТИВНОЙ РЕАЛИЗАЦИИ УКАЗА О БРАДОБРИТИИ), О ТОМ, КАК В ЕГО КЕЛЬЕ (В Г.ЯРОСЛАВЛЕ) СОСТОЯЛИСЬ МНОГИЕ «РАЗГЛАГОЛЬСТВИЯ» «О БРАДОБРИТИИ И НЕБРАДОБРИТИИ», В КОТОРЫХ ПРИНИМАЛИ УЧАСТИЕ МНОЗИ ЧЕСТНИИ ГРАЖДАНЕ». ПРИЧЕМ БОЛЬШИНСТВО СОБЕСЕДНИКОВ МИТРОПОЛИТА ИЗНАЧАЛЬНО БЫЛИ ГОРЯЧИМИ ПРОТИВНИКАМИ ПЕТРОВСКОГО УКАЗА, ЧТО НЕ СКРЫВАЕТСЯ В САМОЙ КНИГЕ: «ВЕЛЯТ НАМ БРАДЫ БРИТЬ, А МЫ ГОТОВЫ ГЛАВЫ НАШИ ЗА БРАДЫ ПОЛОЖИТИ, УНЕ НАМ ЕСТЬ ДА ОТСЕКУТСЯ НАШИ ГЛАВЫ, НЕЖЕ ДА ОБРИЮТСЯ БРАДЫ НАШИ». ИМЕННО ТОГДА ДИМИТРИЙ РОСТОВСКИЙ И ОСОЗНАЛ НЕОБХОДИМОСТЬ НАПЕЧАТАТЬ ТАКУЮ КНИГУ, В КОТОРОЙ ОКАЗАЛАСЬ БЫ СОБРАНА ВСЯ БОГОСЛОВСКАЯ АРГУМЕНТАЦИЯ ПО ДАННОМУ ВОПРОСУ ${ }^{40}$. ОТМЕТИМ, ЧТО В ДАННОМ СЛУЧАЕ СОБРАНИЯ «ЧЕСТНЫХ ГРАЖДАН» В КЕЛЬЕ МИТРОПОЛИТА ДЛЯ ОБСУЖДЕНИЯ АКТУАЛЬНОГО ВОПРОСА О ТОМ, КАК НУЖНО ОТНОСИТЬСЯ К ПЕТРОВСКОМУ УКАЗУ О БРАДОБРИТИИ, НЕ ПРЕДСТАВЛЯЛИСЬ ПЕТРУ НЕЗАКОННЫМИ (ЦАРЬ ЛИЧНО ЗАБОТИЛСЯ О РАСПРОСТРАНЕНИИ ЭТОЙ КНИГИ ДИМИТРИЯ РОСТОВСКОГО И ПОЧТИ НАВЕРНЯКА ЗНАЛ О ЕЕ СОДЕРЖАНИИ $\left.{ }^{41}\right)$. ОДНАКО ПОДОБНЫЕ СОБРАНИЯ ПЕРЕХОДИЛИ В ПЛОСКОСТЬ ГОСУДАРСТВЕННЫХ ПРЕСТУПЛЕНИЙ (С ТОЧКИ ЗРЕНИЯ ПРЕДСТАВИТЕЛЕЙ ВЛАСТИ), ЕСЛИ ОБОРАЧИВАЛИСЬ СТРЕМЛЕНИЕМ КАКОЙ-ТО ГРУППЫ ЛИЦ ОКАЗАТЬ ДАВЛЕНИЕ НА МОНАРХА И ЕГО РЕШЕНИЯ ПУТЕМ ПУБЛИЧНОГО ОБЛИЧЕНИЯ ИЛИ ПОДАЧИ КОЛЛЕКТИВНОЙ ЧЕЛОБИТНОЙ. В ТАКИХ СЛУЧАЯХ ПРОИСХОДИЛО КАК БЫ «ПЕРЕКЛЮЧЕНИЕ РЕЖИМА ПУБЛИЧНОСТИ» ${ }^{42}$, КОГДА «СЛАБАЯ ПУБЛИКА» СТРЕМИЛАСЬ СТАТЬ «СИЛЬНОЙ ПУБЛИКОЙ», ЧТО БЫЛО НЕДОПУСТИМО ДЛЯ ФОРМИРУЮЩЕГОСЯ РЕГУЛЯРНОГО ГОСУДАРСТВА.

РАССМОТРЕНИЕ КНИГИ Е.В.АНИСИМОВА С ТОЧКИ ЗРЕНИЯ КОНЦЕПЦИИ ПУБЛИЧНОЙ СФЕРЫ ЗАСТАВЛЯЕТ ТАКЖЕ ЗАДУМАТЬСЯ НАД ВОПРОСОМ О ТОМ, В КАКОЙ СТЕПЕНИ ВЫСКАЗАННЫЕ ПУБЛИЧНЫЕ СУЖДЕНИЯ О ВЛАСТИ, АВТОРЫ КОТОРЫХ ОКАЗЫВАЛИСЬ В ПРЕОБРАЖЕНСКОМ ПРИКАЗЕ ИЛИ ТАЙНОЙ КАНЦЕЛЯРИИ, МОГЛИ ВОЗДЕЙСТВОВАТЬ НА ВЕРХОВНУЮ ВЛАСТЬ? КАК ПОКАЗЫВАЕТ Е.В. АНИСИМОВ, «ВСЕ САМОДЕРЖЦЫ И САМОДЕРЖИЦЫ XVIII ВЕКА БЫЛИ ПРИЧАСТНЫ К ПОЛИТИЧЕСКОМУ СЫСКУ» (С. 65). Н.Б. ГОЛИКОВОЙ УДАЛОСЬ ОБНАРУЖИТЬ БОЛЕЕ 50 СЛУЧАЕВ ЛИЧНОГО УЧАСТИЯ ПЕТРА В РЕШЕНИИ ПОЛИТИЧЕСКИХ ДЕЛ ПРЕОБРАЖЕНСКОГО ПРИКАЗА 1700-1705 ГГ., ПРИЧЕМ НЕ ТОЛЬКО ЗНАЧИТЕЛЬНЫХ, НО ТАКЖЕ И «МЕЛКИХ» ${ }^{43}$. КАК ОТМЕЧАЕТ Е.В. АНИСИМОВ, «ДЛЯ РАБОТЫ В ТАЙНОЙ КАНЦЕЛЯРИИ ПЕТР ДАЖЕ ВЫДЕЛИЛ ОСОБЫЙ ДЕНЬ ПОНЕДЕЛЬНИК. В ЭТОТ ДЕНЬ ПЕТР ПРИЕЗЖАЛ В ПЕТРОПАВЛОВСКУЮ КРЕПОСТЬ, СЛУШАЛ И ЧИТАЛ ТАМ ДОКЛАДЫ, ВЫПИСКИ И ПРИГОВОРЫ ПО ТЕКУЩИМ ДЕЛАМ, ЯВЛЯЯ СОБОЙ В ОДНОМ ЛИЦЕ И СЛЕДОВАТЕЛЯ, И СУДЬЮ» (С. 66-67). СТОЛЬ ЖЕ ЗНАЧИТЕЛЬНУЮ РОЛЬ ИГРАЛ ПОЛИТИЧЕСКИЙ СЫСК И В ЖИЗНИ ДРУГИХ РОССИЙСКИХ МОНАРХОВ XVIII В. (с. 78-105). В ТАКОМ СЛУЧАЕ, МОГЛА ЛИ ИНФОРМАЦИЯ ПОЛИТИЧЕСКИХ ПРОЦЕССОВ В КАКОЙ-ТО СТЕПЕНИ ИСПОЛЬЗОВАТЬСЯ ПЕТРОМ И ЕГО 
ПРЕЕМНИКАМИ КАК СРЕДСТВО «ОБРАТНОЙ СВЯЗИ», КАК СПОСОБ ПОЛУЧЕНИЯ ИНФОРМАЦИИ ОБ ОБЩЕСТВЕННЫХ НАСТРОЕНИЯХ, КОТОРАЯ МОГЛА ИСПОЛЬЗОВАТЬСЯ ИМИ ПРИ ПРИНЯТИИ РЕШЕНИЙ? В ОДНОЙ ИЗ РАБОТ Я ПОПЫТАЛСЯ ОБОСНОВАТЬ, ЧТО ОБЩЕСТВЕННЫЕ НАСТРОЕНИЯ, ИНФОРМАЦИЮ О КОТОРЫХ ПЕТР ПОЛУЧАЛ ИЗ МАТЕРИАЛОВ ДЕЛ ПРЕОБРАЖЕНСКОГО ПРИКАЗА, ВПОЛНЕ МОГЛИ ВЛИЯТЬ НА ЕГО РЕШИМОСТЬ ПРОВОДИТЬ ТЕ ИЛИ ИНЫЕ КУЛЬТУРНЫЕ ПРЕОБРАЗОВАНИЯ ${ }^{44}$.

ОТМЕНА «СЛОВА И ДЕЛА» В 1762 Г. «НЕ ПРИВЕЛА К ПРЕКРАЩЕНИЮ ПРЕСЛЕДОВАНИЙ ЗА ОСУЖДАЮЩИЕ МОНАРХА И ВЛАСТЬ РАЗГОВОРЫ - ОНИ ПО-ПРЕЖНЕМУ СЧИТАЛИСЬ ПРЕСТУПНЫМИ» (С. 58). ЕКАТЕРИНА ІІ «ОЧЕНЬ РЕВНИВО ОТНОСИЛАСЬ К ТОМУ, ЧТО О НЕЙ ГОВОРЯТ ЛЮДИ, ПИШУТ ГАЗЕТЫ. ВНИМАТЕЛЬНО НАБЛЮДАЛА ИМПЕРАТРИЦА ЗА ОБЩЕСТВЕННЫМ МНЕНИЕМ ВНУТРИ СТРАНЫ» ${ }^{45} .4$ ИЮНЯ 1763 Г. БЫЛ ИЗДАН МАНИФЕСТ «О ВОСПРЕЩЕНИИ НЕПРИСТОЙНЫХ РАССУЖДЕНИЙ И ТОЛКОВ, ПО ДЕЛАМ ДО ПРАВИТЕЛЬСТВА ОТНОСЯЩИМСЯ», В КОТОРОМ ВЫРАЖАЛОСЬ СОЖАЛЕНИЕ О ТОМ, ЧТО НЕКИЕ «РАЗВРАЩЕННЫХ НРАВОВ И МЫСЛЕЙ ЛЮДИ», БУДУЧИ САМИ «ЗАРАЖЕНЫ СТРАННЫМИ РАССУЖДЕНИЯМИ», НЕ ОСНОВАННЫМИ НА ВЛАДЕНИИ ИНФОРМАЦИЕЙ («НЕ ИМЕЯ О ТОМ ПРЯМАГО СВЕДЕНИЯ»), ЗАРАЖАЮТ ИМИ «И ДРУГИХ СЛАБОУМНЫХ» (С.58). ПРИЧЕМ ЭТИ «СЛАБОУМНЫЕ» РАССУЖДЕНИЯ, НЕ ОСНОВАННЫЕ НА «ПРЯМЫХ СВЕДЕНИЯХ», ОТНОСЯТСЯ «НЕ ТОЛЬКО К ГРАЖДАНСКИМ ПРАВАМ И ПРАВИТЕЛЬСТВУ И НАШИМ ИЗДАВАЕМЫМ УСТАВАМ, НО И САМЫМ БОЖЕСТВЕННЫМ УЗАКОНЕНИЯМ». ИМПЕРАТРИЦА «МАТЕРИНСКИ УВЕЩЕВАЛА» СВОИХ ПОДДАННЫХ «УДАЛИТЬСЯ ОТ ВСЯКИХ ВРЕДНЫХ РАССУЖДЕНИЙ, НАРУШАЮЩИХ ПОКОЙ И ТИШИНУ, ПРИЛЕЖА ЕДИНСТВЕННО ЗВАНИЮ СВОЕМУ» ${ }^{46}$.

ИНТЕРЕСНО ЗАМЕТИТЬ, ЧТО Ю. ХАБЕРМАС, АНАЛИЗИРУЯ ГЕНЕЗИС «БУРЖУАЗНОЙ ПУБЛИЧНОЙ СФЕРЫ», ИСПОЛЬЗОВАЛ ПОХОЖИЕ ДОКУМЕНТЫ. НАПРИМЕР, ОН АНАЛИЗИРОВАЛ РЕСКРИПТ ФРИДРИХА ІІ ОТ 1784 Г., СОГЛАСНО КОТОРОМУ ЧАСТНОЕ ЛИЦО НЕ ИМЕЕТ ПРАВА ВЫНОСИТЬ ПУБЛИЧНОЕ СУЖДЕНИЕ О ДЕЙСТВИЯХ СУВЕРЕНА, ТАК КАК ОНО НЕ МОЖЕТ ВЛАДЕТЬ НЕОБХОДИМЫМ ДЛЯ ЭТОГО ОБЪЕМОМ ИНФОРМАЦИИ. ХАБЕРМАС ОБРАЩАЛ ВНИМАНИЕ НА ТО, ЧТО В ЭТОМ РЕСКРИПТЕ «ПУБЛИЧНЫМИ» НАЗЫВАЮТСЯ НЕОДОБРИТЕЛЬНЫЕ СУЖДЕНИЯ В ОТНОШЕНИИ «ПУБЛИЧНОЙ ВЛАСТИ», ЧТО, НЕСОМНЕННО, УЖЕ УКАЗЫВАЕТ НА ВЫДЕЛЕНИЕ «ПУБЛИЧНОЙ СФЕРЫ» «as a forum in which the private people, come together to form a public, readied themselves to compel public authority to legitimate itself before public opinion ${ }^{47}$. НО РАЗВЕ НЕ О ТАКИХ ЖЕ ЯВЛЕНИЯХ СВИДЕТЕЛЬСТВУЕТ ПРОЦИТИРОВАННОЕ Е.В. АНИСИМОВЫМ ПИСЬМО МОСКОВСКОГО ГЛАВНОКОМАНДУЮЩЕГО КН. М.Н. ВОЛКОНСКОГО ОТ ДЕКАБРЯ 1773 Г., НАПИСАННОЕ В САМЫЙ РАЗГАР ПУГАЧЕВСКОГО ВОССТАНИЯ, В ОТВЕТ НА ПРЕДЛОЖЕНИЕ ИМПЕРАТРИЦЫ ОБНОВИТЬ ПРОЦИТИРОВАННЫЙ ВЫШЕ УКАЗ «О ВОСПРЕЩЕНИИ НЕПРИСТОЙНЫХ РАССУЖДЕНИЙ»: «ЧТО КАСАЕТСЯ ДО ВОЗОБНОВЛЕНИЯ ОТ СЕНАТА УКАЗУ О НЕБОЛТАНИИ ЛИШНЯГО, Я ЕЩЕ ДО ДАЛЬНЕЙШАГО В.И.В. ПОВЕЛЕНИЯ УДЕРЖАЛСЯ, В РАЗСУЖДЕНИИ, ЧТО ОНОЙ УКАЗ В ПРОШЕДШЕМ ИЮЛЕ МЕСЕЦЕ ПО ПРЕДЛОЖЕНИЮ МОЕМУ ОТ СЕНАТА УЖЕ ПУБЛИКОВАН БЫЛ, К ТОМУ ЖЕ, ЧТОБ И НЕ ПОДАТЬ В ПУБЛИКЕ ПРИЧИНЫ К БОЛЬШОМУ УВАЖЕНИЮ О ОРЕНБУРГСКОМ ДЕЛЕ; А ПРИКАЗАЛ ОБЕР-ПОЛИЦМЕЙСТЕРУ УПОТРЕБИТЬ НАДЕЖНЫХ ЛЮДЕЙ ДЛЯ ПОДСЛУШИВАНИЯ РАЗГОВОРОВ ПУБЛИКИ В ПУБЛИШНЫХ СОБОРИЩАХ, КАК-ТО: В РЯДАХ, БАНЯХ И КАБАКАХ, ЧТО УЖЕ И ИСПОЛНЯЕТСЯ, А МЕЖДУ ДВОРЯНСТВОМ ТАКЖЕ ВСЯКИЕ РАЗГОВОРЫ ПРИМЕЧАЮТСЯ» ${ }^{48}$. ЭТА ЦИТАТА ПОЗВОЛЯЕТ УСОМНИТЬСЯ В МНЕНИИ О ТОМ, ЧТО В РОССИИ XVIII В. ПОНЯТИЕ «ПУБЛИКА» 
УПОТРЕБЛЯЛОСЬ ИСКЛЮЧИТЕЛЬНО ДЛЯ ОБОЗНАЧЕНИЯ «БЛАГОВОСПИТАННОГО» И «ПРОСВЕЩЕННОГО» ОБЩЕСТВА ${ }^{49}$ (КОНЕЧНО, ЕСЛИ ИСХОДИТЬ ИЗ ТОГО, ЧТО «БЛАГОВОСПИТАННЫЕ» И «ПРОСВЕЩЕННЫЕ» ЛЮДИ НЕ ИМЕЛИ ОБЫКНОВЕНИЯ ЧАСТО ПОСЕЩАТЬ ОБЩЕСТВЕННЫЕ БАНИ И КАБАКИ).

ИТАК, НА ПЕРВЫЙ ВЗГЛЯД МОЖЕТ ПОКАЗАТЬСЯ, ЧТО ПОЛИТИЧЕСКИЙ СУДЕБНОСЛЕДСТВЕННЫЙ ПРОЦЕСС И ПУБЛИЧНАЯ СФЕРА КАК СОЦИАЛЬНЫЕ ЯВЛЕНИЯ НАХОДЯТСЯ НА ПРОТИВОПОЛОЖНЫХ ПОЛЮСАХ И ПРИНЦИПИАЛЬНО НЕ СОВМЕСТИМЫ ДРУГ С ДРУГОМ. РОССИЙСКАЯ ВЛАСТЬ В ЛИЦЕ ОРГАНОВ ПОЛИТИЧЕСКОГО СЫСКА СТАРАТЕЛЬНО ПРЕСЛЕДУЕТ И ЖЕСТОКО НАКАЗЫВАЕТ ВСЕХ ПРОТИВНИКОВ ГОСУДАРЯ И ЕГО ВЛАСТИ, В РЕЗУЛЬТАТЕ ЧЕГО И ВОЗНИКАЮТ ПОЛИТИЧЕСКИЕ ПРОЦЕССЫ. НО, ЕСЛИ ОРГАНЫ ПОЛИТИЧЕСКОГО СЫСКА СУЩЕСТВОВАЛИ, ЭТО СВИДЕТЕЛЬСТВУЕТ И О СУЩЕСТВОВАНИИ НЕКОТОРЫХ НЕЗАВИСИМЫХ ОТ ВЛАСТИ ПУБЛИЧНЫХ ПРОСТРАНСТВ, В КОТОРЫХ ЛЮДИ ОБСУЖДАЛИ НАСУЩНЫЕ ВОПРОСЫ, ПЕРЕХОДЯ ПРИ ЭТОМ ГРАНИЦУ ДОЗВОЛЕННОГО. ЕСЛИ ЭТО ТАК, ТО И ДОКУМЕНТЫ, СОЗДАВАВШИЕСЯ ОРГАНАМИ ПОЛИТИЧЕСКОГО СЫСКА, ПРЕДСТАВЛЯЮТ СОБОЙ УНИКАЛЬНЫЙ ИСТОЧНИК ДЛЯ ИЗУЧЕНИЯ ПУБЛИЧНОЙ СФЕРЫ В РОССИИ XVIII В. (ПУСТЬ И НЕСОВЕРШЕННОЙ), СТОИТ ЛИШЬ ПОСМОТРЕТЬ НА ЭТИ ДОКУМЕНТЫ ПОД ТАКИМ УГЛОМ ЗРЕНИЯ ${ }^{50}$

\section{Вместо заключения: «несовершенная» или «другая» публичная сфера?}

В КОНЦЕ ДЕКАБРЯ 1696 Г. ИЛИ НАЧАЛЕ ЯНВАРЯ 1697 Г. СТАРЕЦ МОСКОВСКОГО АНДРЕЕВСКОГО МОНАСТЫРЯ АВРААМИЙ ПОДАЛ ПЕТРУ І ЧЕЛОБИТНУЮ С СУРОВОЙ КРИТИКОЙ САМЫХ РАЗЛИЧНЫХ ОБЩЕСТВЕННЫХ НЕПОРЯДКОВ (ОТ НЕПОДОБАЮЩЕГО ПОВЕДЕНИЯ МОНАРХА ДО ЗЛОУПОТРЕБЛЕНИЙ В СУДАХ). В НЕЙ ЖЕ ПРЕДСТАВЛЕН ПРОЕКТ ИДЕАЛЬНОГО ОБЩЕСТВЕННОГО УСТРОЙСТВА, В КОТОРОМ ЗАТРАГИВАЮТСЯ РАЗНООБРАЗНЫЕ ВОПРОСЫ - ОТ ОРГАНИЗАЦИИ УПРАВЛЕНИЯ ДО НЕОБХОДИМОСТИ ВВЕДЕНИЯ ГОСУДАРСТВЕННОГО БЮДЖЕТА. ИЗ САМОГО ТЕКСТА СЛЕДУЕТ, ЧТО ЭТА ЧЕЛОБИТНАЯ (ИЛИ «ТЕТРАДИ») ВЫРАЖАЕТ НЕ СТОЛЬКО МНЕНИЕ ЭТОГО ОДНОГО СТАРЦА, СКОЛЬКО КОНСОЛИДИРОВАННУЮ ПОЗИЦИЮ НЕКОЕГО КРУГА ЛИЦ, ЧАСТО СОБИРАВШЕГОСЯ В КЕЛЬЕ АВРААМИЯ (В АНДРЕЕВСКОМ МОНАСТЫРЕ НА ВОРОБЬЕВЫХ ГОРАХ) ДЛЯ РАЗГОВОРОВ НЕ ТОЛЬКО НА ДУХОВНЫЕ ТЕМЫ, НО ТАКЖЕ И О «ВСЯКИХ МИРСКИХ ОБЩИХ НУЖНЫХ ДЕЛАХ».

ОЗНАКОМИВШИСЬ С СОДЕРЖАНИЕМ «ТЕТРАДЕЙ», ПЕТР I ПРИКАЗАЛ АРЕСТОВАТЬ АВРААМИЯ И ВЫЯСНИТЬ, КТО ИМЕННО ПРИНИМАЛ УЧАСТИЕ В ЭТИХ РАЗГОВОРАХ, КАКИЕ ДРУГИЕ «ПОНОСНЫЕ» РЕЧИ ПРО ЦАРЯ ПРИ ЭТОМ ГОВОРИЛИСЬ, И НЕ ИМЕЕТ ЛИ КТО-ТО ИЗ ЭТИХ ЛЮДЕЙ «ВОРОВСКОГО УМЫСЛУ НА ГОСУДАРСКОЕ ЗДОРОВЬЕ». РАССЛЕДОВАНИЕ, КОТОРОЕ ВЕЛОСЬ В ПРЕОБРАЖЕНСКОМ ПРИКАЗЕ В ЯНВАРЕ - МАРТЕ 1697 Г., ВЫЯВИЛО ИМЕНА НЕКОТОРЫХ УЧАСТНИКОВ ЭТОГО «ФОРУМА» (ИЛИ «КРУЖКА», КАК ЕГО ЧАЩЕ НАЗЫВАЮТ В ЛИТЕРАТУРЕ): БОЯРИН МАТВЕЙ БОГДАНОВИЧ МИЛОСЛАВСКИЙ, ПОДЬЯЧИЕ ВЛАДИМИРСКОГО СУДНОГО ПРИКАЗА ИГНАТИЙ БУБНОВ И НИКИФОР КРЕНЕВ, СТРЯПЧИЙ ТРОИЦКОГО МОНАСТЫРЯ КУЗЬМА РУДЕЕВ, КРЕСТЬЯНЕ СЕЛА ПОКРОВСКОГО ИВАН И РОМАН ПОСОШКОВЫ И ДР. ${ }^{51}$ СПУСТЯ МНОГО ЛЕТ ОДИН ИЗ УЧАСТНИКОВ ЭТОГО КРУЖКА» И.Т. ПОСОШКОВ НАПИСАЛ ДЛЯ ПЕТРА І «КНИГУ О СКУДОСТИ И БОГАТСТВЕ» С ИЗЛОЖЕНИЕМ ШИРОКОЙ ПРОГРАММЫ ВЗАИМОСВЯЗАННЫХ 
ПРЕОБРАЗОВАНИЙ, КОТОРЫЕ ПОМОГЛИ БЫ «ЦАРСКИЕ СОКРОВИЩА НАПОЛНИТИ БОГАТСТВОМ» И «НАРОД ОБОГАТИТЬ ${ }^{52}$. ПРИЧЕМ МЕЖДУ «ТЕТРАДЯМИ» СТАРЦА АВРААМИЯ И «КНИГОЙ» ПОСОШКОВА ОБНАРУЖИВАЮТСЯ НЕСОМНЕННЫЕ ОБЩИЕ ЧЕРТЫ ${ }^{53}$.

МОЖНО ЛИ ЭТОТ КЕЙС РАССМАТРИВАТЬ КАК СВИДЕТЕЛЬСТВО СУЩЕСТВОВАНИЯ В РОССИИ КОНЦА XVII В. ПУБЛИЧНОЙ СФЕРЫ? С ОДНОЙ СТОРОНЫ, МЫ, КОНЕЧНО, ЗАМЕТИМ СЕРЬЕЗНЫЕ ОТЛИЧИЯ ОТ ТЕХ ЯВЛЕНИЙ, КОТОРЫЕ ОПИСЫВАЛ Ю. ХАБЕРМАС. ЛЮДИ СОБИРАЛИСЬ ДЛЯ ОБСУЖДЕНИЯ ОБЩЕСТВЕННО ВАЖНЫХ ВОПРОСОВ НЕ В КОФЕЙНОМ ДОМЕ ИЛИ СВЕТСКОМ САЛОНЕ, А В МОНАСТЫРЕ, В КЕЛЬЕ УВАЖАЕМОГО СТАРЦА; КОНСОЛИДИРОВАННОЕ МНЕНИЕ БЫЛО ВЫРАЖЕНО НЕ В ПЕЧАТНОМ СЛОВЕ, А В УНИКАЛЬНОМ ПРОИЗВЕДЕНИИ, НАПИСАННОМ ОТ РУКИ И АДРЕСОВАННОМ ЦАРЮ; НАКОНЕЦ, ВОЗМОЖНОСТИ ТАКИХ «КРУЖКОВ» И «ТЕТРАДЕЙ» ПОВЛИЯТЬ НА БОЛЬШУЮ ПОЛИТИКУ БЫЛИ ВЕСЬМА ОГРАНИЧЕНЫ, ТАК КАК ПОПЫТКИ ДОНЕСТИ СВОИ ИДЕИ ДО ГОСУДАРЯ ОКАЗЫВАЛИСЬ НЕБЕЗОПАСНЫ ДЛЯ ЧЛЕНОВ «ФОРУМА». СТАРЕЦ АВРААМИЙ В САМИХ «ТЕТРАДЯХ» ПОВЕДАЛ О СОМНЕНИЯХ, КОТОРЫЕ ТЕРЗАЛИ ЧЛЕНОВ ЕГО «КРУЖКА», КОГДА ОН ПРЕДЛАГАЛ ОБРАТИТЬСЯ К ЦАРЮ С КОНСТРУКТИВНОЙ КРИТИКОЙ И ПРЕДЛОЖЕНИЯМИ: «СКАЖУТ ДЕ ПРО НАС, БУДТО МЫ ЗАВОДИМ БУНТ»; С ПОДОБНЫМИ ОБРАЩЕНИЯМИ К ГОСУДАРЮ ЛУЧШЕ ИДТИ «ВАШЕЙ БРАТЬЕ, МОНАХОМ», «У ВАС ДЕ... ЖЕН И ДЕТЕЙ НЕТ», А ИЗ МИРСКИХ «КОВО ПОШЛЮТ В СЫЛКУ - ЖЕНА И ДЕТИ ВОСПЛАЧУТ ${ }^{54}$.

НО, С ДРУГОЙ СТОРОНЫ, НЕЛЬЗЯ НЕ ОБРАТИТЬ ВНИМАНИЯ И НА ТО, ЧТО В ДАННОМ КЕЙСЕ ВОСПРОИЗВОДЯТСЯ НЕКОТОРЫЕ ВАЖНЫЕ ЧЕРТЫ ПУБЛИЧНОЙ СФЕРЫ:

- ЛЮДИ ДОБРОВОЛЬНО И РЕГУЛЯРНО ВСТРЕЧАЮТСЯ ДЛЯ ОБСУЖДЕНИЯ ОБЩЕСТВЕННО ВАЖНЫХ ВОПРОСОВ;

- «ФОРУМ» ОТКРЫТ ДЛЯ ПРЕДСТАВИТЕЛЕЙ САМЫХ РАЗНЫХ СОЦИАЛЬНЫХ КРУГОВ - ОТ ВЫСШЕГО ОБЩЕСТВА ДО МОСКОВСКОЙ ПРИКАЗНОЙ БЮРОКРАТИИ И ДАЖЕ КРЕСТЬЯН; СОЦИАЛЬНЫЕ РАЗЛИЧИЯ НЕ БЫЛИ ПОМЕХОЙ ДЛЯ ТОГО, ЧТОБЫ СИДЕТЬ В ОДНОЙ МОНАСТЫРСКОЙ КЕЛЬЕ И НА РАВНЫХ ОБСУЖДАТЬ ВОПРОСЫ БОЛЬШОЙ ПОЛИТИКИ;

- ДИСКУССИИ ПРИВЕЛИ УЧАСТНИКОВ К НЕКОТОРОМУ КОНСЕНСУСУ, К ВЫРАБОТКЕ ОБЩЕГО МНЕНИЯ, РЕЗУЛЬТАТОМ КОТОРОГО И СТАЛА ЧЕЛОБИТНАЯ - ПАМЯТНИК ПУБЛИЦИСТИКИ;

-УЧАСТНИКИ ОБСУЖДАЛИ ВОЗМОЖНОСТИ ПОВЛИЯТЬ НА ПРОИСХОДЯЩЕЕ В СТРАНЕ. ИНТЕРЕСНО, ЧТО ТАКАЯ ПЕРСПЕКТИВА ПРЕДСТАВЛЯЛАСЬ ИМ ВПОЛНЕ РЕАЛЬНОЙ.

НО ЕЩЕ БОЛЕЕ ИНТЕРЕСНО ТО, ЧТО ИХ УСИЛИЯ, СКОРЕЕ ВСЕГО, НЕ ОКАЗАЛИСЬ ТАКИМИ УЖ БЕСПЛОДНЫМИ. КАК ИЗВЕСТНО, В ФЕВРАЛЕ 1697 Г. БЫЛ ОБЪЯВЛЕН ЦАРСКИЙ УКАЗ О РЕФОРМИРОВАНИИ ПОРЯДКА СУДОПРОИЗВОДСТВА. В НЕМ, МЕЖДУ ПРОЧИМ, ПРИЗНАВАЛОСЬ НЕСОВЕРШЕНСТВО СУЩЕСТВУЮЩЕЙ СИСТЕМЫ ПРАВОСУДИЯ, ПРИ КОТОРОЙ «ПРАВЫМ И МАЛОМОЧНЫМ ЛЮДЕМ ВО ОПРАВДАНИЕ ЧИНИТСЯ МНОГАЯ ВОЛОКИТА И НАПРАСНЫЯ ХАРЧИ И УБЫТКИ И РАЗОРЕНЬЕ ${ }^{55}$. ИСТОРИЯ СОЗДАНИЯ ЭТОГО УКАЗА ПЛОХО ИЗУЧЕНА ${ }^{56}$, ОДНАКО МЫ ВПОЛНЕ МОЖЕМ (ПОКА НА УРОВНЕ ГИПОТЕЗЫ) СВЯЗАТЬ ВОЕДИНО ОБЩЕСТВЕННОЕ НЕДОВОЛЬСТВО «НЕПРАВЕДНЫМИ» СУДАМИ, ЯРКО ВЫРАЖЕННОЕ В «ТЕТРАДЯХ» АВРААМИЯ, И ЦАРСКИЙ УКАЗ ОБ ИЗМЕНЕНИИ ФОРМЫ ПРОВЕДЕНИЯ СУДА, ОПУБЛИКОВАННЫЙ ВСЕГО МЕСЯЦ СПУСТЯ ПОСЛЕ ЗНАКОМСТВА ПЕТРА С ЧЕЛОБИТНОЙ СТАРЦА. КАК ИНАЧЕ ОБЪЯСНИТЬ, ПОЧЕМУ ИМЕННО В ЭТОТ МОМЕНТ ЦАРЬ ТАК РЕШИТЕЛЬНО ОБРАЩАЕТСЯ К ПРОБЛЕМАМ СУДОПРОИЗВОДСТВА? НЕТ НИЧЕГО НЕВЕРОЯТНОГО В ТОМ, ЧТО ПЕТРА НЕ ОСТАВИЛИ 
РАВНОДУШНЫМИ УПРЕКИ АВРААМИЯ (КОТОРЫЙ, В ДЕЙСТВИТЕЛЬНОСТИ, ВЫРАЖАЛ ОБЩЕСТВЕННОЕ МНЕНИЕ - И

ПЕТР ЭТО ПОНИМАЛ) В ТОМ, ЧТО ЦАРЬ, «ПОКИНУВ ПРАВЛЕНИЕ ГОСУДАРСТВА СВОЕГО», «ПРИКАЗАЛ ПРАВИТИ» ВЗЯТОЧНИКАМ, КОТОРЫЕ «ГУБЯТ ГОСУДАРСТВО НАГЛО, СУДЯТ НЕПРАВЕДНО И С СУДИМЫХ ЕМЛЮТ, КТО ДАСТ ПОЧЕСТИ ПОСУЛЕННОЙ, ТОТ И ПРАВ», ТАК ЧТО «КОТОРОЕ ДЕЛО МОЧНО БЫЛО ВЕРШИТЬ В ДВА ИЛИ В ТРИ ДНИ, И ТАКИЕ ДЕЛА И В ГОД НЕ ВЕРШАТСЯ, ПРАВАГО НЕ ОПРАВЯТ ДЛЯ ТОГО, ЧТО И С ВИНОВАТАГО ВЗЯТО ${ }^{57}$.

СЛОЖНО НЕ СОГЛАСИТЬСЯ С ТЕМ, ЧТО ПОДОБНЫЕ СЛУЧАИ УКАЗЫВАЮТ НАМ НА СУЩЕСТВОВАНИЕ В ДОПЕТРОВСКОЙ РУСИ НЕКОЕГО «ПРОСТРАНСТВА ДЛЯ ДИСКУССИЙ И ОБМЕНОВ», СВОБОДНОГО ОТ ДДАВЛЕНИЯ СО СТОРОНЫ ГОСУДАРСТВА», В КОТОРОМ ПРОИСХОДИТ «КРИТИКА ДЕЙСТВИЙ ПРАВИТЕЛЬСТВА И ОСНОВ ГОСУДАРСТВЕННОЙ ВЛАСТИ ${ }^{58}$. РАЗУМЕЕТСЯ, МЫ НЕ МОЖЕМ НАЗВАТЬ ЭТУ ПУБЛИЧНУЮ СФЕРУ «БУРЖУАЗНОЙ», ОДНАКО ОНА НЕ СОВПАДАЕТ И С ВЫДЕЛЕННЫМИ ХАБЕРМАСОМ ТИПАМИ «РЕПРЕЗЕНТАТИВНОЙ» И «ПЛЕБЕЙСКОЙ» ПУБЛИЧНОСТИ. В ТАКОМ СЛУЧАЕ, ЧТО ЭТО ЗА ПУБЛИЧНАЯ СФЕРА? ДУМАЕТСЯ, ЧТО СПЕЦИАЛИСТАМ ПО ИСТОРИИ МОСКОВСКОГО И РАННЕИМПЕРСКОГО ПЕРИОДОВ СЛЕДУЕТ ПОДДЕРЖАТЬ ПРИЗЫВ СОСТАВИТЕЛЕЙ СБОРНИКА «НЕСОВЕРШЕННАЯ ПУБЛИЧНАЯ СФЕРА» И ОБРАТИТЬСЯ К «ПЕРЕОСМЫСЛЕНИЮ ПОЛИТИЧЕСКОЙ ФИЛОСОФИИ ПУБЛИЧНОСТИ НА ОСНОВЕ И ПОСЛЕ АНАЛИЗА ОТЕЧЕСТВЕННОГО ИСТОРИЧЕСКОГО МАТЕРИАЛА» ${ }^{59}$. НО КАКОГО МАТЕРИАЛА?

ПО ВСЕЙ ВИДИМОСТИ, НЕ СЛУЧАЙНЫМ ОКАЗЫВАЕТСЯ И ТОТ КРУГ ИСТОЧНИКОВ, КОТОРЫЙ СЛОЖИЛСЯ ВОКРУГ КЕЙСА «КРУЖКА» СТАРЦА АВРААМИЯ: ПУБЛИЦИСТИКА, Т.Е. ЕГО «ТЕТРАДИ», И ПОЛИТИЧЕСКИЙ СУДЕБНО-СЛЕДСТВЕННЫЙ ПРОЦЕСС, ВОЗНИКШИЙ ПОСЛЕ ПОДАЧИ ЭТИХ «ТЕТРАДЕЙ» МОНАРХУ. КАК МНЕ ПРЕДСТАВЛЯЕТСЯ (И Я ПОСТАРАЛСЯ ЭТО ОБОСНОВАТЬ В ДАННОМ ОЧЕРКЕ), ИМЕННО КОМБИНИРОВАННОЕ ИЗУЧЕНИЕ ЭТИХ ДВУХ ВИДОВ ИСТОЧНИКОВ С ПРИМЕНЕНИЕМ КОНЦЕПТУАЛЬНОГО АППАРАТА Ю. ХАБЕРМАСА, ЕГО КРИТИКОВ И ПОСЛЕДОВАТЕЛЕЙ ОТКРЫВАЕТ ПЕРЕД НАМИ ИНТЕРЕСНЫЕ ПЕРСПЕКТИВЫ ДЛЯ ВЫЯВЛЕНИЯ ИНФОРМАЦИИ О РАЗЛИЧНЫХ ПУБЛИЧНЫХ СФЕРАХ И РЕЖИМАХ ПУБЛИЧНОСТИ В РОССИИ XVII-XVIII ВВ.

\section{NOTES}

1. Jürgen Habermas, The Structural Transformation of the Public Sphere: An Inquiry into a Category of Bourgeois Society (Cambridge, МА: МІТ Press, 1989). В 2016 Г. ИЗДАТЕЛЬСТВО «ВЕСЬ МИР» ВЫПУСТИЛО РУССКИЙ ПЕРЕВОД ГЛАВНОЙ КНИГИ ЮРГЕНА ХАБЕРМАСА: Ю. ХАБЕРМАС, СТРУКТУРНОЕ ИЗМЕНЕНИЕ ПУБЛИЧНОЙ СФЕРЫ: ИССЛЕДОВАНИЯ ОТНОСИТЕЛЬНО КАТЕГОРИИ БУРЖУАЗНОГО ОБЩЕСТВА (М.: ВЕСЬ МИР, 2016). ОДНАКО КАЧЕСТВО ПЕРЕВОДА БЫЛО ПОСТАВЛЕНО ПОД СОМНЕНИЕ СПЕЦИАЛИСТАМИ: Г. ЮДИН, “РЕЦЕНЗИЯ НА КНИГУ: ХАБЕРМАС Ю. СТРУКТУРНАЯ ТРАНСФОРМАЦИЯ ПУБЛИЧНОЙ СФЕРЫ: ИССЛЕДОВАНИЯ ОТНОСИТЕЛЬНО КАТЕГОРИИ БУРЖУАЗНОГО ОБЩЕСТВА (2016)," ФИЛОСОФИЯ. ЖУРНАЛ ВЫСШЕЙ ШКОЛЫ ЭКОНОМИКИ 1 (2017): 128-130. ПО ЭТОЙ ПРИЧИНЕ Я ПОЛЬЗУЮСЬ АВТОРИЗОВАННЫМ АНГЛИЙСКИМ ПЕРЕВОДОМ. 
2. УКАЖУ ЛИШЬ НЕКОТОРЫЕ ОБЗОРЫ: Lloyd Kramer, "Habermas, History, and Critical Theory," in Habermas and the Public Sphere (Cambridge, MA: MIT Press, 1992), 236-258; James Van Horn Melton, The Rise of the Public in Enlightenment Europe (Cambridge: Cambridge University Press, 2001), 1-15; Massimo Rospocher, "Beyond the Public Sphere: A Historiographical Transition," in Beyond the Public Sphere: Opinions, Publics, Spaces in Early Modern Europe (Bologna; Berlin: Duncker \& Humblot, 2012), 9-28.

3. СМ., НАПР.: Sphären von Öffentlichkeit in Gesellschaften sowjetischen Typs: Zwischen parteistaatlicher Selbstinszenierung und kirchlichen Gegenwelten (Frankfurt am Main: Peter Lang, 2003); А.С. ТУМАНОВА, ОБЩЕСТВЕННЫЕ ОРГАНИЗАЦИИ РОССИИ В ГОДЫ ПЕРВОЙ МИРОВОЙ ВОЙНЫ (1914ФЕВРАЛЬ 1917 г.) (М.: РОсСПЭН, 2014); Mikhail Velizhev, "The Moscow English Club and the Public Sphere in Early Nineteenth Century Russia," in The Europeanized Elite in Russia, 1762-1825. Public Role and Subjective Self (DeKalb: Northern Illinois University Press, 2016), 220-237.

4. СМ., НАПР.: Leidulf Melve, Inventing the Public Sphere: The Public Debate during the Investiture Contest (c. 1030-1122) (Leiden - Boston: Brill, 2007); L'espace public au Moyen Âge: débats autour de Jürgen Habermas (P.: Presses univ. de France, 2011).

5. См., НАПР.: Victor M. Uribe-Uran, "The Birth of a Public Sphere in Latin America during the Age of Revolution," Comparative Studies in Society and History, 42, 2 (2000): 425-457; Rudolf G. Wagner, "The Early Chinese Newspapers and the Chinese Public Sphere," European Journal of East Asian Studies, 1, 1 (2001): 1-33; Public sphere in Muslim societies (Albany: State University of New York Press, 2002); Babak Rahimi, Theater State and the Formation of Early Modern Public Sphere in Iran: Studies on Safavid Muharram Rituals, 1590-1641 CE (Leiden: Brill, 2011); Farshid Emami, "Coffeehouses, Urban Spaces, and the Formation of a Public Sphere in Safavid Isfahan," Muqarnas: An Annual On The Visual Cultures of The Islamic World, 33 (2016): 177-220.

6. Habermas, The Structural Transformation of the Public Sphere, XVII-XIX, 1-140. ОБСТОЯТЕЛЬНЫЙ СОЦИОЛОГИЧЕСКИЙ АНАЛИЗ ТЕОРИИ ПУБЛИЧНОЙ СФЕРЫ Ю. ХАБЕРМАСА СМ.: ПУБЛИЧНАЯ СФЕРА: ТЕОРИЯ, МЕТОДОЛОГИЯ, КЕЙССТАДИ (М.: ООО «ВАРИАНТ», ЦСПГИ, 2013).

7. СМ.: НЕСОВЕРШЕННАЯ ПУБЛИЧНАЯ СФЕРА. ИСТОРИЯ РЕЖИМОВ ПУБЛИЧНОСТИ В РОССИИ. СБОРНИК СТАТЕЙ (М.: НОВОЕ ЛИТЕРАТУРНОЕ ОБОЗРЕНИЕ, 2021), 29. ДАЛЕЕ ССЫЛКИ НА ЭТО ИЗДАНИЕ ПРИВОДЯТСЯ В САМОМ ТЕКСТЕ В СКОБКАХ. ОТМЕТИМ, ЧТО САМ ХАБЕРМАС НЕ УТВЕРЖДАЛ, ЧТО «БУРЖУАЗНАЯ ПУБЛИЧНАЯ СФЕРА» - ЭТО ЕДИНСТВЕННЫЙ ТИП ПУБЛИЧНОСТИ. БОЛЕЕ ТОГО, В ПРЕДИСЛОВИИ К ПЕРВОМУ ИЗДАНИЮ УЧЕНЫЙ ОГОВОРИЛСЯ, ЧТО ОСТАВЛЯЕТ ЗА РАМКАМИ СВОЕГО РАССМОТРЕНИЯ ИНЫЕ ТИПЫ ПУБЛИЧНОСТИ, В ТОМ ЧИСЛЕ ТАК НАЗЫВАЕМУЮ «ПЛЕБЕЙСКУЮ ПУБЛИЧНУЮ СФЕРУ» («plebeian public sphere»), ХАРАКТЕРИЗУЮЩЕЮСЯ, ПРЕЖДЕ ВСЕГО, НЕГРАМОТНОСТЬЮ ЛЮДЕЙ, КОТОРЫХ ОНА ОБЪЕДИНЯЕТ (Habermas, The Structural Transformation of the Public Sphere, XVIII).

8. ПУБЛИЧНАЯ СФЕРА (Public Sphere)," in Э. ГИДДЕНС, Ф. САТТОН, ОСНОВНЫЕ ПОНЯТИЯ В социолоГИИ (М.: ВЫСШАЯ ШКОЛА ЭКОНОМИКИ, 2018), 237-238.

9. КЕМБРИДЖСКАЯ ШКОЛА: ТЕОРИЯ И ПРАКТИКА ИНТЕЛЛЕКТУАЛЬНОЙ ИСТОРИИ (М.: НОВОЕ ЛИТЕРАТУРНОЕ ОБОЗРЕНИЕ, 2018).

10. ПРОБЛЕМА «НЕСОВЕРШЕНСТВА» РОССИЙСКОГО ПУБЛИЧНОГО ОБЩЕНИЯ ОКАЗАЛАСЬ В ЦЕНТРЕ ВНИМАНИЯ И АВТОРОВ КОЛЛЕКТИВНОЙ МОНОГРАФИИ СО ЗВУЧНЫМ НАЗВАНИЕМ ““СИНДРОМ ПУБЛИЧНОЙ НЕМОТЫ". ИСТОРИЯ И СОВРЕМЕННЫЕ ПРАКТИКИ ПУБЛИЧНЫХ ДЕБАТОВ В РОССИИ» ПОД РЕДАКЦИЕЙ Н.Б. ВАХТИНА И Б.М. ФИРСОВА (М.: НОВОЕ ЛИТЕРАТУРНОЕ ОБОЗРЕНИЕ, 2017).

11. Nancy Fraser, "Rethinking the Public Sphere: A Contribution to the Critique of Actually Existing Democracy," in Habermas and the Public Sphere, 109-143.

12. МНЕНИЕ О ЗАРОЖДЕНИИ «ПУБЛИЧНОЙ СФЕРЫ» В РОССИИ В КОНЦЕ XVIII В. - НАЧАЛЕ XIX В. ПРОСЛЕЖИВАЕТСЯ И В ДРУГИХ РАБОТАХ. СМ., НАПР.: В. КАПЛУН, «ЧТО ТАКОЕ ПРОСВЕЩЕНИЕ? РОЖДЕНИЕ ПУБЛИЧНОЙ СФЕРЫ И ПУБЛИЧНОЙ ПОЛИТИКИ В РОССИИ», in ПУБЛИЧНОЕ 
ПРОСТРАНСТВО, ГРАЖДАНСКОЕ ОБЩЕСТВО И ВЛАСТЬ: ОПЫТ РАЗВИТИЯ И ВЗАИМОДЕЙСТВИЯМ.: РОССПЭН, 2008), 333-345.

13. Д.И. АНТОНОВ, СМУТА В КУЛЬТУРЕ СРЕДНЕВЕКОВОЙ РУСИ: ЭВОЛЮЦИЯ ДРЕВНЕРУССКИХ МИФОЛОГЕМ В КНИЖНОСТИ НАЧАЛА ХVII ВЕКА (М: РГГУ, 2009).

14. АНТОНОВ, ЦАРИ И САМОЗВАНЦЫ: БОРЬБА ИДЕЙ В РОССИИ СМУТНОГО ВРЕМЕНЦ(М.: РГГУ, 2019), 9. ДАЛЕЕ ССЫЛКИ НА ЭТО ИЗДАНИЕ ПРИВОДЯТСЯ В ТЕКСТЕ В КРУГЛЫХ СКОБКАХ.

15. Б.А. УСПЕНСКИЙ, «ИСТОРИЯ И СЕМИОТИКА: ВОСПРИЯТИЕ ВРЕМЕНИ КАК СЕМИОТИЧЕСКАЯ ПРОБЛЕМА», in Б.А. УСПЕНСКИЙ, ЭТЮДЫ О РУССКОЙ ИСТОРИИ (СПБ.: АЗБУКА, 2002), 11.

16. ИСТОЧНИКОВЕДЕНИЕ: УЧЕБ. ПОСОБИЕ (М.: ВЫСШАЯ ШКОЛА ЭКОНОМИКИ, 2015), 99.

17. «ПУБЛИЦИСТИКА - ВИД ИСТОРИЧЕСКИХ ИСТОЧНИКОВ, ВОЗНИКАЮЩИЙ В ОБЩЕСТВЕННОЙ СФЕРЕ. ПУБЛИЦИСТИКА ПРИЗВАНА ВЫРАЖАТЬ МНЕНИЕ КАКОЙ-ЛИБО СОЦИАЛЬНОЙ ГРУППЫ ОБ ОБЩЕСТВЕННО ЗНАЧИМОЙ ПРОБЛЕМЕ» (ИСТОЧНИКОВЕДЕНИЕ, 331).

18. «ОТВЕТ КИРИЛЛОВСКИХ СТАРЦЕВ НА ПОСЛАНИЕ ИОСИФА ВОЛОЦКОГО», in БИБЛИОТЕКА ЛИТЕРАТУРЫ ДРЕВНЕЙ РУСИ (СПБ.: НАУКА, 2000), Т. 9, 216-221.

19. К.Ю. ЕРУСАЛИМСКИЙ, «ПУБЛИЦИСТ И ЦЕНТРАЛИЗОВАННОЕ ГОСУДАРСТВО: И.С. ПЕРЕСВЕТОВ В ТВОРЧЕСТВЕ А.А. ЗИМИНА», ДИАЛОГ СО ВРЕМЕНЕМ, 38 (2012): 101.

20. ТАМ ЖЕ.

21. РАЗУМЕЕТСЯ, Д.И. АНТОНОВ ОСОЗНАЕТ, ЧТО ЕГО ИССЛЕДОВАНИЕ ПЕРЕСЕКАЕТСЯ С РАБОТАМИ РЯДА ПРЕДШЕСТВЕННИКОВ, В ЧАСТНОСТИ ИЗВЕСТНОЙ СТАТЬЕЙ А.И. ЯКОВЛЕВА: «“БЕЗУМНОЕ МОЛЧАНИЕ" (ПРИЧИНЫ СМУТЫ ПО ВЗГЛЯДАМ РУССКИХ СОВРЕМЕННИКОВ ЕЯ)», in СБОРНИК СТАТЕЙ, ПОСВЯЩЕННЫХ ВАСИЛИЮ ОСИПОВИЧУ КЛЮЧЕВСКОМУ(М.: ПЕЧАТНЯ С.П. ЯКОВЛЕВА, 1909), 651-678. Д.И. АНТОНОВ ОБСТОЯТЕЛЬНО РАЗБИРАЕТ ЭТИ ИССЛЕДОВАНИЯ В ИСТОРИОГРАФИЧЕСКОМ ОБЗОРЕ (С. 16-21). В ЧАСТНОСТИ, В ОТНОШЕНИИ УПОМЯНУТОЙ СТАТЬИ А.И. ЯКОВЛЕВА ПОКАЗАНО, ЧТО ЭТА РАБОТА В НЕКОТОРЫХ МЕСТАХ МОДЕРНИЗИРОВАЛА СМЫСЛЫ», ТАК КАК АНАЛИЗ В ЦЕЛОМ ОСУЩЕСТВЛЯЛСЯ «СКВОЗЬ ПРИЗМУ СОЦИАЛЬНЫХ ПРЕДСТАВЛЕНИЙ НАЧАЛА ХХ В.» (С. 16-17).

22. О.А. ДЕРЖАВИНА, «ДЬЯК ИВАН ТИМОФЕЕВ И ЕГО “ВРЕМЕННИК”», in ВРЕМЕННИК ИВАНА ТИМОФЕЕВА (М. - Л.: АКАД. НАУК СССР, 1951), 351.

23. ДЕРЖАВИНА, «АРХЕОГРАФИЧЕСКИЙ КОММЕНТАРИЙ», in ВРЕМЕННИК ИВАНА ТИМОФЕЕВА, 415, 426.

24. ДЕРЖАВИНА, «ДЬЯК ИВАН ТИМОФЕЕВ И ЕГО “ВРЕМЕННИК”», 353.

25. ЗДЕСЬ СЛЕДУЕТ ПОСТАВИТЬ ВОПРОС О СООТНОШЕНИИ СРЕДНЕВЕКОВЫХ «ПУБЛИЧНЫХ СФЕР» И ТЕХ «textual communities», КОТОРЫЕ БЫЛИ ВЫДЕЛЕНЫ САЙМОНОМ ФРАНКЛИНОМ: Simon Franklin, Writing, Society and Culture in Early Rus, c. 950-1300 (Cambridge: Cambridge University Press, 2002).

26. Е.В. АНИСИМОВ, ДЕРЖАВА И ТОПОР: ЦАРСКАЯ ВЛАСТЬ, ПОЛИТИЧЕСКИЙ СЫСК И РУССКОЕ ОБЩЕСТВО В XVIII ВЕКЕ (М.: НОВОЕ ЛИТЕРАТУРНОЕ ОБОЗРЕНИЕ, 2019), 10. ДАЛЕЕ ССЫЛКИ НА ЭТО ИЗДАНИЕ ПРИВОДЯТСЯ В ТЕКСТЕ В КРУГЛЫХ СКОБКАХ.

27. Е.В. АНИСИМОВ, ДЫБА И КНУТ. ПОЛИТИЧЕСКИЙ СЫСК И РУССКОЕ ОБЩЕСТВО ХVIII ВЕКЕ. (М.: НОВОЕ ЛИТЕРАТУРНОЕ ОБОЗРЕНИЕ, 1999), 53.

28. «ДА БУДЕТ СЫЩЕТСЯ ПРО НИХ ДОПРЯМА, ЧТО ОНИ В ГОРОДЕХ И В ПОЛКАХ К ВОЕВОДАМ ПРИХОДИЛИ ДЛЯ ЧЕЛОБИТЬЯ, А НЕ ДЛЯ ВОРОВСТВА, И ИХ ПО СЫСКУ СМЕРТЬЮ НЕ КАЗНИТИ. А ВОЕВОДАМ И ПРИКАЗНЫМ ЛЮДЕМ, КОТОРЫЕ НА НИХ ОТПИШУТ К ГОСУДАРЮ ЛОЖНО, ЗА ТО ЧИНИТИ ЖЕСТОКОЕ НАКАЗАНИЕ, ЧТО ГОСУДАРЬ УКАЖЕТ»: «СОБОРНОЕ УЛОЖЕНИЕ 1649 ГОДА», in РОССИЙСКОЕ ЗАКОНОДАТЕЛЬСТВО Х-ХХ ВЕКОВ (М.: ЮРИДИЧЕСКАЯ ЛИТЕРАТУРА, 1985), Т. 3, 89.

29. СМ., НАПР.: П.П. СМИРНОВ, ЧЕЛОБИТНЫЕ ДВОРЯН И ДЕТЕЙ БОЯРСКИХ ВСЕХ ГОРОДОВ В ПЕРВОЙ ПОЛОВИНЕ ХVII ВЕКА (М.: СИНОДАЛЬНАЯ ТИПОГРАФИЯ, 1915); К.В. БАЗИЛЕВИЧ, “КОЛЛЕКТИВНЫЕ ЧЕЛОБИТЬЯ ТОРГОВЫХ ЛЮДЕЙ И БОРЬБА ЗА РУССКИЙ РЫНОК В ПЕРВОЙ ПОЛОВИНЕ XVII В.," in 
ИЗВЕСТИЯ АН СССР. СЕРИЯ 7: ОТДЕЛЕНИЕ ОБЩЕСТВЕННЫХ НАУқ 2 (1932): 91-123; Д.А. ВЫСОЦКИЙ, «КОЛЛЕКТИВНЫЕ ДВОРЯНСКИЕ ЧЕЛОБИТНЫЕ XVII В. КАК ИСТОРИЧЕСКИЙ ИСТОЧНИК», in ВСПОМОГАТЕЛЬНЫЕ ИСТОРИЧЕСКИЕ ДИСЦИПЛИНЫ (Л.: НАУКА, 1987), Т. 19, 125-138; П.В. СЕДОВ, ЗАКАТ МОСКОВСКОГО ЦАРСТВА: ЦАРСКИЙ ДВОР КОНЦАХVІІ ВЕКА (СПБ.: ДМИТРИЙ БУЛАНИН, 2008), 21-30; В.Н. ГЛАЗЬЕВ, «КОЛЛЕКТИВНЫЕ ЧЕЛОБИТНЫЕ КАК СРЕДСТВО ВЗАИМОДЕЙСТВИЯ ОБЩЕСТВА И ВЛАСТИ ВО ВТОРОЙ ПОЛОВИНЕ XVII В. (ПО МАТЕРИАЛАМ ЮЖНЫХ УЕЗДОВ РОССИИ)», in РУСЬ, РОССИЯ: СРЕДНЕВЕКОВЬЕ И НОВОЕ ВРЕМЯ 4 (2015): 316-321; А.В. ТОПЫЧКАНОВ, ПОЛИТИЧЕСКОЕ ПРОСТРАНСТВО ЦАРСКИХ ЗАГОРОДНЫХ РЕЗИДЕНЦИЙ ВТОРОЙ ПОЛОВИНЫХVII ВЕКА (М.: ИНДРИК, 2019), 196-204.

30. Evgenii Akelev, "The Barber of All Russia. Lawmaking, Resistance, and Mutual Adaptation during Peter the Great's Cultural Reforms," Kritika: Explorations in Russian and Eurasian History, 17, 2 (2016): 267-268.

31. ВОССТАНИЕ МОСКОВСКИХ СТРЕЛЬЦОВ. 1698 ГОД (МАТЕРИАЛЫ СЛЕДСТВЕННОГО ДЕЛА)(М.: НАУКА, 1980), 41-42; М.М. БОГОСЛОВСКИЙ, ПЕТР І. МАТЕРИАЛЫ ДЛЯ БИОГРАФИИ(М.: ОГИЗ ГОСПОЛИТИЗДАТ, 1946), Т. 3, 30-36; А.Н. КАЗАКЕВИЧ, «СЛЕДСТВЕННОЕ ДЕЛО А.С. ШЕИНА ПОД ВОСКРЕСЕНСКИМ МОНАСТЫРЕМ О ВОССТАНИИ МОСКОВСКИХ СТРЕЛЬЦОВ 1698 Г.», in ИССЛЕДОВАНИЯ ПО ИСТОЧНИКОВЕДЕНИЮ ИСТОРИИ СССР ДООКТЯБРЬСКОГО ПЕРИОДА(М.: АН СССР, ИНСТИТУТ ИСТОРИИ СССР, 1982), 167.

32. НАПРИМЕР, В.В. ВОЛКОВ ВЫСКАЗАЛ ПРЕДПОЛОЖЕНИЕ, ЧТО «В ДОПЕТРОВСКОЙ РОССИИ ЖИЗНЬ ДВОРЯН, СОСТОЯВШИХ НА СЛУЖБЕ У ЦАРЯ, РАЗДЕЛЯЛАСЬ НА ДВЕ ГЛАВНЫЕ ЧАСТИ: ВРЕМЯ, КОТОРОЕ ПРОВОДИЛОСЬ НА СЛУЖБЕ, И ВРЕМЯ, КОТОРОЕ ПРОВОДИЛОСЬ В ПРИВАТНОЙ СФЕРЕ ДОМАШНЕГО ХОЗЯЙСТВА. ВОСЕМНАДЦАТОЕ СТОЛЕТИЕ СТАЛО СВИДЕТЕЛЕМ ВОЗНИКНОВЕНИЯ И РОСТА ТРЕТЬЕЙ СФЕРЫ, ПЕРВОНАЧАЛЬНО ХАРАКТЕРИЗОВАВШЕЙСЯ ОСОБЫМ ПОВЕДЕНИЕМ ЧЕЛОВЕКА ПО ОТНОШЕНИЮ К ДРУГИМ ЛЮДЯМ: ПУБЛИЧНОЙ СФЕРЫ»: В.В. ВОЛКОВ, ФОРМЫ ОБЩЕСТВЕННОЙ ЖИЗНИ: ПУБЛИЧНАЯ СФЕРА И ПОНЯТИЕ ОБЩЕСТВА В РОССИЙСКОЙ ИМПЕРИИ: ДИССЕРТАЦИЯ ... КАНДИДАТА СОЦИОЛОГИЧЕСКИХ НАУК (КЕМБРИДЖ, 1995), 53. ДУГЛАС СМИТ ПОЛАГАЕТ, ЧТО «ВЛАСТИ МОСКОВСКОГО ЦАРСТВА ПОДАВЛЯЛИ И ОГРАНИЧИВАЛИ ДЕЙСТВИЯ СВОИХ ПОДДАННЫХ», В ТО ВРЕМЯ КАК ПЕТРОВСКИЕ РЕФОРМЫ ВЫСВОБОЖДАЛИ «СКРЫТУЮ ДО ПОРЫ СОЗИДАТЕЛЬНУЮ ЭНЕРГИЮ ОБЩЕСТВА»: Д. СМИТ, РАБОТА НАД ДИКИМ КАМНЕМ: МАСОНСКИЙ ОРДЕН И РУССКОЕ ОБЩЕСТВО ВХVІІІ ВЕКЕ (М.: НОВОЕ ЛИТЕРАТУРНОЕ ОБОЗРЕНИЕ, 2006), 57. О ПОЯВЛЕНИИ «ПУБЛИЧНОСТИ» ИМЕННО В ПЕТРОВСКУЮ ЭПОХУ (ВМЕСТЕ С «ВНЕДРЕНИЕМ “ЕВРОПЕИЗИРОВАННЫХ" ФОРМ ВЗАИМОДЕЙСТВИЯ И НОВОГО ТИПА ПОЛИТИЧЕСКОГО ОБЩЕНИЯ») ПИШЕТ ДМИТРИЙ КАЛУГИН КАК О НЕСОМНЕННОМ ФАКТЕ: Д. КАЛУГИН, «"МНОГО СПИРАШАСЯ, НЕ ОБРЕТОША ИСТИННЫ", ИЛИ ПОЭТИКА КОММУНИКАЦИИ ВЛАСТИ И ОБЩЕСТВА В РОССИИ ДРЕВНЕЙ И НОВОЙ», in «СИНДРОМ ПУБЛИЧНОЙ НЕМОТЫ». ИСТОРИЯ И СОВРЕМЕННЫЕ ПРАКТИКИ ПУБЛИЧНЫХ ДЕБАТОВ В РОССИИ (М.: НОВОЕ ЛИТЕРАТУРНОЕ ОБОЗРЕНИЕ, 2017), 29.

33. АНИСИМОВ, ДЫБА И КНУТ, 56; РГАДА, Ф. 371, ОП. 1, Д. 1857, 25-27.

34. КАК В 1703 Г. ВЫСКАЗАЛСЯ ОДИН «ЗАХРЕБЕТНИК» О ПРОИЗВЕДЕНИИ ОРУЖЕЙНЫХ ЗАЛПОВ В ЧЕСТЬ ГОСУДАРЯ, «ДИКОВИНА ДЕ, ЦАРСКИЕ ИМЯНИНЫ, ДАРОМ ДЕ ПОРОХ ТЕРЯТЬ, ПЛЕВАТЬ ДЕ НА ТО ДЕЛО»: Evgenii Trefilov, "Proof of Sincere Love for the Tsar: Popular Monarchism in the Age of Peter the Great," Kritika: Explorations in Russian and Eurasian History, 18, 3 (2017): 486.

35. ИЗУЧЕНИЕ ПОЛИТИЧЕСКИХ ПРОЦЕССОВ XVII-XVIII В. С ТОЧКИ ЗРЕНИЯ ОБЩЕСТВЕННОПОЛИТИЧЕСКОГО СОЗНАНИЯ ПРЕИМУЩЕСТВЕННО НЕОБРАЗОВАННЫХ СЛОЕВ РОССИЙСКОГО ОБЩЕСТВА XVII-XVIII ВВ. НАЧАТО УЖЕ ДАВНО И СТАЛО ВАЖНЫМ НАПРАВЛЕНИЕМ ОТЕЧЕСТВЕННОЙ ИСТОРИОГРАФИИ. НО ЗАМЕТИМ, ЧТО ИССЛЕДОВАТЕЛИ, КАК ПРАВИЛО, ФОКУСИРОВАЛИСЬ НА САМИХ ПУБЛИЧНЫХ ВЫСКАЗЫВАНИЯХ, А НЕ НА РАЗЛИЧНЫХ СОЦИАЛЬНЫХ КОНТЕКСТАХ ИХ ПОЯВЛЕНИЯ. СМ, НАПР.: С.В. БАХРУШИН, “ПОЛИТИЧЕСКИЕ ТОЛКИ В ЦАРСТВОВАНИЕ МИХАИЛА ФЕДОРОВИЧА," in С.В. БАХРУШИН, ТРУДЫ ПО ИСТОЧНИКОВЕДЕНИЮ, 
ИСТОРИОГРАФИИ И ИСТОРИИ РОССИИ ПЕРИОДА ФЕОДАЛИЗМА (М.: НАУКА, 1987), 87-117; Н.Б. ГОЛИКОВА, ПОЛИТИЧЕСКИЕ ПРОЦЕССЫ ПРИ ПЕТРЕІ: ПО МАТЕРИАЛАМ ПРЕОБРАЖЕНСКОГО ПРИКАЗА (М.: ИЗДАТЕЛЬСТВО МОСКОВСКОГО УНИВЕРСИТЕТА), 1957; П.В. ЛУКИН, НАРОДНЫЕ ПРЕДСТАВЛЕНИЯ О ГОСУДАРСТВЕННОЙ ВЛАСТИ В РОССИИ ХVII ВЕКА (М.: НАУКА, 2000).

36. РГАДА, Ф. 371 , ОП. 1 , Д. 245.

37. О ПОДГОТОВКЕ УКАЗА О БРАДОБРИТИИ 1705 Г. И ЕГО РЕАЛИЗАЦИИ СМ.: Akelev, “Is It Possible to Make Money from Beards? The Beard Tax and Russian State Economics at the Beginning of the Eighteenth-Century," Cahiers du Monde Russe, 61, 1-2 (2020): 81-104.

38. Akelev, "The Barber of All Russia," 253-255.

39. Ibid., 256.

40. ДИМИТРИЙ (ТУПТАЛО), МИТРОПОЛИТ РОСТОВСКИЙ И ЯРОСЛАВСКИЙ, РАЗСУЖДЕНИЕ О ОБРАЗЕ БОЖИИ И ПОДОБИИ В ЧЕЛОВЕЦЕ (М.: МОСКОВСКИЙ ПЕЧАТНЫЙ ДВОР, 1714), 7-9.

41. СМ.: РГАДА, Ф. 9, ОП. 6, Д. 47, 167-167 ОБ. (БЛАГОДАРЮ А.В. ТОПЫЧКАНОВА, ОБРАТИВШЕГО МОЕ ВНИМАНИЕ НА ЭТОТ ДОКУМЕНТ); РГАДА, Ф. 248, ОП. 2, КН. 19, 238-242.

42. О «ПЕРЕКЛЮЧЕНИИ РЕЖИМОВ ПУБЛИЧНОСТИ» СМ. ЗАМЕЧАТЕЛЬНУЮ СТАТЬЮ ТИМУРА АТНАШЕВА «ПЕРЕКЛЮЧАЯ РЕЖИМЫ ПУБЛИЧНОСТИ: КАК НИНА АНДРЕЕВА СОДЕЙСТВОВАЛА ПРЕВРАЩЕНИЮ ГЛАСНОСТИ В СВОБОДУ СЛОВА» В СБОРНИКЕ «НЕСОВЕРШЕННАЯ ПУБЛИЧНАЯ СФЕРА» (С. 447-478).

43. ГОЛИКОВА, ПОЛИТИЧЕСКИЕ ПРОЦЕССЫ ПРИ ПЕТРЕ, 39.

44. Akelev, “The Barber of All Russia," 241-275.

45. АНИСиМОВ, ДЫБА И КнУТ, 88.

46. ПОЛНОЕ СОБРАНИЕ ЗАКОНОВ РОССИЙСКОЙ ИМПЕРИИ С 1649 ГОДА: СОБРАНИЕ ПЕРВОЕ С 1649 ПО 12 ДЕКАБРЯ 1825 ГОДУ (ДАЛЕЕ - ПСЗ) (СПБ.: ТИПОГРАФИЯ II-ГО ОТДЕЛЕНИЯ СОБСТВЕННОЙ ЕГО ИМПЕРАТОРСКОГО ВЕЛИЧЕСТВА КАНЦЕЛЯРИИ, 1830), Т. 16, по. 11843.

47. Habermas, The Structural Transformation of the Public Sphere, 25-26.

48. АНИСИМОВ, ДЫБА И КНУТ, 89. ВЫДЕЛЕНО МНОЙ. - Е.А.

49. СМИТ, РАБОТА НАД ДИКИМ КАМНЕМ, 56.

50. ЭТО ПОКАЗАЛА АРЛЕТТ ФАРЖ, КОТОРАЯ, ОТТОЛКНУВШИСЬ ОТ КОНЦЕПЦИИ Ю. ХАБЕРМАСА, ОБРАТИЛАСЬ К ИЗУЧЕНИЮ «ПЛЕБЕЙСКОЙ ПУБЛИЧНОЙ СФЕРЫ» ПАРИЖА ХVIII В. НА ОСНОВЕ, МЕЖДУ ПРОЧИМ, ДОКУМЕНТОВ АРХИВА БАСТИЛИИ: Arlette Farge, Dire et mal dire. L'opinion publique au XVIII siècle (P.: Le Seuil, 1992).

51. Н.А. БАКЛАНОВА, “ТЕТРАДИ СТАРЦА АВРААМИЯ,” ИСТОРИЧЕСКИЙ АРХИВ (М. - Л., 1954), Т. VI, 131-155; РГАДА, Ф. 371, ОП. 2, СТБ. 484; Б.Б. КАФЕНГАУЗ, И.Т. ПОСОШКОВ. ЖИЗНЬ И ДЕЯТЕЛЬНОСТЬ (М. - Л.: ИЗДАТЕЛЬСТВО АКАД. НАУК СССР, 1950), 173-181.

52. И.Т. ПОСОШКОВ, КНИГА О СКУДОСТИ И БОГАТСТВЕ. ЗАВЕЩАНИЕ ОТЕЧЕСКОЕ (М.: РОССПЭН, 2010).

53. ЕЩЕ ДО ОБНАРУЖЕНИЯ «ТЕТРАДЕЙ» СТАРЦА АВРААМИЯ (КОГДА БЫЛО ИЗВЕСТНО ТОЛЬКО СЛЕДСТВЕННОЕ ДЕЛО) М.М. БОГОСЛОВСКИЙ ПРЕДПОЛОЖИЛ, ЧТО «В КЕЛЬЕ АВРААМИЯ НАЧИНАЛА... РАБОТАТЬ РЕФОРМАТОРСКАЯ МЫСЛЬ БУДУЩЕГО ПИСАТЕЛЯ-ПУБЛИЦИСТА ИВАНА ПОСОШКОВА» (БОГОСЛОВСКИЙ, ПЕТР І. МАТЕРИАЛЫ ДЛЯ БИОГРАФИИ (М.: ОГИЗ ГОСПОЛИТИЗДАТ, 1940), Т. 1, 386). Н.А. БАКЛАНОВА, КОТОРОЙ УДАЛОСЬ ОБНАРУЖИТЬ И ОПУБЛИКОВАТЬ «ТЕТРАДИ» СТАРЦА АВРААМИЯ, ВЫСКАЗАЛАСЬ НА ЭТОТ СЧЕТ БОЛЕЕ ОПРЕДЕЛЕННО: «ТРУДНО СРАВНИВАТЬ НЕОФОРМЛЕННЫЕ ОТРЫВОЧНЫЕ НАБРОСКИ, СДЕЛАННЫЕ НА ЗАРЕ ПЕТРОВСКИХ РЕФОРМ, С РАЗНОСТОРОННИМ ПЛАНОМ ПРЕОБРАЗОВАНИЙ, СОЗДАННЫМ В КОНЦЕ ЦАРСТВОВАНИЯ ПЕТРА, ПОЧТИ ЧЕРЕЗ 30 ЛЕТ (И КАКИХ 30 ЛЕТ!) ПОСЛЕ ПОДАЧИ “ТЕТРАДЕЙ” АВРААМИЯ. ОДНАКО ВСЕ ЖЕ МОЖНО НАЙТИ ОБЩИЕ ЧЕРТЫ В ЗАПИСКЕ АВРААМИЯ И КНИГЕ ПОСОШКОВА» (БАКЛАНОВА, «ТЕТРАДИ СТАРЦА АВРААМИЯ», 142).

54. БАКЛАНОВА, «ТЕТРАДИ СТАРЦА АВРААМИЯ», 147.

55. пСЗ, Т. 3, no. 1572 . 
56. В ЛИТЕРАТУРЕ ПОЯВЛЕНИЕ УКАЗА О ЗАМЕНЕ СУДА РОЗЫСКОМ 1697 Г. СВЯЗЫВАЕТСЯ С ОПИСАННЫМ В «ДНЕВНЫХ ЗАПИСКАХ ЖЕЛЯБУЖСКОГО» ДЕЛОМ В.Т. И С.В. ЖЕЛЯБУЖСКИХ И А.М. АПРАКСИНА (СМ., НАПР.: БОГОСЛОВСКИЙ, ПЕТР І. МАТЕРИАЛЫ ДЛЯ БИОГРАФИИ, Т. 1, 355). ОДНАКО ЭТА ВЕРСИЯ НУЖДАЕТСЯ В РЕВИЗИИ, ТАК КАК НЕЯСНО, КАК НЕОБХОДИМОСТЬ РЕФОРМИРОВАНИЯ ПОРЯДКА СУДОПРОИЗВОДСТВА МОГЛА ПРОИСТЕКАТЬ ИЗ ЭТОГО ОТДЕЛЬНОГО ДЕЛА.

57. БАКЛАНОВА, “ТЕТРАДИ СТАРЦА АВРААМИЯ,” 145.

58. Р. ШАРТЬЕ, КУЛЬТУРНЫЕ ИСТОКИ ФРАНЦУЗСКОЙ РЕВОЛЮЦИИ (М.: ИСКУССТВО, 2001), 30-31.

59. НЕСОВЕРШЕННАЯ ПУБЛИЧНАЯ СФЕРА, 44.

\section{AUTEUR}

\section{ЕВГЕНИЙ АКЕЛЬЕВ}

HSE University

eakelev[at]hse.ru 